UNIVERSIDADE DE SÃO PAULO

ESCOLA DE ENGENHARIA DE SÃO CARLOS

DEPARTAMENTO DE ENGENHARIA DE TRANSPORTES

PÓS-GRADUAÇÃO EM ENGENHARIA DE TRANSPORTES

\title{
QUANTIFICAÇÃO DAS SOLICITAÇÕES DINÂMICAS DE VEÍCULOS RODOVIÁRIOS DE CARGA SOBRE OS PAVIMENTOS ATRAVÉS DO PROGRAMA TRUCKSIM
}

\author{
Aluna: Patrícia Theodorovski Garbin \\ Orientador: Prof. Dr. José Leomar Fernandes Júnior
}

Dissertação submetida ao Departamento de Transportes da Escola de Engenharia de São Carlos - Universidade de São Paulo para obtenção do título de Mestre.

São Carlos-SP 
AUTORIZO A REPRODUÇÃO TOTAL OU PARCIAL DESTE TRABALHO, POR QUALQUER MEIO CONVENCIONAL OU ELETRÔNICO, PARA FINS DE ESTUDO E PESQUISA, DESDE QUE CITADA A FONTE.

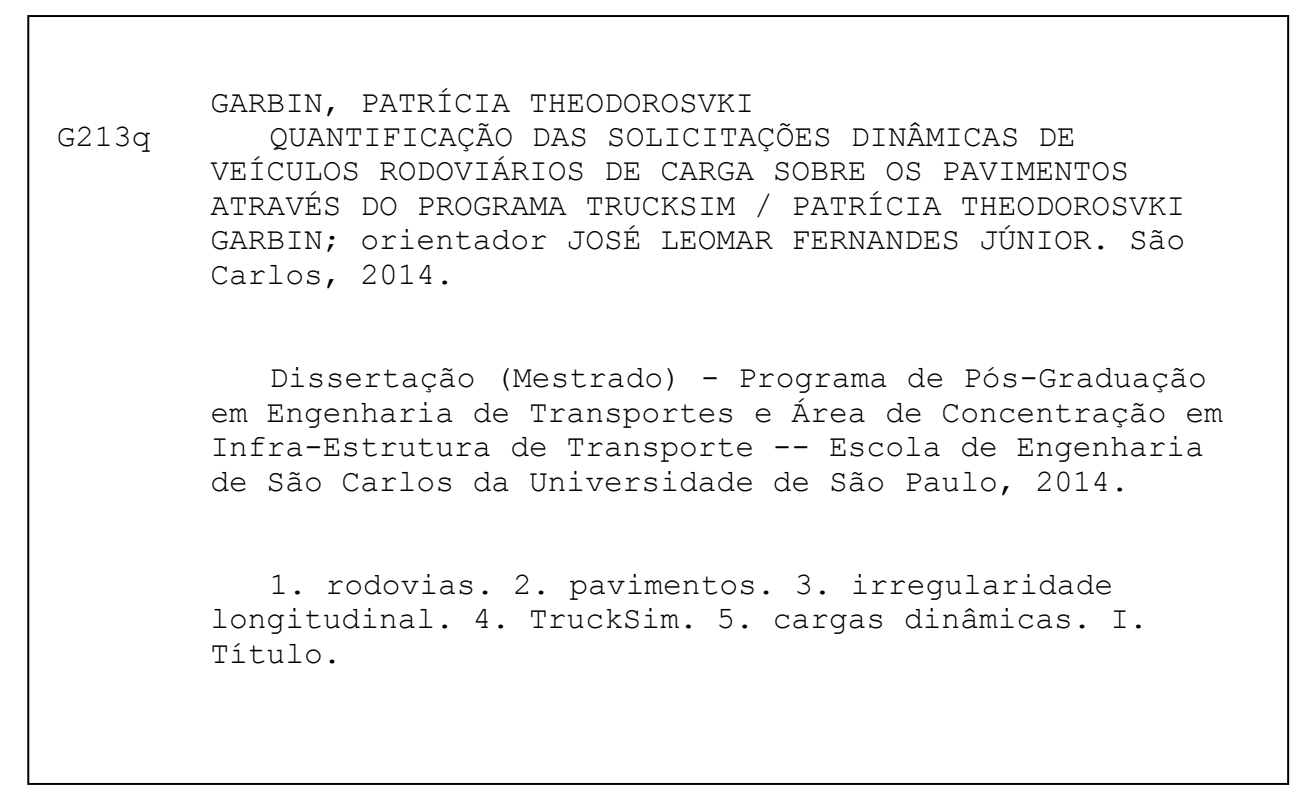




\section{FOLHA DE JULGAMENTO}

Candidata: Engenheira PATRÍCIA THEODOROVSKY GARBIN.

Título da dissertação: "Quantificação das solicitações dinâmicas de veículos rodoviários de carga sobre os pavimentos através do programa trucksim".

Data da defesa: 21/08/2014

\section{Comissão Julgadora:}

Prof. Associado José Leomar Fernandes Júnior (Orientador)

(Escola de Engenharia de São Carlos/EESC)

Profa. Dra. Ana Paula Furlan

(Escola de Engenharia de São Carlos/EESC)

Prof. Dr. Rudney da Conceição Queiroz

(Faculdades Integradas de Araraquara/FIAR)

\section{Resultado:}

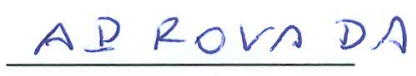

APRONADA

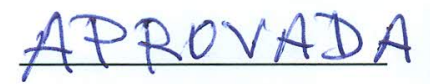

Coordenador do Programa de Pós-Graduação em Engenharia de Transportes: Prof. Associado Paulo César Lima Segantine

Presidente da Comissão de Pós-Graduação:

Prof. Associado Paulo César Lima Segantine 

"Your work is going to fill a large part of your life, and the only way to be truly satisfied is to do what you believe is great work. And the only way to do great work is to love what you do. If you haven't found it yet, keep looking. Don't settle. As with all matters of the heart, you'll know when you find it. And, like any great relationship, it just gets better and better as the years roll on. So keep looking until you find it. Don't settle."

Steve Jobs (Discurso aos formandos de Stanford, jun/2005) 



\section{DEDICATÓRIA}

Aos meus pais, Augusta e Vicente, pela confiança depositada em mim e todo investimento em minha boa formação educacional; ao meu irmão, Marcelo, por todo companheirismo e amizade; ao meu eterno namorado, Nando, por todo amor, companheirismo e apoio para conclusão deste trabalho. 



\section{AGRADECIMENTOS}

Agradeço ao Prof. Dr. José Leomar Fernandes Júnior, pela orientação fornecida, pela confiança e, sobretudo, pelo incansável incentivo para concluir este trabalho.

Agradeço a todo corpo docente do Departamento de Engenharia de Transportes da EESC/USP, com os quais tive o privilégio de conviver desde a graduação e foram fundamentais para a escolha de minha área de especialização.

Agradeço aos funcionários das secretarias de graduação e pós-graduação do Departamento de Engenharia de Transportes da EESC/USP, pelo apoio e colaboração fornecida durante elaboração deste trabalho.

Agradeço a toda minha família e todos os meus amigos, que sempre estiveram presentes, acreditando e apoiando meus projetos de aperfeiçoamento acadêmico e profissional.

Agradeço a Deus, acima de tudo, por ter permitido a conclusão deste trabalho e por ter me permitido conviver com pessoas tão especiais durante esta jornada. 



\section{SUMÁRIO}

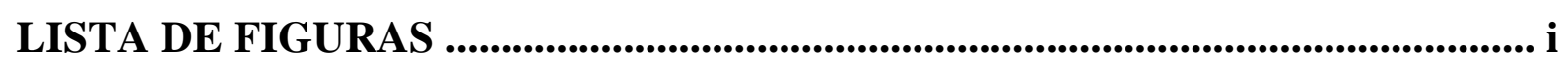

LISTA DE TABELAS ................................................................................... ii

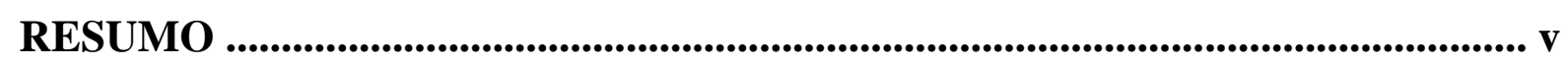

ABSTRACT ................................................................................................................. vii

1. INTRODUÇÃ

1.1 Objetivos ............................................................................................................................... 3

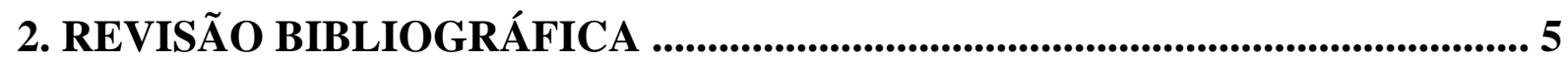

2.1 Fatores do Tráfego que Afetam o Desempenho dos Pavimentos ....................... 5

2.2 Efeito da Irregularidade dos Pavimentos nas Cargas Dinâmicas ...................... 7

2.3 Interação Veículo-Via ........................................................................................................ 10

2.4 Conceito de Equivalência de Cargas .................................................................... 14

2.5 O Projeto DIVINE ........................................................................................................... 16

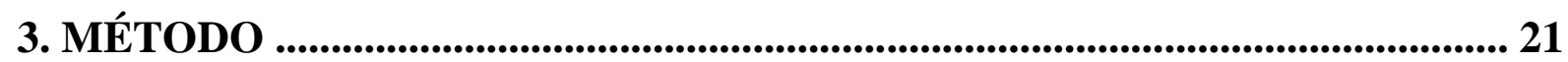

4. LEGISLAÇÃO BRASILEIRA PARA LIMITES DE CARGA.......................... 25

4.1. Classificação dos Veículos e Aplicação da Legislação .......................................... 28

4.2. Análise do Impacto da Legislação e Variação da Tolerância no Pavimento à Luz do Conceito de Fator de Equivalência de Carga .................................................... 29

5. PROGRAMAÇÃO DAS SIMULAÇÕES ....................................................... 35

5.1. Seleção de Veículos para Simulação ........................................................................ 36

5.2. Seleção de Perfis Longitudinais de Pavimentos para Simulação .................... 37

5.3. Seleção de Variáveis para Simulação ........................................................................ 37

5.4 Resultados Esperados nas Simulações ........................................................................ 38 
6. RESULTADOS E ANÁLISE DOS RESULTADOS ........................................ 41

6.1. Mudanças nas Considerações Iniciais ............................................................... 41

6.2. Veículo 2C .............................................................................................................................. 43

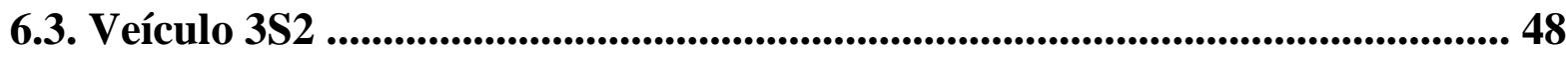

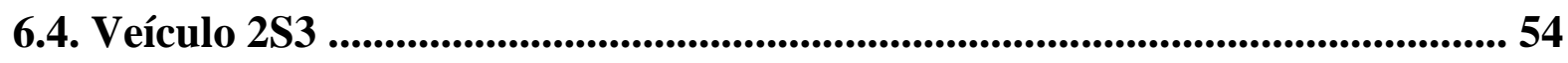

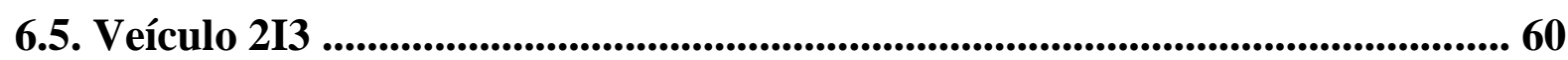

6.6. Comparação de Resultados ..................................................................................... 65

7. CONCLUSÕES E SUGESTÕES PARA TRABALHOS FUTUROS ............... 69

7.1. Sugestões para Trabalhos Futuros .................................................................. 70

REFERÊNCIAS BIBLIOGRÁFICAS ................................................................. 73

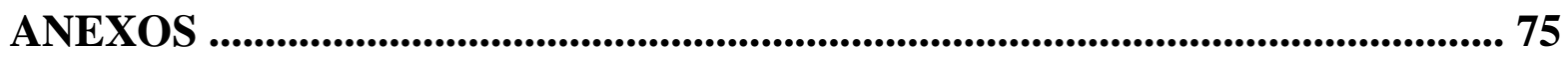




\section{LISTA DE FIGURAS}

Figura 1: Correspondência entre o IRI e a Superfície de Referência 9

Figura 2: Comparação das forças dinâmicas nos pneus com o uso de suspensões passiva e semiativa

Figura 3: Comparação do índice de trincas no pavimento para o uso de suspensões ativa, semiativa e passiva

Figura 4: Diferença de evolução da condição funcional de um pavimento para diferentes condições estruturais 16

Figura 5: Tipos de eixos e de rodagem mais comuns no Brasil ............................................. 26

Figura 6: Impacto do incremento da carga no FEC (por veículo) .................................. 33

Figura 7: Gráfico da força normal atuante nos pneus em uma das simulações .................... 39

Figura 8: Coordenadas do gráfico da força normal atuante nos pneus ........................ 39

Figura 9: veículo $2 \mathrm{C}$......................................................................................................... 43

Figura 10: Gráfico Efeito dinâmico (\%) x IRI (m/mm) ................................................... 45

Figura 11: Gráfico Variação do efeito dinâmico com aumento da solicitação. ....... 46

Figura 12: Gráfico Efeito dinâmico no FEC $(\%)$ x IRI $(\mathrm{m} / \mathrm{mm})$................................... 47

Figura 13: Gráfico Impacto do incremento da carga no FEC, considerando o efeito dinâmico decorrente da interação veículo-via 48

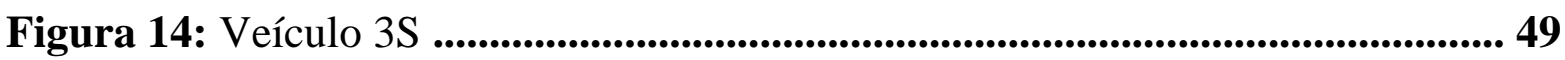

Figura 15: Gráfico Efeito dinâmico (\%) x IRI (m/mm) ................................................. 51

Figura 16: Gráfico Variação do efeito dinâmico com aumento da solicitação .......... 52

Figura 17: Gráfico Efeito dinâmico no FEC $(\%)$ x IRI (m/mm) ................................... 53 
Figura 18: Gráfico Impacto do incremento da carga no FEC, considerando o efeito dinâmico decorrente da interação veículo-via 53

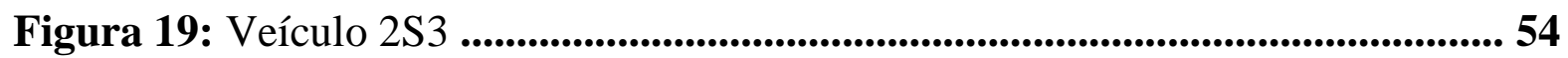

Figura 20: Gráfico Efeito dinâmico (\%) x IRI (m/mm) ................................................. 57

Figura 21: Gráfico Variação do efeito dinâmico com aumento da solicitação........... 57

Figura 22: Gráfico Efeito dinâmico no FEC (\%) x IRI (m/mm) ................................. 59

Figura 23: Gráfico Impacto do incremento da carga no FEC, considerando o efeito dinâmico decorrente da interação veículo-via ....................................................................59

Figura 24: Veículo 2I3 .......................................................................................60

Figura 25: Gráfico Efeito dinâmico (\%) x IRI (m/mm) .............................................. 62

Figura 26: Gráfico Variação do efeito dinâmico com aumento da solicitação .......... 63

Figura 27: Gráfico Efeito dinâmico no FEC $(\%)$ x IRI $(\mathrm{m} / \mathrm{mm})$.................................. 64

Figura 28: Gráfico Impacto do incremento da carga no FEC, considerando o efeito dinâmico decorrente da interação veículo-via ........................................................................ 65 


\section{LISTA DE TABELAS}

Tabela 1: Correspondência entre o IRI e a Condição do Pavimento ............................... 9

Tabela 2: Fatores de equivalência de carga da AASHTO ................................................. 15

Tabela 3: Fatores de equivalência de carga do USACE .................................................... 15

Tabela 4: Classificação e legislação aplicada ...................................................................... 30

Tabela 5: Classificação e legislação aplicada, considerando a tolerância de 7,5\% .. 31

Tabela 6: Cálculo dos FEC para os Veículos de Carga 2C, 3S2, 2S3 e 2I3 ................ 34

Tabela 7: FEC para excesso de 7,5\% na carga estática ....................................................... 34

Tabela 8: Seleção de perfis para simulação ....................................................................... 37

Tabela 9: Comparação do IRI crítico para o Efeito Dinâmico na Carga e no FEC .. 66

Tabela 10: Impacto máximo no FEC decorrente do Efeito Dinâmico para excesso de

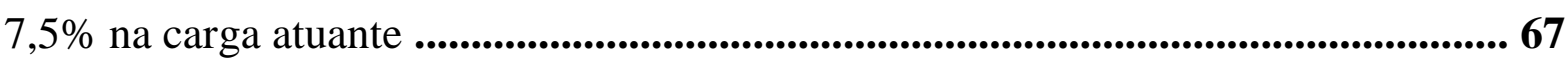




\section{RESUMO}

GARBIN, P. T. Quantificação das solicitações dinâmicas de veículos rodoviários de carga sobre os pavimentos através do TRUCKSIM. 2014.138 f. Dissertação (Mestrado). Escola de Engenharia de São Carlos, Universidade de São Paulo, São Carlos, 2014.

O desenvolvimento de novas técnicas de dimensionamento, construção e gerência de pavimentos requer o conhecimento dos efeitos dinâmicos da interação veículo-via, que dependem da irregularidade longitudinal do pavimento e de fatores associados ao veículo, como o espaçamento entre eixos, a velocidade de operação, caraterísticas de suspensão, a pressão de enchimento dos pneus e o tipo de rodagem dos eixos traseiros (rodagem dupla ou simples). Esta pesquisa tem por objetivo principal a quantificação das solicitações dinâmicas de veículos rodoviários de carga sobre os pavimentos, mediante utilização do programa computacional TruckSim e visa a quantificação dos efeitos dos fatores carga por eixo, tipo de veículo, velocidade dos veículos e irregularidade longitudinal sobre o desempenho dos pavimentos. Os resultados mostram que os efeitos dinâmicos, particularmente quando os pavimentos estão em condição ruim (IRI superior a 4), têm potencial de intensificar as forças atuantes na via em até $280 \%$, considerando-se um excesso de carga de 7,5\%, que é a tolerância estabelecida pela legislação brasileira, e que, de uma maneira global, podem reduzir a vida em serviço de um pavimento em até $87 \%$.

Palavras-chave: rodovias, pavimentos, irregularidade longitudinal, TruckSim, cargas dinâmicas. 


\section{ABSTRACT}

GARBIN, P. T. Quantifying the dynamic stresses of road freight vehicles on the pavements, by using the computer program TruckSim. 2014.138 f. Dissertação (Mestrado). Escola de Engenharia de São Carlos, Universidade de São Paulo, São Carlos, 2014.

The development of new techniques for design, construction and management of pavements requires the knowledge of the dynamic effects associated to vehicle-track interactions, which depends on the pavement roughness and vehicle characteristics, such as the spacing between axles, the operational speed, characteristics of suspension, the tire inflation pressure and wheel type of rear axle (dual or single). The main goal of this research is quantifying the dynamic stresses of road freight vehicles on the pavements, by using the computer program TruckSim, and aims to quantify the effects of the factors: axle load, vehicle type, vehicle speed and longitudinal roughness on the pavement performance. The results show that the dynamic effects, particularly when the pavements are in poor condition (IRI greater than 4), have the potential to intensify the forces acting on the road up to $280 \%$, considering an overload of $7.5 \%$, which is the tolerance established by Brazilian law, and that in global effects it can reduce the service-life of a pavement up to $87 \%$.

Key-words: highways, pavements, roughness, TruckSim, dynamic loads. 


\section{INTRODUÇÃO}

Os pavimentos rodoviários representam um valioso patrimônio, cuja conservação e restauração oportunas são essenciais para a sua preservação. Qualquer interrupção ou redução na intensidade ou na frequência dos serviços necessários à manutenção desse patrimônio implica em aumentos substanciais nos custos de operação dos veículos e na necessidade de investimentos cada vez mais vultosos para sua recuperação.

A qualidade da malha rodoviária está diretamente relacionada às condições de conservação da superfície de rolamento, às condições estruturais do pavimento e às características geométricas da via - fatores que determinam a satisfação do usuário em termos de conforto, economia e segurança e que estão associados, respectivamente, à gerência de pavimentos, que estabelece as estratégias de manutenção e reabilitação, ao dimensionamento dos pavimentos, materiais utilizados e métodos construtivos, e ao projeto geométrico.

A competitividade do mercado, pressionada pela globalização, tem levado as empresas a buscarem maior eficiência e produtividade, metas que exigem redução nos custos de transportes, principal componente do custo logístico das mercadorias. A necessidade de ganhos na produtividade e redução nos custos de transportes dos produtos, associada à evolução tecnológica e políticas de sustentabilidade sócio-ambiental, vem ampliando sucessivamente a demanda pelo uso de veículos maiores e mais pesados, que levam ao aumento das solicitações do tráfego sobre a superfície de rolamento. 
O aumento das solicitações do tráfego compromete o nível de serviço, a capacidade operacional, a segurança das rodovias e interfere substancialmente na integridade estrutural dos pavimentos. Por outro lado, o crescimento na demanda pelo uso destes veículos é justificado, principalmente, pelo incremento da eficiência no transporte de carga, resultando na redução da emissão de gases tóxicos e de ruídos, além da menor exposição de veículos nas rodovias devido à redução no número de viagens.

As mudanças nas características do transporte de cargas conduzem a estudos para a elaboração de alternativas para adequação das rodovias a essas mudanças. O aprimoramento dos métodos de dimensionamento, construção e gerência de pavimentos pode contribuir para mitigar os danos aos pavimentos causados pelo aumento das solicitações do tráfego. A revisão da legislação de pesos e dimensões de veículos que trafegam em vias públicas, a devida fiscalização, por meio de instalação de balanças em locais estratégicos, e a aplicação de punição aos infratores também poderiam auxiliar no controle dos efeitos deletérios das solicitações do tráfego.

Desta forma, o desenvolvimento de novas técnicas de dimensionamento, construção e gerência de pavimentos requer o adequado conhecimento dos efeitos das solicitações do tráfego no pavimento, ou seja, deve ser baseado na quantificação dos efeitos dos principais fatores intervenientes na interação veículo-pavimento.

A ação provocada pelo tráfego dos veículos nos pavimentos e nas pontes, de caráter dinâmico, é influenciada por diversos fatores de tráfego, tais como carga por eixo, pressão de enchimento dos pneus, tipo de rodagem, tipo de pneu, distribuição da pressão de contato pneu-pavimento, tipo de veículo, tipo de suspensão e velocidade dos veículos. Além disso, também é importante a condição da superfície de rolamento, particularmente em termos da irregularidade longitudinal. 
A interação veículo-pavimento tem sido objeto de pesquisas em muitas instituições do mundo. Trata-se de um assunto complexo, porém de extrema importância para os organismos rodoviários e para a sociedade, pois melhores métodos de construção e gerência de pavimentos podem reduzir os custos de manutenção e reabilitação dos pavimentos e os custos operacionais dos veículos, reduzindo os custos de transporte.

Geralmente, as disciplinas que tratam dos tópicos da infraestrutura de transportes e dos veículos são independentes, não os considerando como parte de um mesmo sistema. A situação torna-se ainda mais complexa à luz dos resultados do projeto de pesquisa DIVINE (Dynamic Interaction between Vehicles and Infrastructure Experiment), que indicaram ser a deterioração dos pavimentos dependente não apenas da carga estática, como é normalmente considerado nos métodos de dimensionamento de pavimentos tradicionais, mas também do comportamento dinâmico dos veículos, do perfil longitudinal da via e da variabilidade estrutural dos pavimentos.

\subsection{Objetivos}

Esta pesquisa procura contribuir para o aprimoramento das técnicas de construção e gerência de pavimentos visando à amenização dos efeitos provocados pelo aumento das cargas do tráfego e, dessa forma, prolongar a vida útil dos pavimentos.

Tem por objetivo principal a quantificação das solicitações dinâmicas de veículos rodoviários de carga sobre os pavimentos. Mediante utilização da ferramenta computacional TRUCKSIM, visa à quantificação dos efeitos dos fatores carga por eixo, tipo de veículo, tipo de suspensão, velocidade dos veículos e irregularidade longitudinal sobre o desempenho dos pavimentos.

O TRUCKSIM é uma ferramenta computacional desenvolvida pelo UMTRI (The University of Michigan Transportation Research Institute) para a simulação e análise da interação dinâmica de ações provocadas por veículos pesados na infraestrutura 
(pavimentos e pontes). O TRUCKSIM utiliza modelos matemáticos validados experimentalmente, aos quais não permite o acesso, mas permite a seleção dos dados de entrada como o tipo de suspensão, pneus, configuração de veículos, perfil do pavimento, velocidade de operação, carga aplicada, entre outros.

Destaca-se que o conhecimento dos efeitos dinâmicos das cargas do tráfego pode contribuir para a adequação dos limites legais de carga por eixo no Brasil e fornecer alternativas para o aumento da eficiência do transporte de cargas, tanto pela redução de custos operacionais dos veículos e como pela redução dos custos de manutenção e reabilitação de rodovias. 


\section{REVISÃO BIBLIOGRÁFICA}

Os problemas associados a segurança, economia e conforto do transporte rodoviário são, em sua maioria, influenciados por características da via e dos veículos e pela maneira como esses dois elementos (veículos e via) interagem (KULAKOWSKI, 1994). Porém, tanto as propriedades dinâmicas dos veículos quanto as dos pavimentos sempre foram consideradas isoladamente, em estudos paralelos que não consideravam a interação entre os mesmos. Com o intuito de eliminar esses conflitos, desde 1990 têm sido realizadas conferências sobre a interação veículo-via ("Vehicle-TirePavement Interface Conference"), que muito têm contribuído para a evolução dos estudos acerca da interação dinâmica veículo-pavimento (BARBOSA, 1999).

\subsection{Fatores do Tráfego que Afetam o Desempenho dos Pavimentos}

Fernandes Jr. (1994) descreveu diversos fatores de tráfego e propriedades dinâmicas que afetam o comportamento estrutural dos pavimentos. Alguns fatores relacionados são: a carga por eixo, o peso bruto total combinado, o tipo de eixo, o espaçamento entre eixos, o tipo de suspensão, as cargas dinâmicas e as características dos pneus. Destacou que a carga por eixo, independente de fatores ambientais, do comportamento estrutural dos pavimentos e de outros fatores combinados, é o fator que mais afeta a deterioração do pavimento, pois é exponencial a relação entre as cargas por eixo e a deterioração do pavimento. 
Outra constatação feita foi que quando carregando uma mesma carga por eixo, os pneus extralargos resultam em Fatores de Equivalência de Cargas de duas a quatro vezes maiores que os correspondentes às rodas duplas convencionais, ou seja, podem reduzir a vida em serviço dos pavimentos a menos da metade. E, mesmo quando acompanhados por suspensão pneumática, os pneus extralargos ainda são muito mais danosos que as rodas duplas.

A carga estática aplicada no pavimento é o fator isolado que tem maior efeito nos danos por fadiga, devido à relação exponencial entre o aumento do carregamento e o aumento dos danos causados, enquanto que o peso bruto do veículo tem influência direta na deformação permanente, que é linearmente relacionada ao peso (GILLESPIE e KARAMIHAS, 1994).

Outras constatações de Gillespie e Karamihas (1994) foram:

- O espaçamento entre eixos tem pouca influência nos danos por fadiga e não influencia a deformação permanente - outros estudos citados por Fernandes, Jr., 1994 destacam a influência do espaçamento entre eixos, particularmente dos eixos em tandem triplo, no sentido de que menores espaçamentos estariam associados a uma menor recuperação do pavimento e, portanto, a maiores deteriorações;

- A distribuição desigual da carga estática em um grupo de eixos em tandem tem efeito moderado nos danos por fadiga, pois o aumento da carga em um dos eixos provoca, pela "lei da quarta-potência" (evolução potencial da deterioração do pavimento com o aumento da carga por eixo), efeito maior do que o provocado pela redução de carga nos demais eixos;

- Os fatores de distribuição de carga e as cargas estáticas dependem, principalmente, da irregularidade longitudinal da via, da velocidade e do tipo de suspensão do veículo. Entretanto, tais características não estão diretamente ligadas ao comportamento dinâmico dos veículos. 


\subsection{Efeito da Irregularidade dos Pavimentos nas Cargas Dinâmicas}

Irregularidade é o desvio de pontos da superfície do pavimento de uma rodovia em relação a um plano de referência. Ela afeta a dinâmica e qualidade de rolamento de veículos e as ações de cargas dinâmicas transmitidas à via, podendo gerar aceleração vertical e lateral, sendo a aceleração vertical o principal fator que afeta a sensação de conforto dos motoristas e passageiros (ASTM STANDARD DEFINITIONS E 867).

A geometria da superfície do pavimento de interesse à Engenharia Rodoviária abrange uma variação de $0,01 \mathrm{~mm}$ a $100 \mathrm{~mm}$ em termos de irregularidade longitudinal, isto é, uma variação de 10.000 para um. Essa variação é muito ampla para ser representada em uma única escala, mas pode ser descrita e medida em quatro escalas: microtextura, macrotextura, megatextura e irregularidade longitudinal.

As micro e macrotexturas são necessárias para garantir o atrito pneu-pavimento em condições de superfície molhada, enquanto a megatextura é indesejável, uma vez que está relacionada a ruído e vibrações provenientes da interação pneu-pavimento (HEGMON, 1992).

A irregularidade da via estimula o comportamento dinâmico do veículo, de modo que a carga instantânea por eixo pode ser muito maior do que a carga estática por eixo. Uma superfície de rolamento com baixa irregularidade, ou seja, IRI (Índice de Irregularidade Longitudinal) igual a $1,25 \mathrm{~m} / \mathrm{km}$, equivalente a um ISA (Índice de Serventia Atual) de 4,25, resulta em cargas dinâmicas muito menores do que as provocadas por uma superfície de rolamento com alta irregularidade, por exemplo, IRI igual a 3,75 m/km, equivalente a um ISA de 2,5 (YI e HEDRICK, 1992).

Por mais novo que seja e por melhor que tenha sido o controle de sua construção, um pavimento sempre apresenta irregularidade longitudinal inicial, pois não é possível construir uma superfície perfeitamente lisa. A carga transmitida pelo tráfego ao 
pavimento tem efeito dinâmico, isto é, a força exercida pela roda no pavimento pode ser maior ou menor do que a carga estática na roda. Quanto maior a irregularidade da superfície de rolamento, maior a componente dinâmica da força, contribuindo para o aumento da irregularidade. Portanto, pode-se dizer que a irregularidade da via é ampliada pela própria irregularidade (HEGMON, 1992).

Os pavimentos são dimensionados para suportar as solicitações do tráfego com uma expectativa de vida que, geralmente, não é alcançada. O volume de tráfego de veículos pesados e suas respectivas cargas, muitas vezes, ultrapassam as previsões nas quais o dimensionamento é baseado. Além disso, o dimensionamento é baseado na carga estática, enquanto as cargas dinâmicas, que resultam da irregularidade da via, apresentam maior magnitude (HEGMON, 1992).

A condição da rodovia pode ser descrita tanto do ponto de vista do usuário, a partir de uma avaliação funcional, que estabelece a qualidade de rolamento e segurança, quanto do ponto de vista técnico, através de uma avaliação estrutural, que quantifica a capacidade de suporte do pavimento.

A qualidade de rolamento está diretamente ligada à irregularidade longitudinal e afeta o conforto ao usuário e os custos operacionais, pois quanto mais rugosa a superfície, maiores os custos com manutenção dos veículos, consumo de combustível, desgaste de pneus e tempo de viagem. Fatores como segurança (resistência ao rolamento) e ambientais (ruído) também são afetados pela irregularidade da via (OECD, 1998).

Sayers e Karamihas (1998) apresentam uma escala de irregularidade relacionada a uma superfície de rolamento de referência, conforme figura 1. O Departamento Nacional de Infraestrutura de Transportes (DNIT) relaciona, em seu Manual de Restauração de Pavimentos Asfálticos (2006), o IRI à condição da superfície de rolamento, conforme tabela 1 . 


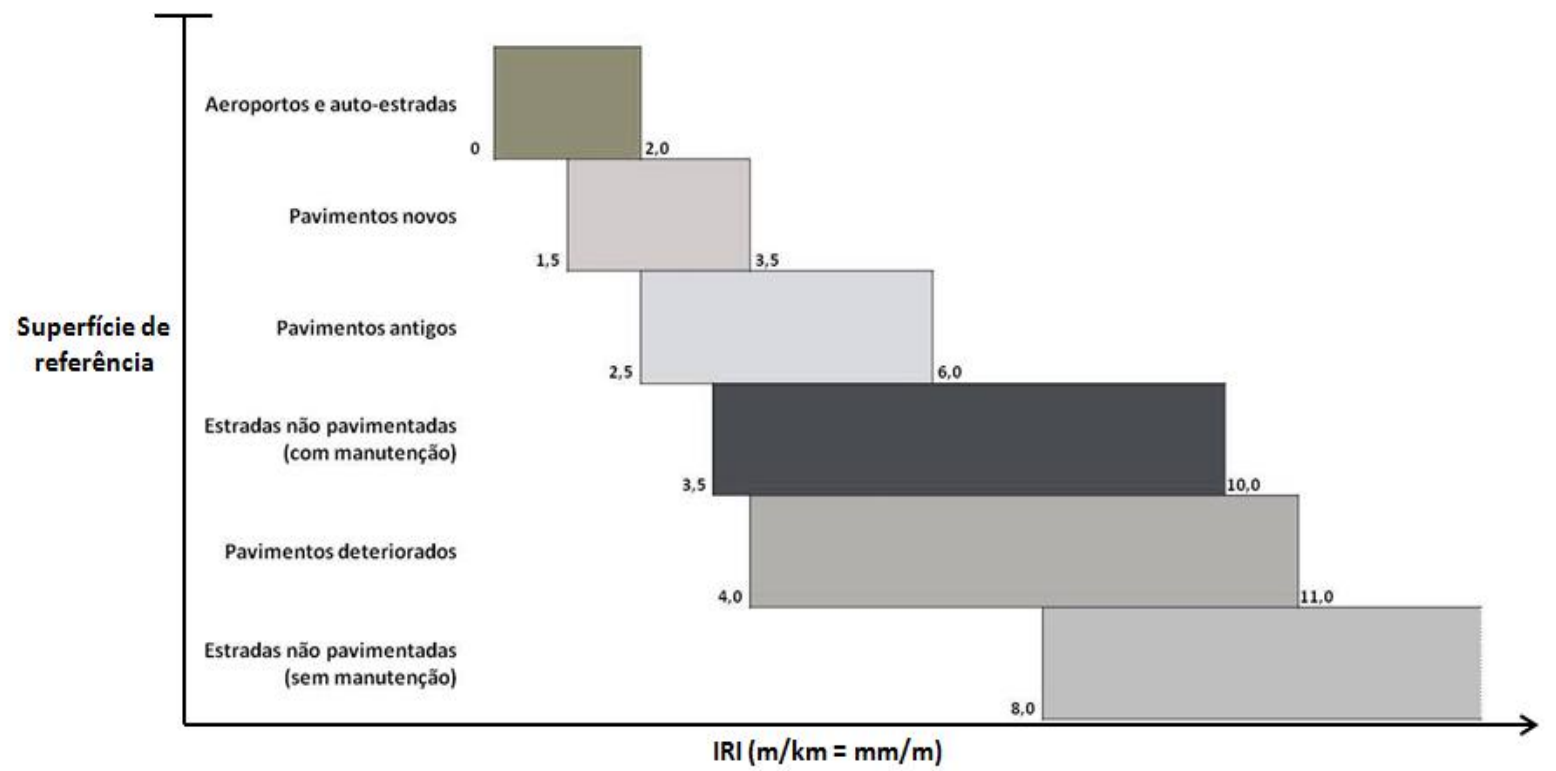

Figura 1: Correspondência entre o IRI e a Superfície de Referência (SAYERS e KARAMIHAS, 1998 - adaptado)

Tabela 1: Correspondência entre o IRI e a Condição do Pavimento.

\begin{tabular}{|c|c|}
\hline Condição do Pavimento & IRI $(\mathbf{m} / \mathbf{k m})$ \\
\hline Excelente & $1,0-1,9$ \\
\hline Bom & $1,9-2,7$ \\
\hline Regular & $2,7-3,5$ \\
\hline Ruim & $3,5-4,6$ \\
\hline Péssimo & $>4,6$ \\
\hline
\end{tabular}

Fonte: Manual de Restauração de Pavimentos Asfálticos, 2006 - DNIT

A irregularidade longitudinal do pavimento pode ser quantificada por sistemas de medida do tipo resposta, perfilômetros ou por painéis de avaliações subjetivas. Os sistemas do tipo resposta consistem na somatória da variação da distância entre eixo e carroceria do veículo padrão, trafegando em velocidade padrão. Os perfilômetros obtêm o perfil longitudinal da via através de medidas das elevações ao longo das trilhas de roda. Por último, o painel de avaliações subjetivas consiste no julgamento da 
via por um ou mais avaliadores e os resultados são convertidos em uma escala numérica.

\subsection{Interação Veículo-Via}

Os problemas associados à segurança, economia e conforto do transporte rodoviário são, em sua maioria, influenciados por características da via e dos veículos e pela maneira como esses dois elementos (veículos e via) interagem (KULAKOWSKI, 1994).

Partindo do princípio que os veículos de carga são os principais responsáveis pela deterioração dos pavimentos, devido às elevadas tensões impostas pelas cargas por eixo, Gillespie e Karamihas (1994) estudaram o mecanismo de interação veículopavimento para determinar quais características dos veículos estão mais relacionadas aos danos no pavimento. Foram estudadas várias combinações veículo-pavimento visando à determinação de relações sistemáticas entre as propriedades dos veículos e seus efeitos sobre os pavimentos.

A carga vertical aplicada no pavimento por um veículo tem duas componentes: carga estática e carga dinâmica. A carga estática depende do peso e da geometria dos veículos. O efeito dinâmico das cargas é causado pela vibração do veículo devido à excitação da rodovia e é altamente dependente das características de suspensão do veículo e da irregularidade da superfície da via (YI e HEDRICK, 1992).

O efeito dinâmico das cargas tem significativo impacto nos danos ao pavimento, sendo que uma significativa melhoria no desempenho dos pavimentos poderia ser alcançada pela melhoria nos sistemas de suspensão dos veículos. O uso de suspensão semiativa para reduzir o efeito dinâmico causado por cargas sucessivas na rodovia reduz a variação de carga por eixo e os picos de carga, como mostra a figura 2. A figura 3 mostra que $50 \%$ das trincas por fadiga ocorrem, em média, em 12,7 anos com o uso de 
suspensão comum, enquanto esse prazo pode ser estendido para 15,3 anos com o uso de suspensão semiativa (YI e HEDRICK, 1992).

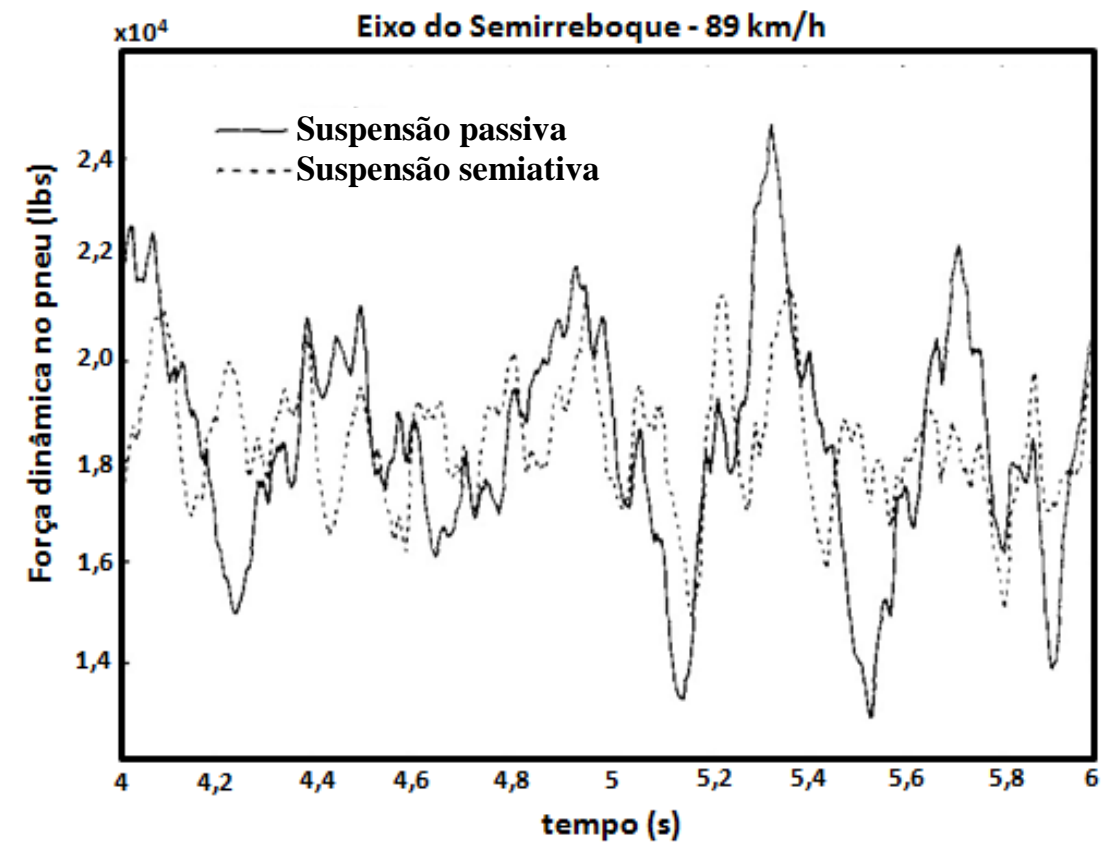

Figura 2: Comparação das forças dinâmicas nos pneus com o uso de suspensões passiva e semiativa (YI e HEDRICK, 1992 - adaptado) 


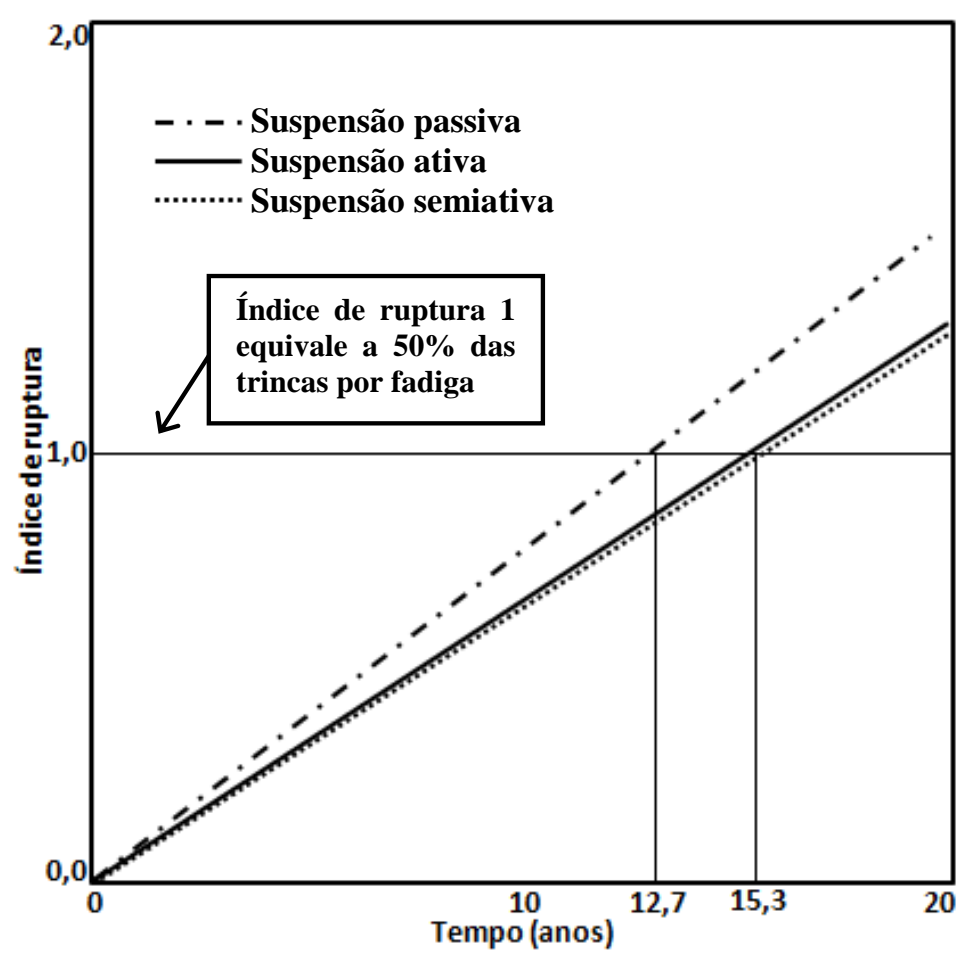

Figura 3: Comparação do índice de trincas no pavimento para o uso de suspensões ativa, semiativa e passiva (YI e HEDRICK, 1992 - adaptado)

Segundo Côrte-Real (2002), as funções da suspensão estão classificadas em dois fatores básicos: as que estão relacionadas ao conforto (determinado pelo controle da massa suspensa) e as que estão relacionadas à segurança (determinada pelo controle da roda). Os sistemas passivos possuem características fixas que são projetadas para atender apenas uma única condição de projeto (valor nominal), impossibilitando o seu uso em situações extremas. Já as suspensões ativas e semiativas, podem ter seus parâmetros adaptados e ajustados às condições de operação exigidas pelo ambiente. Os sistemas totalmente ativos e os sistemas semiativos têm como diferença fundamental que estes não podem introduzir energia no sistema oscilatório. Assim, as forças exercidas pelos atuadores semiativos terão sempre sentidos contrários aos deslocamentos relativos (molas) e velocidades relativas (amortecedores) de seus terminais. Esta restrição nos sentidos das forças não existe no caso dos atuadores totalmente ativos. 
A velocidade do veículo influencia os danos por fadiga no pavimento devido à irregularidade da via, que causa vibração no veículo e em sua suspensão, provocando picos de carga dinâmica. A velocidade afeta, também, a duração do carregamento, diminuindo-a, o que, para materiais visco-elásticos, como é o caso dos pavimentos flexíveis, reduz os danos no pavimento.

Assim, para superfícies perfeitamente lisas ( $I R I=0)$, os danos, particularmente o acúmulo de deformação permanente nas trilhas de roda, diminuem com o aumento da velocidade, devido ao menor tempo de aplicação da carga, enquanto que, para superfícies altamente rugosas, os efeitos dinâmicos prevalecem e os danos aumentam com o aumento da velocidade (GILLESPIE e KARAMIHAS, 1994).

$\mathrm{Lu}$ (1985) estudou o efeito da irregularidade da via na resistência ao rolamento do veículo, que consiste de três parcelas: resistência do pneu trafegando sobre uma via perfeitamente lisa; resistência à irregularidade da via; resistência associada ao movimento da suspensão provocado pela irregularidade da via. Os resultados obtidos mostram que a resistência ao rolamento aumenta com o aumento da irregularidade e da velocidade do veículo. Destacam, também, que uma melhoria na condição da superfície da via capaz de reduzir a resistência ao rolamento em $10 \%$ implicaria na redução do consumo de combustível da ordem de $2 \%$.

Wambold (1985) avalia os efeitos da irregularidade da via nas características dinâmicas dos veículos. O autor cita como as principais penalidades, impostas ao motorista pela irregularidade da via, a insatisfação e desconforto do motorista, o comprometimento da segurança, o aumento no consumo de combustível, o aumento do efeito dinâmico sobre as cargas, além dos danos aos veículos. 


\subsection{Conceito de Equivalência de Cargas}

Fernandes Jr. (1994) salienta que a análise dos efeitos do tráfego sobre o desempenho de pavimentos é dificultada pelo fato do volume do tráfego e da magnitude das cargas impostas pelo tráfego variarem ao longo da vida em serviço do pavimento.

Assim, o conhecimento dos efeitos cumulativos das solicitações do tráfego é fundamental para o desenvolvimento de métodos de dimensionamento e sistemas de gerência de pavimentos, efeitos esses que têm sido expressos por um denominador comum, os Fatores de Equivalência de Cargas (FEC).

Os FEC permitem a conversão de aplicações de diferentes solicitações em um número equivalente de aplicações da solicitação-padrão, possibilitando o dimensionamento e a previsão do desempenho de pavimentos para o tráfego misto real. O conceito de equivalência de cargas é importante também para a alocação de responsabilidades sobre os custos de manutenção e restauração de rodovias, pois permite a comparação de danos causados por diferentes solicitações.

Os trechos experimentais da AASHTO e os estudos do USACE (Corpo de Engenheiros do Exército Norte-americano) forneceram subsídios para o desenvolvimento de fatores de equivalência de carga por eixo. Foram avaliados os efeitos do carregamento na perda de serventia para diversas estruturas de pavimento, que foram submetidas ao carregamento de veículos com diferentes tipos de eixos e cargas. Os fatores de equivalência da AASHTO baseiam-se na perda de serventia do pavimento, enquanto os obtidos pelo USACE baseiam-se nos efeitos do carregamento a uma profundidade de aproximadamente $33 \mathrm{~cm}$, que estão associados ao acúmulo de deformação permanente nas trilhas de roda. As expressões para cálculo dos fatores de equivalência de carga são apresentadas nas tabelas 2 e 3. 
Tabela 2: Fatores de equivalência de carga da AASHTO

\begin{tabular}{|l|c|}
\hline \multicolumn{1}{|c|}{ Tipo de Eixo } & Fatores de Equivalência de Carga $(\mathbf{P}$ em tf) \\
\hline Simples de rodagem simples & $\mathrm{FEC}=(\mathrm{P} / 7,77)^{4,32}$ \\
\hline Simples de rodagem dupla & $\mathrm{FEC}=(\mathrm{P} / 8,17)^{4,32}$ \\
\hline Tandem duplo (rodagem dupla) & $\mathrm{FEC}=(\mathrm{P} / 15,08)^{4,14}$ \\
\hline Tandem triplo (rodagem dupla) & $\mathrm{FEC}=(\mathrm{P} / 22,95)^{4,22}$ \\
\hline
\end{tabular}

$\mathrm{P}=$ Peso bruto total sobre o eixo

Tabela 3: Fatores de equivalência de carga do USACE

\begin{tabular}{|l|c|l|}
\hline \multicolumn{1}{|c|}{ Tipo de Eixo } & $\begin{array}{c}\text { Faixas de } \\
\text { Cargas (t) }\end{array}$ & $\begin{array}{c}\text { Fatores de Equivalência de } \\
\text { Carga }(\mathbf{P} \text { em tf) }\end{array}$ \\
\hline Dianteiro simples e traseiro simples & $0-8$ & FEC $=2,0782 \times 10^{-4} \times \mathrm{P}^{4,0175}$ \\
& $\geq 8$ & FEC $=1,8320 \times 10^{-6} \times \mathrm{P}^{6,2542}$ \\
\hline Tandem duplo & $0-11$ & $\mathrm{FEC}=1,5920 \times 10^{-4} \times \mathrm{P}^{3,472}$ \\
& $\geq 11$ & $\mathrm{FEC}=1,5280 \times 10^{-6} \times \mathrm{P}^{5,484}$ \\
\hline Tandem triplo & $0-18$ & $\mathrm{FEC}=8,0359 \times 10^{-5} \times \mathrm{P}^{3,3549}$ \\
& $\geq 18$ & $\mathrm{FEC}=1,3229 \times 10^{-7} \times \mathrm{P}^{5,5789}$ \\
\hline
\end{tabular}

Na prática, os Fatores de Equivalência de Carga são utilizados no cálculo do número $\mathrm{N}$, que representa o número de repetições do eixo padrão em um determinado período de tempo, isto é, a vida útil de projeto, levando-se em conta a projeção de crescimento de tráfego ao longo da vida útil. O número $\mathrm{N}$ é utilizado para dimensionamento da seção transversal do pavimento.

A condição estrutural é associada à capacidade de suporte do subleito e das camadas do pavimento, ao longo do tempo, ou seja, há diminuição da capacidade estrutural com a deterioração do pavimento. Depende, portanto, da espessura das camadas e das características dos materiais usados, sendo influenciada, também, pelo método 
construtivo e pelo controle de qualidade da execução, além da variabilidade da integridade dos materiais ao longo da rodovia (OECD, 1998).

Ullidtz (1987) enfatiza que as condições estrutural e funcional não devem ser expressas por um único índice. Um pavimento com pobre condição funcional e boa condição estrutural pode apresentar o mesmo índice que um pavimento com boa condição funcional e pobre condição estrutural e, conforme apresentado na figura 4, os dois pavimentos podem ter desempenhos ao longo do tempo completamente diferentes. Pela mesma razão recomenda-se que um levantamento de defeitos não seja usado para descrever a condição estrutural do pavimento.

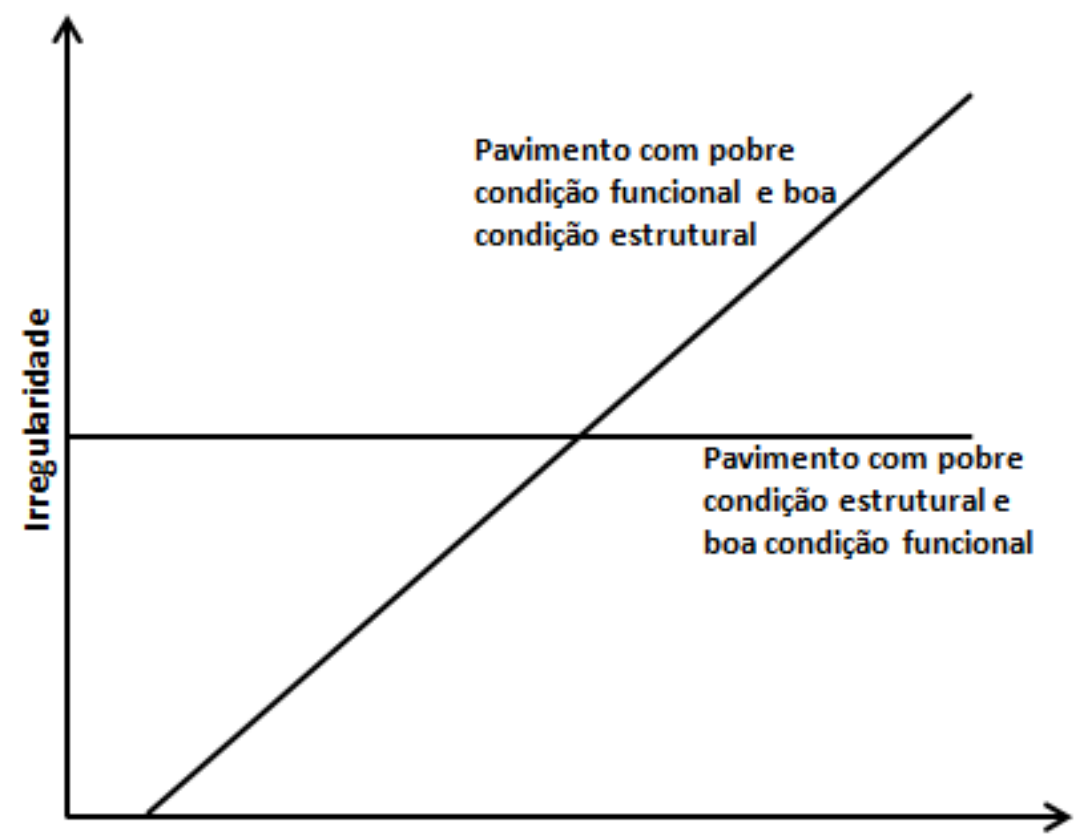

Figura 4: Diferença de evolução da condição funcional de um pavimento para diferentes condições estruturais (ULLIDTZ, 1987 - adaptado)

\subsection{O Projeto DIVINE}

O projeto DIVINE (Dynamic Interaction Between Vehicles and Infrastructure Experiment), conduzido pela OECD (1998), estudou a interação dinâmica entre 
veículo e infraestrutura (pavimentos e pontes) e teve como intuito apoiar decisões políticas que afetam a infraestrutura rodoviária e os custos do transporte de carga e fornecer evidências científicas dos efeitos dinâmicos de veículos de carga e seus sistemas de suspensão na infraestrutura e no custo do transporte de carga.

Seus resultados contribuíram para o desenvolvimento de novas práticas de dimensionamento, construção, manutenção e gerência de pavimentos, pontes e veículos. Para a redução dos custos, o DIVINE propôs o aumento da eficiência do transporte através do aumento dos limites de peso permitido nas vias para veículos comprovadamente menos danosos, ou seja, veículos com maior número de eixos ou utilizando suspensão mais amigáveis (road friendly suspensions).

A proposta é justificada pelo fato de que a deterioração é muito mais influenciada pelo aumento da carga por eixo transmitida ao pavimento do que pelo aumento do peso bruto total do veículo. Seguem alguns resultados apresentados no Relatório Técnico do Projeto DIVINE (OECD, 1998):

- Para pavimentos relativamente espessos (160 mm de material betuminoso), a tensão horizontal medida na base da camada é quase diretamente proporcional à força dinâmica nas rodas, enquanto no caso de pavimentos mais delgados, apesar das tensões serem maiores em magnitude, estas são menos sensíveis à força dinâmica nas rodas e aparentam ser influenciadas pela condição da superfície de contato pneu-pavimento;

- Um acréscimo de $10 \%$ na força dinâmica produz um aumento em torno de 7 a $12 \%$ na deformação permanente, no caso de pavimentos espessos;

- Os danos ao pavimento advindos da concentração da carga dinâmica na rodovia são altamente dependentes da superfície da via, do tipo de suspensão dos veículos que trafegam sobre a via, da configuração dos eixos e da velocidade do veículo; 
- As cargas dinâmicas de veículos com suspensão pneumática é da ordem de metade da magnitude das cargas dinâmicas dos veículos com suspensão convencional em feixe de molas;

- Em uma superfície lisa, a taxa cumulativa de carga por eixo em um ponto é em torno de $10 \%$, enquanto em superfícies irregulares há um efeito de concentração, que aumenta em até 20 vezes esse valor ("repetibilidade espacial");

- Os ensaios de carregamento dinâmico do Projeto DIVINE demonstraram que o pavimento se deteriora pelo menos $15 \%$ mais rapidamente com o uso de suspensão convencional em feixe de molas do que com o uso de suspensão pneumática.

Para reduzir o efeito dos veículos pesados no pavimento é necessário o controle do carregamento dinâmico, tanto para baixas freqüências (corpo do veículo - eixo do veículo) como para altas freqüências (eixo do veículo - rodas do veículo). A maioria das irregularidades do pavimento está relacionada a baixas freqüências, para as quais os veículos com suspensão a ar provocam, geralmente, menor freqüência natural, embora não possam apresentar, necessariamente, melhor desempenho para altas freqüências.

As propriedades que tornam as suspensões mais adequadas às vias são: baixa rigidez das molas, baixo atrito de Coulomb e um nível adequado de amortecimento. As suspensões a ar são mais propensas a preencher tais requisitos, desde que tenham adequada manutenção e tenham sido adequadamente dimensionadas. As suspensões em feixe de molas dificilmente cumprem esses requisitos e, geralmente, não alcançam o nível de desempenho desejado.

O DIVINE mostrou, também, que para as suspensões em grupos de eixos (tandem duplo ou tandem triplo), o controle da equalização do sistema de suspensão é importante, assim como os efeitos da pressão de contato pneu-pavimento. 
O efeito dinâmico do carregamento gerado pelo sistema de suspensão é sensível tanto à freqüência quanto ao amortecimento e esses dois parâmetros não são independentes. Uma suspensão com amortecimento em torno de $20 \%$ e frequiência abaixo de $2 \mathrm{~Hz}$ seria o ideal para a redução do carregamento dinâmico, porém, por razões práticas, é muito difícil o dimensionamento de um sistema de suspensão que obedeça a esses parâmetros. Testes executados durante o DIVINE demonstraram que há um limite na redução da carga dinâmica quando se reduz a freqüência ou se aumenta o amortecimento, entretanto, um amortecimento maior que $20 \%$ contribuiria para o aumento da segurança dos veículos de carga e a redução da vibração dos eixos sob condições severas de irregularidade.

O DIVINE não fornece informações diretas sobre a alocação de custos em uma rodovia, mas indica que os procedimentos de avaliação e dimensionamento de pavimentos podem superestimar os efeitos das cargas aplicadas pelos veículos relativamente aos efeitos de variabilidade da construção. O relatório enfatiza, também, a necessidade de um melhor entendimento dos efeitos dos fatores dos veículos sobre a deterioração da via, indispensável para o desenvolvimento de veículos "menos danosos". Mas sem negligenciar o conhecimento das condições iniciais e atuais da via e dos efeitos ambientais.

Uma significativa parcela dos custos de construção e manutenção do pavimento é atribuída ao tráfego de veículos pesados, os quais estão relacionados à carga por eixo. $\mathrm{O}$ método de atribuição geralmente está relacionado à lei da quarta-potência, a qual indica que os danos no pavimento aumentam exponencialmente com o aumento da carga. O conceito de que todos os veículos de carga danificam a via, no entanto, deve ser revisto, pois os resultados do DIVINE mostraram que a deterioração dos pavimentos pelos veículos pesados depende, além da carga estática, do desempenho dinâmico do veículo, do perfil longitudinal da via e da variabilidade estrutural do pavimento. 
Nas análises de alocação de custos devem ser considerados os custos diretos do tráfego rodoviário, associados à diminuição do conforto e da velocidade do tráfego, além do aumento nos custos de manutenção, consumo de combustível e danos às cargas, e também os custos indiretos, referentes ao aumento do número de viagens que seria necessário para controlar a deterioração da infraestrutura.

O aumento de eficiência defendido neste trabalho é baseado na redução dos custos diretos, mediante controle das cargas dinâmicas, como por exemplo, com uso de suspensão pneumática e manutenção dos pavimentos com baixa irregularidade longitudinal, mas sem redução dos limites legais de carga por eixo, ou seja, sem o aumento dos custos indiretos que ocorreria caso a proteção da infraestrutura se desse apenas com a limitação das cargas por eixo e o conseqüente aumento do número de viagens necessárias para o transporte das cargas. 


\section{MÉTODO}

A quantificação das solicitações dinâmicas de veículos rodoviários de carga sobre os pavimento é feita a partir da simulação do comportamento dinâmico do veículo trafegando sobre o pavimento, considerando a variabilidade de fatores como a condição da superfície de rolamento, em termos de irregularidade longitudinal, e a configuração do veículo, principalmente quanto à carga solicitante por eixo.

É utilizada a ferramenta computacional TRUCKSIM, desenvolvida pelo UMTRI (The University of Michigan Transportation Research Institute) para a simulação e análise da interação dinâmica de ações provocadas por veículos pesados na infraestrutura (pavimentos e pontes).

A programação das simulações consiste na seleção de dados de entrada como características do veículo (suspensão, pressão de enchimento dos pneus, tipo de eixos, tipo de rodagem), características da via (irregularidade longitudinal do pavimento; geometria vertical e horizontal da via) e situação de operação (carga aplicada por eixo e velocidade), tendo como dados de saída os esforços atuantes nos pneus (forca longitudinal, força transversal e força vertical), além dos valores de aceleração vertical dos pneus e a aceleração vertical do centro de gravidade do veículo.

Os veículos utilizados nas simulações são veículos de carga recorrentes em rodovias brasileiras, de configurações homologadas pelo DENATRAN, sendo um caminhão semipesado com capacidade de 16 t (caminhão toco), utilizado para médias e longas 
distâncias, e três extrapesados com capacidade aproximada de 40 t (trator + semirreboque), utilizados para longas distâncias.

As simulações são executadas sob situação de limite legal de carga e limite legal de carga $+20 \%$, a velocidades de 70,90 e $110 \mathrm{~km} / \mathrm{h}$, que resulta no estabelecimento de curvas de tendência do efeito dinâmico, possibilitando a análise do comportamento dos fatores em relação à situação da simulação.

Para análise crítica dos resultados, são propostas análises quantitativas e qualitativas da força vertical máxima atuante $\left(\mathrm{F}_{\mathrm{zmáx}}\right)$ por eixo. A análise quantitativa consiste na verificação da relação entre a força máxima atuante (carga aplicada/estática, irregularidade longitudinal, velocidade) em relação à força solicitante (carga aplicada/estática). A análise qualitativa consiste neste mesma relação, porém em termos de FEC (fator de equivalência de carga), que converte diferentes solicitações em um número equivalente de aplicações da solicitação-padrão, permitindo estimar seus efeitos no desempenho do pavimento, uma vez que os FEC são utilizados no cálculo do $\mathrm{N}$, importante para dimensionamento da seção transversal do pavimento. Para os cálculos dos FEC, foram usadas as equações da AASHTO, relacionadas à perda de serventia do pavimento, mais relacionadas à irregularidade longitudinal do que as equações do USACE, que levam em conta os efeitos do carregamento a uma profundidade de $33 \mathrm{~cm}$, associados a deformação permanente nas trilhas de roda.

Para conhecimento dos limites legais de carga, é feito o levantamento da legislação de pesos e dimensões em vigor no Brasil, assim como sua evolução, principalmente a partir de 1997, quando foi publicado o novo Código de Trânsito Brasileiro, que dispõe em seu artigos $99^{\circ}$ e $100^{\circ}$ que os veículos trafeguem em vias públicas dentro dos limites de pesos e dimensões estabelecidos pelo CONTRAN.

O conhecimento e quantificação dos efeitos que influenciam o comportamento dinâmico da interação veículo-via contribuem para o desenvolvimento de alternativas 
para redução da deterioração do pavimento devido a estes efeitos, bem como a redução dos custos operacionais do veículo, através do controle da parcela dinâmica desta interação. Contribuem, ainda, para subsidiar decisões políticas de alteração dos limites de pesos e dimensões e programas de incentivos (financeiros, fiscais e outros) à utilização de veículos comprovadamente menos danosos às vias públicas, como, por exemplo, veículos com suspensões semiativas, que reduzem os picos de carga e geram menos danos aos pavimentos. 


\section{LEGISLAÇÃO BRASILEIRA PARA LIMITES DE CARGA}

O artigo 99 do Código de Trânsito Brasileiro - CTB dispõe que "somente poderá transitar pelas vias terrestres o veículo cujo peso e dimensões atenderem aos limites estabelecidos pelo CONTRAN", enquanto o artigo 100 estabelece que "nenhum veículo pode transitar com peso bruto total ou peso bruto total combinado superior ao fixado pelo fabricante”.

O CTB, em seu anexo I, define Peso Bruto Total (PBT) como o peso máximo que o veículo transmite ao pavimento, constituído da soma da tara mais a lotação e Peso Bruto Total Combinado (PBTC) como o peso máximo transmitido ao pavimento pela combinação de um caminhão-trator mais seu semirreboque ou do caminhão mais o seu reboque ou reboques.

Em atendimento ao artigo 99 do CTB, o Conselho Nacional de Trânsito - CONTRAN publicou em as resoluções $n^{\circ}$ 12/98 e 68/98 que estabeleciam os limites de pesos e dimensões para veículos que transitem em vias públicas terrestres e os requisitos necessários à circulação de Combinação de Veículos de Carga - CVC, os quais eram permitidos trafegar mediante Autorização Especial de Tráfego - AET. O PBT/PTBC permitido era $45 \mathrm{t}$, respeitado o limite de carga por eixo ou grupo de eixos e a capacidade máxima de tração - CMT, conforme disposto no artigo $2^{\circ}$ da resolução $n^{\circ}$ 12/98, dependendo de sua configuração e tipo de rodagem. 
Os tipos de eixos e rodagem mais comuns atualmente no Brasil estão esquematizados na figura 5, com seus respectivos limites legais.

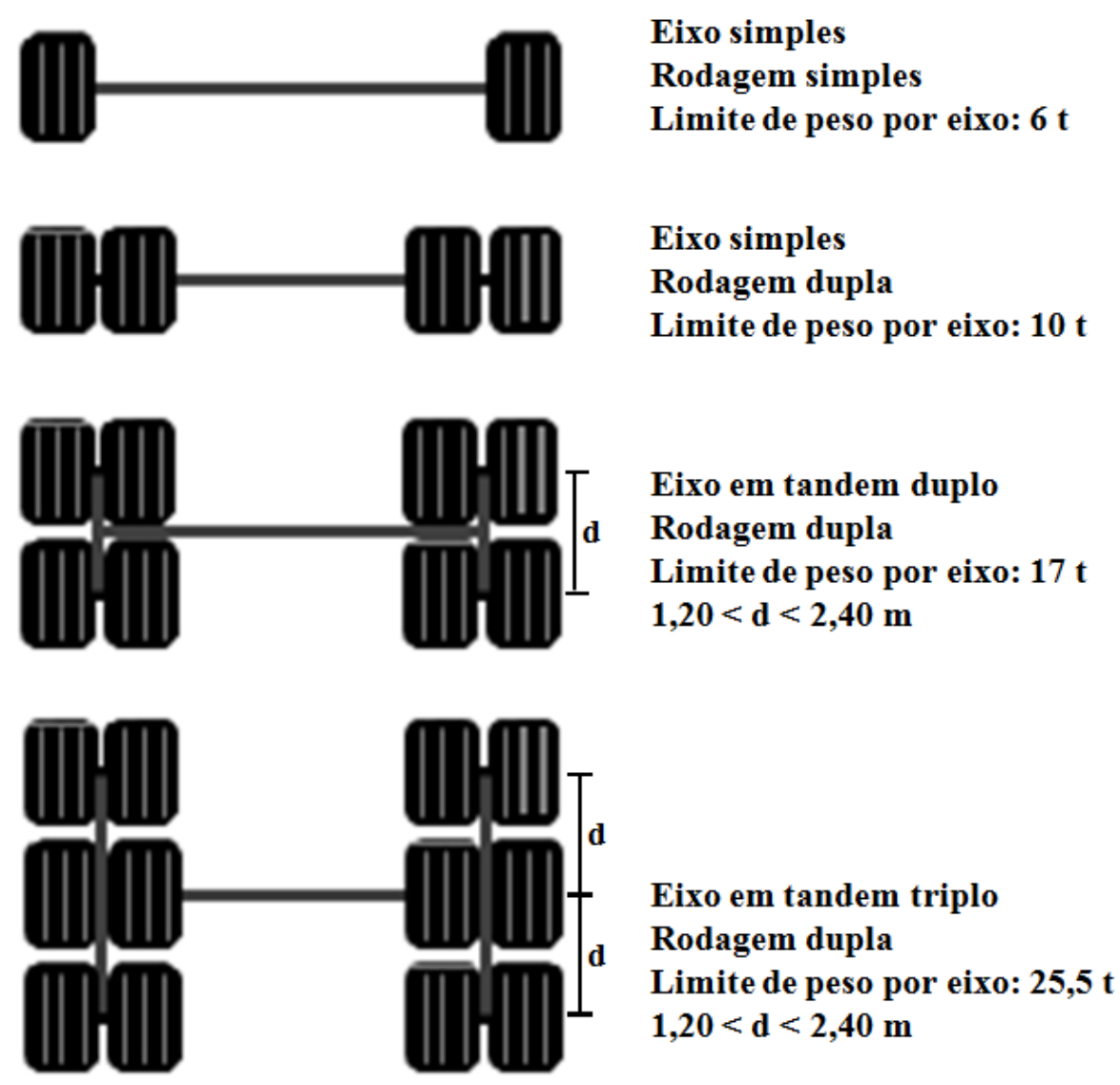

Figura 5: Tipos de eixos e de rodagem mais comuns no Brasil

Em 2005, a resolução CONTRAN no 184 liberou o tráfego de CVC sem AET, especificando seu limite de carga em 57 t, incluindo a unidade tratora, com, no máximo, sete eixos, comprimento mínimo de 17,5 m, máximo de 19,8 m, entre outros requisitos.

A liberação do tráfego de CVC sem AET, somada à necessidade do aumento na eficiência do transporte de carga, levaram ao aumento da utilização deste tipo de veículo, resultando em problemas de tráfego nas rodovias, principalmente em rampas íngremes de pista única e em dispositivos de acessos e interseções, além de solicitações adicionais ao pavimento. 
Nos anos seguintes, foram publicadas as resoluções $n^{\circ}$ 210/06, 211/06 e 258/07 que estabelecem os limites de peso e dimensões, os requisitos de segurança necessários para o tráfego de CVC e a metodologia de aferição de pesos dos veículos e os percentuais de tolerância. As resoluções $n^{\circ}$ 210/06 e 211/06 revogaram, respectivamente, as resoluções nº12/98 e 68/98 do CONTRAN.

A modificação básica introduzida pela resolução $n^{0}$ 210/06 do CONTRAN foi o estabelecimento do limite de PBT/PBTC não superior ao limite legal da classificação, baseado na distribuição dos eixos, obtido pela soma dos valores dos limites por eixo ou grupos de eixos. Cabe informar que os limites legais de carga por eixo ou grupo de eixos não foram alterados, isto é, permaneceram como os estabelecidos na resolução ${ }^{\circ}$ 12/98, ilustrados na figura 5 .

Ficou estabelecido que toda composição que tenha limite legal de carga maior que $45 \mathrm{t}$ só terá como limite de PBT/PBTC o obtido pela soma de seus limites por eixo ou grupos de eixo (limite legal) se esta composição tiver um comprimento mínimo de 16 m para combinações do tipo caminhão + semirreboque e de 17,5 m para combinações do tipo caminhão + reboque ou CVC com mais de duas unidades incluída a unidade tratora. As composições que tenham comprimento total inferior ao mínimo estabelecido pela resolução ficam limitadas ao máximo de 45 t de PBT/PBTC, mesmo que sua classificação tenha limite legal superior.

A resolução $n^{\circ}$ 211/06 fixa os requisitos para o tráfego de CVC com mais de duas unidades com peso bruto total acima de $57 \mathrm{t}$ e comprimento acima de $19,8 \mathrm{~m}$; e para aquelas que, mesmo com peso bruto de até $57 \mathrm{t}$, tenham comprimento superior a 19,8 m. A principal mudança promovida pela resolução $n^{\circ} 211$ foi o estabelecimento das composições homologadas para o transporte de carga, especificando seus limites de pesos e dimensões. 
A portaria n $n^{\circ}$ 63/09 do Departamento Nacional de Trânsito - DENATRAN homologa os veículos e as combinações de veículos de transporte de carga e de passageiros e apresenta em seu anexo I as silhuetas homologadas com seus respectivos limites de comprimento, PBT e PBTC.

No intuito de compensar eventuais erros no equipamento de aferição do peso de veículos no momento da autuação, em 1985, foi sancionada a lei $\mathrm{n}^{\circ} 7408 / 85$, conhecida como Lei da Balança, que instituía uma tolerância de 5\% sobre o limite de carga legal. Posteriormente, esta tolerância de 5\% foi diversas vezes alterada por resoluções do CONTRAN, variando de 5 a $10 \%$ e chegando a ser aplicada ao peso declarado em nota fiscal.

Atualmente, a resolução $n^{\circ}$ 258/07, alterada pela resolução $n^{\circ}$ 467/13 do CONTRAN, fixa em 7,5\% a tolerância máxima sobre os limites de peso bruto transmitido por eixo de veículo à superfície das vias públicas. A mesma resolução define a metodologia de aferição do peso e estabelece as medidas administrativas em caso de infração.

As sanções previstas para o veículo que trafega acima de seu limite de carga estão dispostas no art. 231 do CTB, regulamentado pela resolução $n^{\circ}$ 258/2007 do CONTRAN e incorrem em multa sobre o excedente do limite legal, acrescido da tolerância de 7,5\%. Para o excesso de carga em um eixo ou um grupo de eixos, sem exceder o PBTC, o CONTRAN estabelece o remanejamento da carga, se exceder o PBTC, deve ocorrer o transbordo da carga antes da liberação do veículo.

\subsection{Classificação dos Veículos e Aplicação da Legislação}

A configuração básica é a quantidade de unidades veiculares que compõe o veículo e a quantidade de eixos e grupos de eixos, independentemente da rodagem. A rodagem é definida pela quantidade de pneus por extremidade de eixo, podendo ser simples ou dupla. 
A classificação do veículo é estabelecida por um código de até dois algarismos intercalados por uma letra, por exemplo, 2S3. Para todas as classes o primeiro algarismo indica a quantidade de eixos da unidade tratora enquanto que o segundo algarismo, caso exista, indica a quantidade de eixos das unidades rebocadas.

As letras para representação das classes são C, S, I e J, como seguem:

- $\quad \mathbf{C}=$ veículo simples (caminhão ou ônibus) ou veículo trator + reboque;

- $\mathbf{S}=$ veículo trator (cavalo mecânico) + semirreboque;

- $\quad \mathbf{I}$ = veículo trator + semirreboque com distância entre-eixos maior que 2,40 m (eixos isolados);

- $\mathbf{J}=$ veículo trator + semirreboque com um eixo isolado e um eixo em tandem.

A tabela 4 apresenta alguns exemplos de veículos recorrentes em rodovias brasileiras, com suas respectivas classificações e limites legais de carga. A tabela 5 apresenta alguns exemplos de veículos recorrentes em rodovias brasileiras, com suas respectivas classificações e limites legais de carga, considerando o limite de tolerância atual. Convém ressaltar que a utilização da tolerância como "limite extra" de carga é comum na prática.

\subsection{Análise do Impacto da Legislação e Variação da Tolerância no Pavimento à Luz do Conceito de Fator de Equivalência de Carga}

Os FEC permitem a conversão de aplicações de diferentes solicitações em um número equivalente de aplicações da solicitação-padrão. Serão, portanto, calculados os fatores de equivalência de carga (FEC) para cada um dos veículos selecionados, uma vez que este cálculo é dado pelo somatório dos FEC para cada um dos eixos, uma vez que os eixos trabalham sempre em conjunto, de acordo com a configuração de cada veículo. 
Tabela 4: Classificação e legislação aplicada

\begin{tabular}{|c|c|c|c|}
\hline Veículo & Classificação & $\begin{array}{c}\text { Tipo de Eixo e de } \\
\text { Rodagem }\end{array}$ & $\begin{array}{l}\text { Limites legais por } \\
\text { eixo, PBT e PBTC }\end{array}$ \\
\hline $\begin{array}{l}\text { inv } \\
\mathbf{E}_{1}\end{array}$ & $2 \mathrm{C}$ & 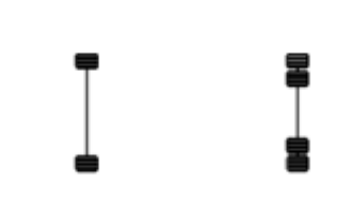 & $\begin{array}{l}\text { Caminhão: } \\
\mathrm{E}_{1}=6 \mathrm{t} \\
\mathrm{E}_{2}=10 \mathrm{t} \\
\mathrm{PBT}=\mathrm{PBTC}=16 \mathrm{t}\end{array}$ \\
\hline $\mathrm{E}_{1}$ & $3 \mathrm{~S} 2$ & 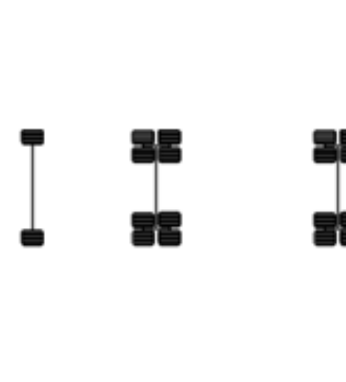 & $\begin{array}{l}\text { Caminhão trator } \\
\text { trucado }+ \\
\text { semirreboque: } \\
E_{1}=6 \mathrm{t} \\
\mathrm{E}_{2} \mathrm{E}_{3}=17 \mathrm{t} \\
\mathrm{E}_{4} \mathrm{E}_{5}=17 \mathrm{t} \\
\mathrm{PBT}=\mathrm{PBTC}=40 \mathrm{t}\end{array}$ \\
\hline 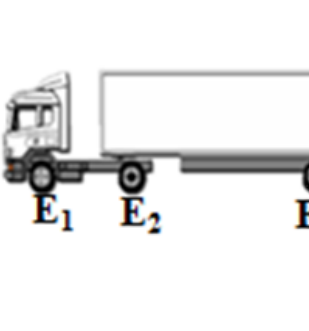 & $2 \mathrm{~S} 3$ & - & $\begin{array}{l}\text { Caminhão trator }+ \\
\text { semirreboque: } \\
E_{1}=6 \mathrm{t} \\
E_{2}=10 \mathrm{t} \\
E_{3} E_{4} E_{5}=25,5 \mathrm{t} \\
\mathrm{PBT}=\mathrm{PBTC}=41,5 \mathrm{t}\end{array}$ \\
\hline $\begin{array}{lll} & \\
\mathrm{E}_{1} & \mathrm{E}_{2} & \mathrm{E}_{3}\end{array}$ & $2 \mathrm{I} 3$ & 1 & $\begin{array}{l}\text { Caminhão trator }+ \\
\text { semirreboque: } \\
E_{1}=6 \mathrm{t} \\
E_{2}=10 \mathrm{t} \\
E_{3}=E_{4}=E_{5}=10 \mathrm{t} \\
\mathrm{PBT}=\mathrm{PBTC}=46 \mathrm{t}, \\
\text { se comprimento total } \\
\text { for maior que } 16 \mathrm{~m} . \\
\text { Se não, } \mathrm{PBT}=45 \mathrm{t}\end{array}$ \\
\hline
\end{tabular}


Tabela 5: Classificação e legislação aplicada, considerando a tolerância de 7,5\%

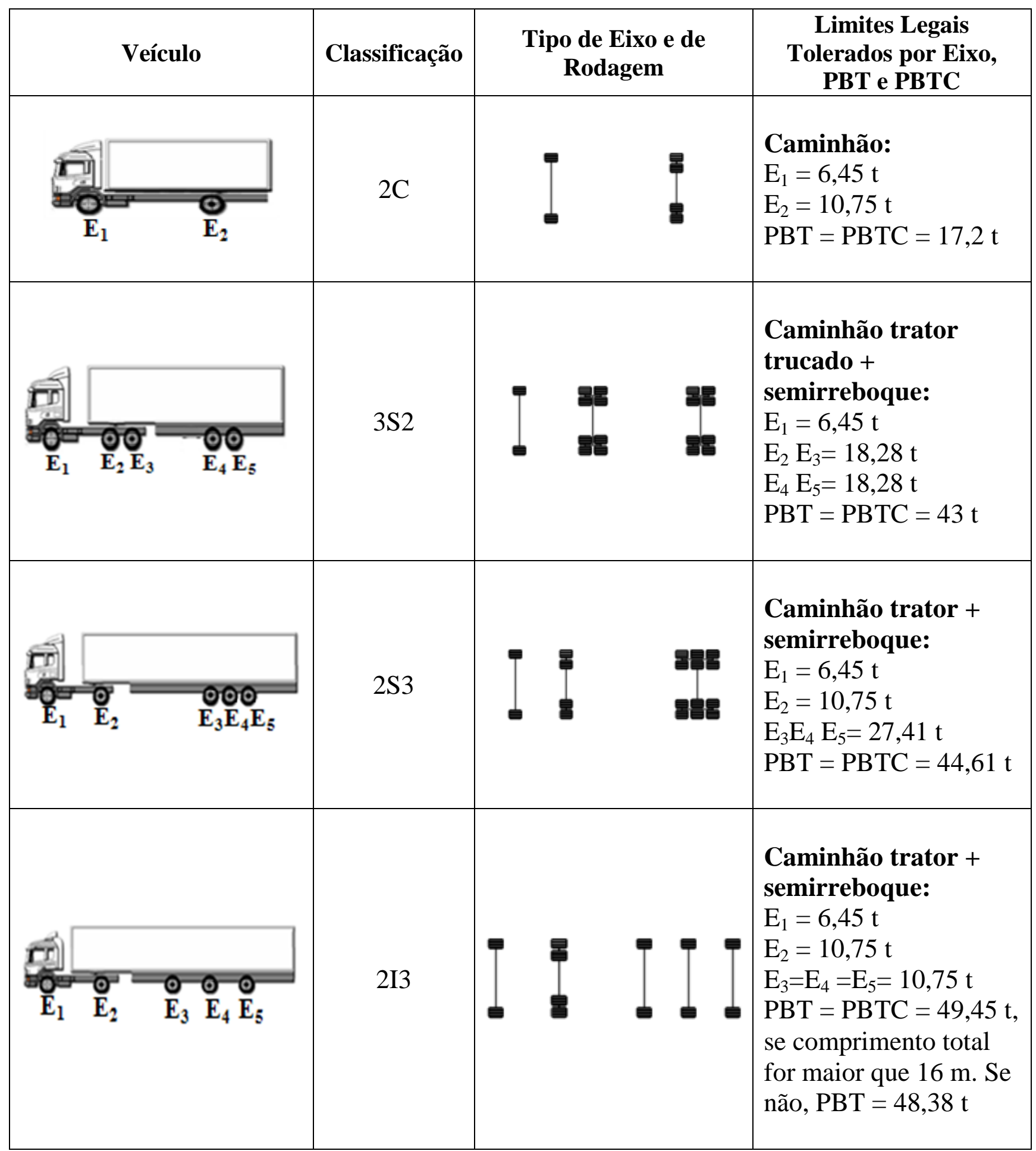


Considerando que a serventia esteja mais relacionada à irregularidade longitudinal do pavimento do que à deformação nas trilhas de roda, utilizam-se as equações propostas pela AASHTO para cálculo dos FEC.

A tabela 6 apresenta os FEC para cada um dos eixos e o $\mathrm{FEC}_{\text {total }}$ para cada veículo. $\mathrm{O}$ dimensionamento do pavimento considera a contagem de tráfego convertida em solicitações de eixo-padrão, isto é, cada veículo toco, de classificação $2 \mathrm{C}$, corresponde a 2,722 solicitações do eixo-padrão, assim como o veículo 3S2 corresponde a 3,612, o veículo 2S3 corresponde a 4,282 e o veículo 2I3 corresponde a 9,905. Cabe observar a discrepância dos FEC entre os veículos em tandem triplo e com três eixos espaçados, verifica-se que o veículo com três eixos espaçados, embora apenas 10,8\% mais carregado, representa um fator de equivalência de carga 131,3\% maior que o veículo em tandem triplo. Tal discrepância demonstra a não linearidade entre a carga aplicada por veículo e seu dano resultante na estrutura do pavimento.

Ainda, com relação ao limite de tolerância sobre o limite de carga legal por eixo e por veículo (PBTC), a figura 6 representa o impacto do incremento de carga no aumento do fator de carga. Observa-se o comportamento semelhante para os quatro veículos analisados quando submetidos a aumento de carga proporcional ao seu carregamento, como é o caso dos limites de tolerância estabelecidos pelo CONTRAN. A tolerância aplicada atualmente, de 7,5\%, resulta em um aumento de FEC médio de 36,2\%, considerando aplicação estática da carga. Isto significa que a tolerância de 7,5\% pode representar redução da vida útil em até $26 \%$. Cabe atentar que o aumento percentual do FEC, em relação ao aumento da carga, tem comportamento semelhante, da ordem da quarta-potência, para os veículos analisados, por este motivo, foi utilizada a linha de tendência da média dos valores para determinação da curva de variação $(\Delta)$ do FEC em função do excesso percentual, $x$. Tem-se, portanto:

$$
\Delta \mathrm{FEC}(\mathrm{x})=1,7329 \mathrm{x}^{4}+5,2839 \mathrm{x}^{3}+6,9848 \mathrm{x}^{2}+4,27 \mathrm{x}+9 \mathrm{E}^{-08}
$$

Onde x é $\mathrm{o}$ aumento percentual da carga. 


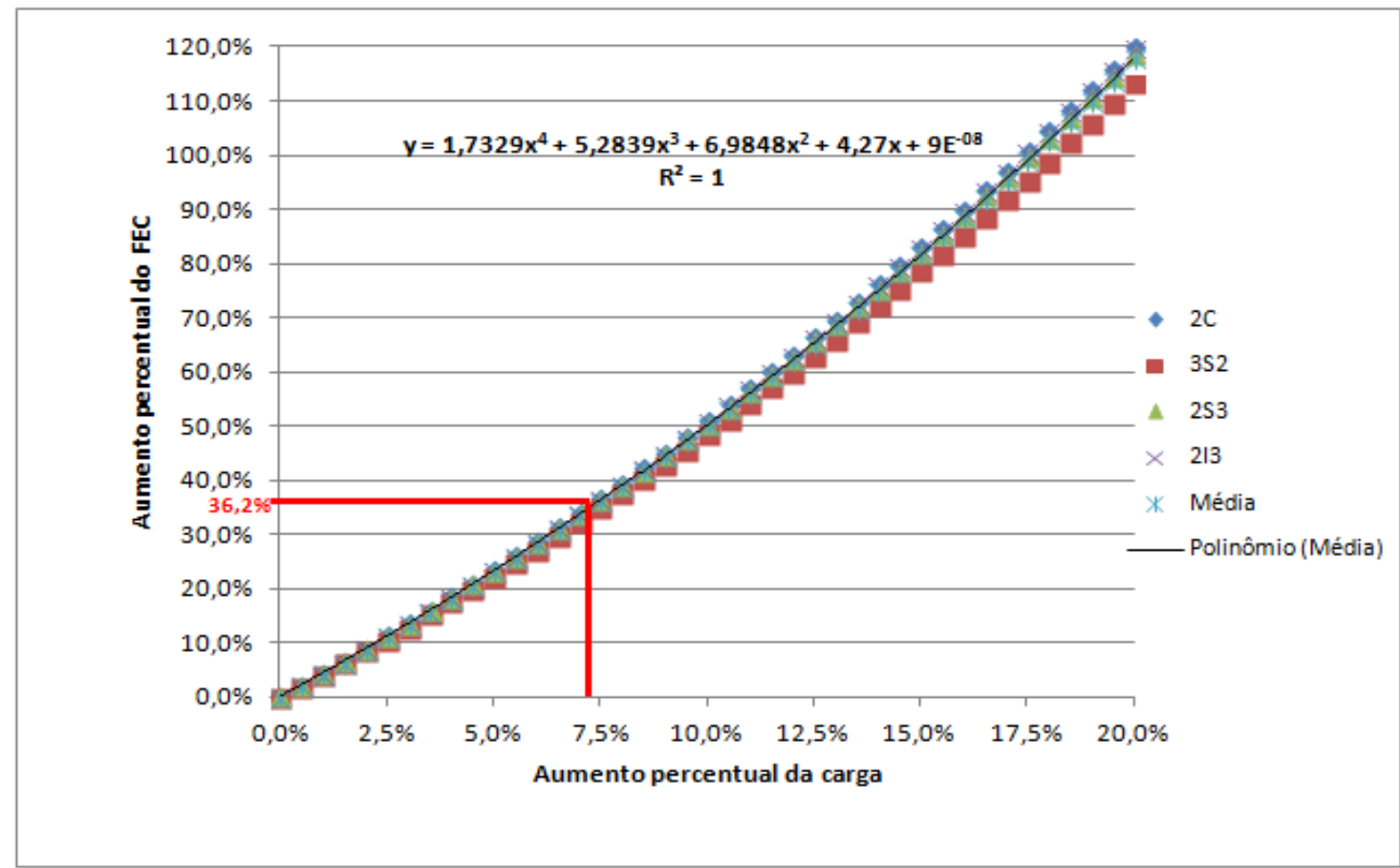

Figura 6: Impacto do incremento da carga no FEC (por veículo)

Tomando-se o aumento de 7,5\% como ponto notável, por ser o limite de tolerância atual, segundo resolução do CONTRAN, os valores de aumento percentual de FEC para este ponto estão apresentados na tabela 7. 
Tabela 6: Cálculo dos FEC para os Veículos de Carga 2C, 3S2, 2S3 e 2I3

\begin{tabular}{|c|c|c|c|}
\hline Veículo & Classificação & $\begin{array}{l}\text { Limites legais por eixo, } \\
\text { PBT e PBTC }\end{array}$ & FEC \\
\hline$\frac{n}{\mathrm{E}_{1}}$ & $2 \mathrm{C}$ & $\begin{array}{l}\mathrm{E}_{1}=6 \mathrm{t} \\
\mathrm{E}_{2}=10 \mathrm{t} \\
\mathrm{PBT}=\mathrm{PBTC}=16 \mathrm{t}\end{array}$ & $\begin{array}{l}\mathrm{FEC} \mathrm{E}_{1}=0,327 \\
\mathrm{FEC} \mathrm{E}_{2}=2,394 \\
\mathrm{FEC}_{\text {total }}=2,722\end{array}$ \\
\hline $\begin{array}{lll}\mathbf{E}_{1} & \mathbf{E}_{2} \mathbf{E}_{3} & \mathbf{E}_{4} \mathbf{E}_{5}\end{array}$ & $3 \mathrm{~S} 2$ & $\begin{array}{l}E_{1}=6 t \\
E_{2} E_{3}=17 t \\
E_{4} E_{5}=17 t \\
\text { PBT }=\text { PBTC }=40 t\end{array}$ & $\begin{array}{c}\mathrm{FEC} \mathrm{E}_{1}=0,327 \\
\mathrm{FEC} \mathrm{E}_{2} \mathrm{E}_{3}=1,642 \\
\mathrm{FEC} \mathrm{E}_{4} \mathrm{E} 5=1,642 \\
\mathrm{FEC}_{\text {total }}=3,612\end{array}$ \\
\hline $\mathrm{E}_{1} \quad \mathrm{E}_{2}$ & $2 \mathrm{~S} 3$ & $\begin{array}{l}E_{1}=6 t \\
E_{2}=10 t \\
E_{3} E_{4} E_{5}=25,5 t \\
P B T=P B T C=41,5 t\end{array}$ & $\begin{array}{c}\mathrm{FEC} \mathrm{E}_{1}=0,327 \\
\mathrm{FEC} \mathrm{E}_{2}=2,394 \\
\mathrm{FEC} \mathrm{E}_{3} \mathrm{E}_{4} \mathrm{E} 5=1,560 \\
\mathrm{FEC}_{\text {total }}=4,282\end{array}$ \\
\hline $\mathrm{E}_{1} \mathrm{E}_{2}$ & $2 \mathrm{I} 3$ & $\begin{array}{l}\mathrm{E}_{1}=6 \mathrm{t} \\
\mathrm{E}_{2}=10 \mathrm{t} \\
\mathrm{E}_{3}=\mathrm{E}_{4}=\mathrm{E}_{5}=10 \mathrm{t} \\
\mathrm{PBT}=\mathrm{PBTC}=46 \mathrm{t} \\
\text { (comprimento total } \\
\text { maior que } 16 \mathrm{~m} \text { ) }\end{array}$ & $\begin{array}{c}\mathrm{FEC} \mathrm{E}_{1}=0,327 \\
\mathrm{FEC} \mathrm{E}_{2}=2,394 \\
\mathrm{FEC} \mathrm{E}_{3}=\mathrm{E}_{4}=\mathrm{E} 5=2,394 \\
\mathrm{FEC}_{\text {total }}=9,905\end{array}$ \\
\hline
\end{tabular}

Tabela 7: FEC para excesso de 7,5\% na carga estática

\begin{tabular}{|c|c|}
\hline Veículo & $\begin{array}{c}\text { FEC para excesso } \\
\text { de carga de 7,5\% }\end{array}$ \\
\hline $2 \mathrm{C}$ & $36,7 \%$ \\
\hline $3 \mathrm{~S} 3$ & $35,1 \%$ \\
\hline $2 \mathrm{~S} 3$ & $36,3 \%$ \\
\hline $2 \mathrm{I} 3$ & $36,7 \%$ \\
\hline
\end{tabular}




\section{PROGRAMAÇÃO DAS SIMULAÇÕES}

O TRUCKSIM é uma ferramenta computacional desenvolvida pelo UMTRI (The University of Michigan Transportation Research Institute) para a simulação e análise da interação dinâmica de ações provocadas por veículos pesados na infraestrutura (pavimentos e pontes). A ferramenta utiliza modelos matemáticos validados experimentalmente, aos quais não permite o acesso, mas permite a seleção dos dados de entrada como características dos veículos e da via, bem como da situação de operação do veículo, em termos de carga aplicada por eixo e velocidade operacional).

A programação das simulações consiste na seleção de dados de entrada como características do veículo (suspensão, pressão de enchimento dos pneus, tipo de eixos, tipo de rodagem), características da via (irregularidade longitudinal do pavimento; geometria vertical e horizontal da via) e situação de operação (carga aplicada por eixo e velocidade), tendo como dados de saída os esforços atuantes nos pneus (forca longitudinal, força transversal e força vertical), além dos valores de aceleração vertical dos pneus e a aceleração vertical do centro de gravidade do veículo.

O TRUCKSIM permite a realização da análise do comportamento de variados fatores associado à dinâmica dos pavimentos, destacando-se neste trabalho a configuração do veículo, a irregularidade longitudinal da via e a velocidade de operação. Cada um dos 
fatores pode ser alterado permitindo a verificação da sensibilidade de cada fator no comportamento do sistema veículo-via.

Para que todos os fatores sejam analisados, faz-se uso de uma matriz fatorial (anexo 1) em que são descritas as condições das simulações a serem realizadas (veículo, peso por eixo, velocidade e irregularidade longitudinal) e inseridos os dados de saída das simulações. O procedimento de utilização do TRUCKSIM é a seleção do veículo, a seleção do perfil do pavimento (irregularidade longitudinal), a seleção das cargas aplicadas por eixo, a velocidade operacional do veículo e, por fim, a execução do programa (run), isto é, do modelo matemático, selecionado automaticamente pela ferramenta. O TRUCKSIM permite a exportação dos dados de saída e conta com o TRUCKSIM Data Convert, que extrai, por exemplo, apenas os maiores valores de força vertical para cada uma das simulações.

\subsection{Seleção de Veículos para Simulação}

Para as simulações foram selecionados os veículos exemplificados na tabela 2. Isto é, um caminhão toco, com CMT e PBT/PBTC de 16 t, e três semirreboques, com CMT e PBT/PBTC iguais ou maiores que $40 \mathrm{t}$.

O caminhão $2 \mathrm{C}$, conhecido popularmente como caminhão toco, é recorrente em vias públicas pela sua compacidade, pois tem comprimento total máximo de $14 \mathrm{~m}$. Pode ser aplicado tanto no transporte urbano como rodoviário, para curtas, médias e longas distâncias.

Os caminhões semirreboques são veículos maiores, conhecidos popularmente como extrapesados, com alta capacidade de carga, possuem um caminhão trator, de dois ou três eixos, com uma unidade de carga (semirreboque), sem capacidade tratora, com um a três eixos traseiros de variadas configurações. Para este trabalho foram elencados três semirreboques: um caminhão trucado + semirreboque em tandem duplo, um 
caminhão trator + semirreboque em tandem triplo e um caminhão trator + semirreboque com três eixos espaçados.

Postas estas configurações de veículos, será possível estabelecer o incremento de danos decorrente do incremento de carga permitido pela tolerância legal, além da quantificação dos efeitos dinâmicos para cada uma das composições, tanto por eixo ou grupo de eixos, como total.

\subsection{Seleção de Perfis Longitudinais de Pavimentos para Simulação}

Foram utilizados pavimentos em condições da superfície de rolamento distintas, conforme tabela 8, para verificação da influência da irregularidade da via no efeito dinâmico da carga. Os valores de IRI são pré-fixados pelo TRUCKSIM.

Tabela 8: Seleção de perfis para simulação

\begin{tabular}{|c|c|c|}
\hline Perfil & Condição da Superfície & IRI $(\mathbf{m} / \mathbf{k m}=\mathbf{m m} / \mathbf{m})$ \\
\hline$\# 1$ & Excelente & 1,636 \\
\hline$\# 2$ & Regular & 3,463 \\
\hline$\# 3$ & Ruim & 4,379 \\
\hline
\end{tabular}

\subsection{Seleção de Variáveis para Simulação}

Selecionados os perfis e os veículos, foram elencadas as variáveis para execução das simulações, sendo a matriz fatorial completa, utilizada para organização dos resultados, apresentada no anexo 1. Para cada combinação veículo x perfil, são feitas simulações considerando-se cargas correspondentes ao limite legal e ao limite legal acrescido de $20 \%$, para obtenção de uma curva do efeito dinâmico em relação à carga estática aplicada, sendo cada combinação simulada com velocidades de 70, 90 e 110 $\mathrm{km} / \mathrm{h}$. 
Após, complementarmente, são comparados os efeitos dinâmicos provenientes de rodagem dupla e rodagem simples com pneus extralargos. $\mathrm{E}$ outros fatores considerados são o tipo de suspensão (pneumática e convencional, em feixe de molas) e a pressão de enchimento dos pneus (80,100 e 120 psi), uma vez que são variáveis que interferem substancialmente no efeito dinâmico da carga, tanto para baixas frequências (corpo do veículo - eixo do veículo) como para altas frequências (eixo do veículo - rodas do veículo).

\subsection{Resultados Esperados nas Simulações}

Em cada simulação, são obtidos, através da ferramenta computacional, todos os esforços atuantes em cada um dos pneus (forca longitudinal, força transversal e força vertical). Estes resultados são fundamentais para este trabalho, pois os esforços atuantes nos pneus atuam também no pavimento com mesmo módulo e direção, mas em sentido contrário.

Além dos esforços atuantes nos pneus, são medidas a aceleração vertical dos pneus e a aceleração vertical do centro de gravidade do veículo - principal fator que indica a sensação de conforto dos motoristas e passageiros.

Os resultados são fornecidos pelo TRUCKSIM através de gráficos e valores em

função do tempo do percurso, como indicado na figura 7 e na figura 8. O TRUCKSIM Data Convert permite a extração dos valores de picos de carga durante a simulação, facilitando a seleção dos dados de saída utilizados para as análises. 


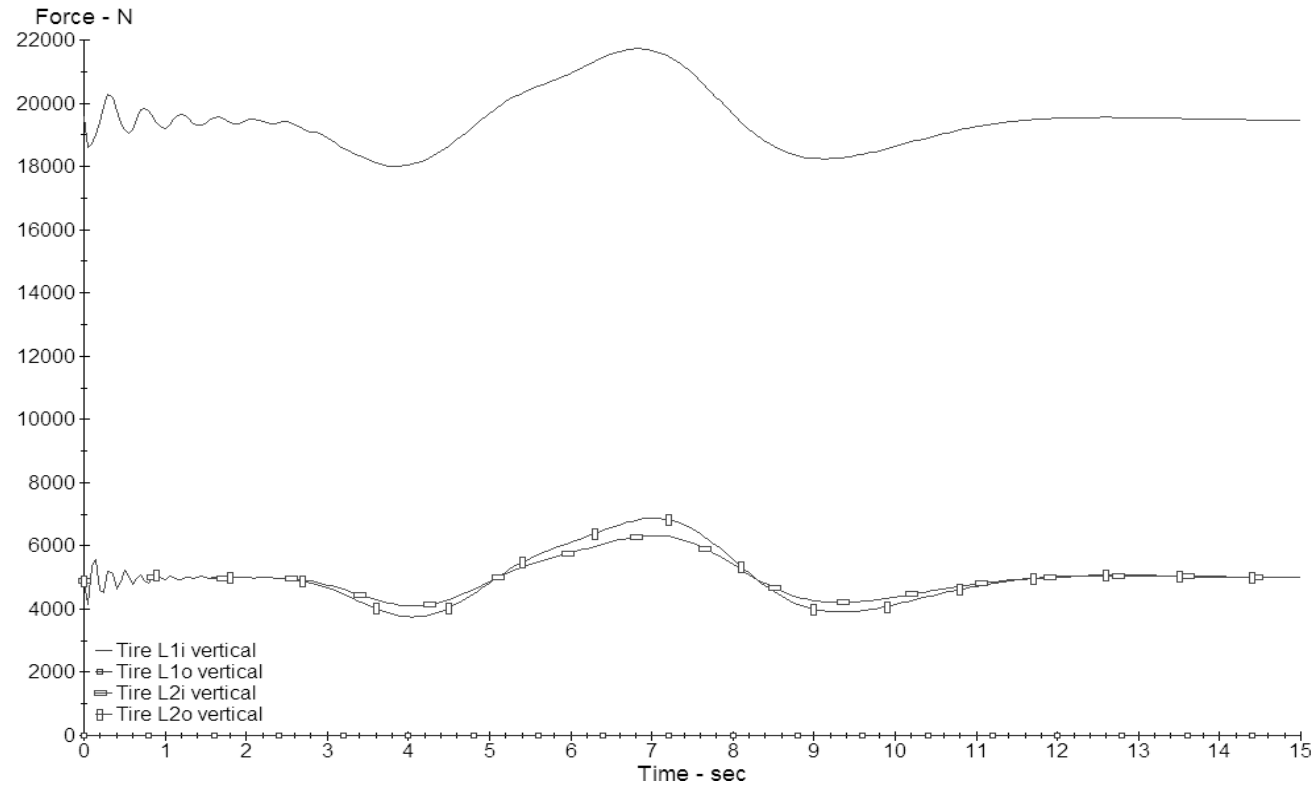

Figura 7: Gráfico da força normal atuante nos pneus em uma das simulações

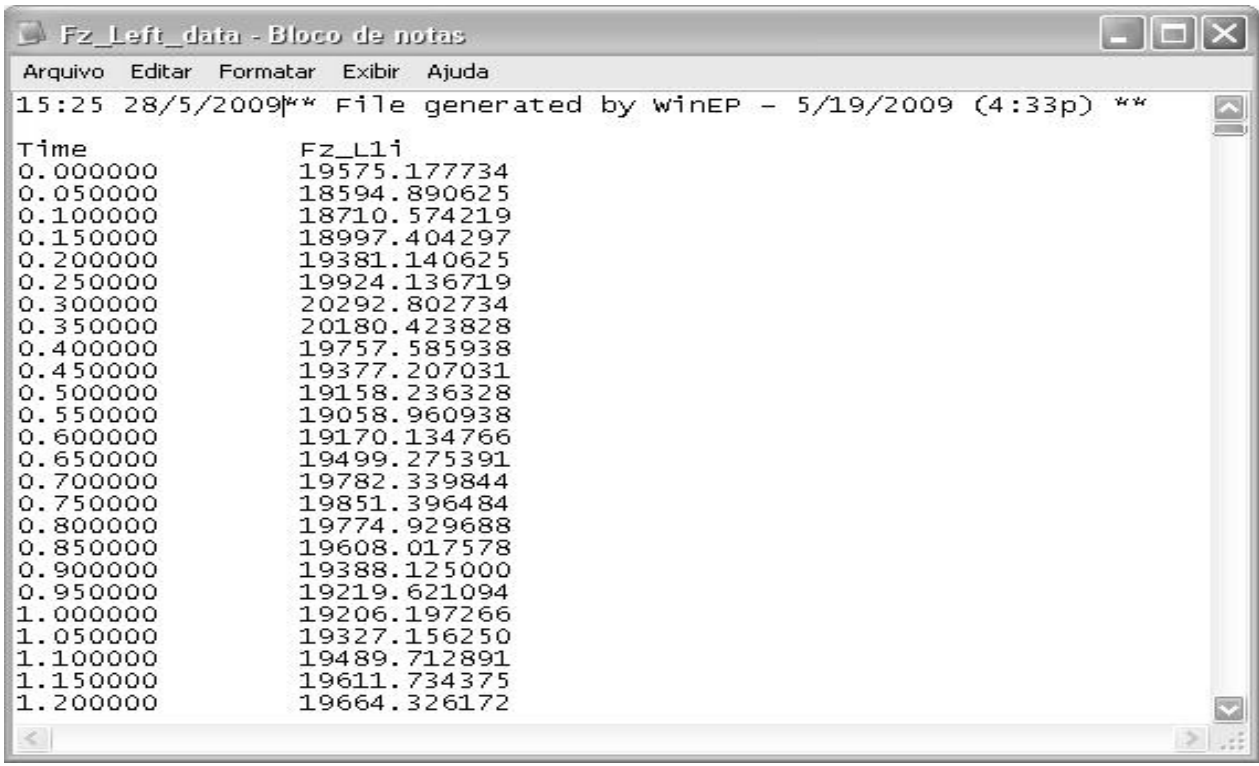

Figura 8: Coordenadas do gráfico da força normal atuante nos pneus 


\section{RESULTADOS E ANÁLISE DOS RESULTADOS}

\subsection{Mudanças nas Considerações Iniciais}

A versão utilizada do TRUCKSIM (Basic TRUCKSIM) não permite alterar parâmetros como a pressão de enchimento dos pneus e o tipo de suspensão. Por este motivo, tais parâmetros não puderam ser analisados neste trabalho. A ferramenta SUSPENSIONSIM, também desenvolvida pelo UMTRI, permite a alteração de parâmetros de suspensão, porém não foi prevista a necessidade de sua aquisição quando da concepção deste trabalho, inviabilizando a análise destes parâmetros.

No TRUCKSIM, as cargas nos pneus são fixadas pelo próprio programa, portanto não foi possível alterá-las e ajustá-las de modo a obter cargas por eixo iguais as cargas propostas, isto é, o limite legal de carga por eixo estabelecido pelas resoluções CONTRAN n 210 e $n^{\circ}$ 211/2006. Assim, procedeu-se com as simulações para os veículos elencados, considerando valores aproximados ao limite legal de carga e valores, em média, $20 \%$ maiores que estes, não acarretando prejuízo ao objetivo de se estabelecer curvas de tendências de efeito dinâmico em função da velocidade e irregularidade longitudinal da via.

Para análise da mudança no comportamento dinâmico decorrente da substituição de rodagem dupla por rodagem simples com pneus extralargos nos eixos traseiros. é utilizada uma condição específica de carga, devido às limitações impostas pela 
própria ferramenta.

Os resultados estão apresentados nas matrizes fatoriais dos anexos 2 a 5 .

Para análise crítica dos resultados, são propostas análises quantitativas e qualitativas da força vertical máxima atuante $\left(\mathrm{F}_{\text {zmáx }}\right)$ por eixo. A análise quantitativa consiste na verificação da relação entre a força máxima atuante (carga aplicada/estática, irregularidade longitudinal, velocidade) em relação à força solicitante (carga aplicada/estática).

A análise qualitativa consiste neste mesma relação, porém em termos de FEC (fator de equivalência de carga), que converte diferentes solicitações em um número equivalente de aplicações da solicitação-padrão, permitindo estimar seus efeitos no desempenho do pavimento. Considerando-se que o dimensionamento do pavimento é baseado no número de solicitações do eixo padrão, será feita comparação entre os fatores de equivalência de carga estática e dinâmica, isto é, será verificado o incremento de solicitações do eixo padrão decorrentes do efeito dinâmico proveniente de variáveis como velocidade e irregularidade longitudinal do pavimento.

Adicionalmente, será avaliado o efeito dinâmico decorrente da substituição de rodagem dupla por rodagem simples com pneus extralargos nos eixos traseiros.

Para os cálculos dos FEC, foram propostas as equações da AASHTO, relacionadas à perda de serventia do pavimento, mais relacionadas à irregularidade longitudinal do que as equações do USACE, que levam em conta os efeitos do carregamento a uma profundidade de $33 \mathrm{~cm}$, associados a deformação permanente nas trilhas de roda. As equações foram apresentadas anteriormente na tabela 2, reproduzida a seguir. 
Tabela 2: Fatores de equivalência de carga da AASHTO

\begin{tabular}{|l|c|}
\hline \multicolumn{1}{|c|}{ Tipo de Eixo } & Fatores de Equivalência de Carga (P em tf) \\
\hline Simples de rodagem simples & FEC $=(\mathrm{P} / 7,77)^{4,32}$ \\
\hline Simples de rodagem dupla & FEC $=(\mathrm{P} / 8,17)^{4,32}$ \\
\hline Tandem duplo (rodagem dupla) & $\mathrm{FEC}=(\mathrm{P} / 15,08)^{4,14}$ \\
\hline Tandem triplo (rodagem dupla) & $\mathrm{FEC}=(\mathrm{P} / 22,95)^{4,22}$ \\
\hline
\end{tabular}

$\mathrm{P}=$ Peso bruto total sobre o eixo

\subsection{Veículo $2 \mathrm{C}$}

O veículo $2 \mathrm{C}$, representado pela figura 9 , é um caminhão de dois eixos, popularmente conhecido como caminhão toco, com eixo dianteiro simples, de rodagem simples, e eixo traseiro simples, de rodagem dupla. A capacidade de carga deste tipo de veículo é $16 \mathrm{t}$, sendo $6 \mathrm{t}$ no eixo dianteiro e $10 \mathrm{t}$ no eixo traseiro.

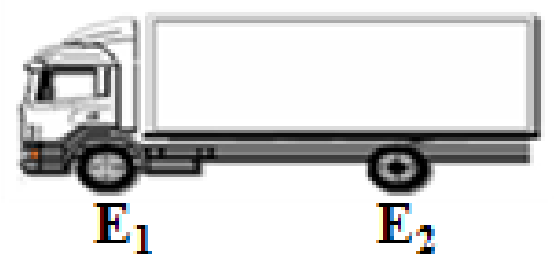

Figura 9: Veículo 2C

Como o programa não permite a entrada de dados customizados, serão feitas simulações para o limite legal e o limite legal acrescido de aproximadamente $20 \%$, limitado aos valores disponíveis no programa:

Limite Legal (LL):

$$
\begin{aligned}
& E_{1}=6 t \\
& E_{2}=10 t \\
& E_{1}+E_{2}=16 t
\end{aligned}
$$

Limite Legal + 20\% (LL + 20\%):

$$
\begin{aligned}
& E_{1}{ }^{\prime}=7 t \\
& E_{2}{ }^{\prime}=12 t \\
& E_{1}{ }^{\prime}+E_{2}{ }^{\prime}=19 t
\end{aligned}
$$


Os resultados das forças solicitantes máximas estão representados no anexo 2, conjuntamente com o cálculo do efeito dinâmico para cada um dos eixos e para a combinação dos eixos.

Considerando os eixos dianteiros $\left(\mathrm{E}_{1}\right)$ e traseiro isoladamente $\left(\mathrm{E}_{2}\right)$, os resultados da simulação apresentaram, para o eixo dianteiro, as forças atuantes menores que as solicitantes, ou seja, o efeito dinâmico decorrente da interação veículo-via provocou alívio das forças solicitantes em até 33,8\% em relação à força atuante (anexo 6).

Para o eixo traseiro, houve intensificação das forças solicitantes em até $39,1 \%$, para o caso do perfil de pavimento de maior irregularidade e trafegando a velocidade de 110 $\mathrm{km} / \mathrm{h}$, no entanto, esta intensificação não ocorre para o perfil de pavimento de menor irregularidade, considerado em excelente condição de rolamento, havendo, para este caso, alívio das forças atuantes em até 39,6\% (anexo 6).

Considerando a análise combinada dos eixos, os resultados apresentaram grande variação no efeito dinâmico, desde o alívio de até 37\%, para menor irregularidade e trafegando a $70 \mathrm{~km} / \mathrm{h}$, à intensificação de $24,4 \%$, para maior irregularidade e trafegando a $110 \mathrm{~km} / \mathrm{h}$ (anexo 6).

Observa-se, de forma generalizada, o aumento do efeito dinâmico com o aumento da velocidade e da irregularidade longitudinal. Atenta-se ainda que, para o veículo trafegando em superfície em excelente condição de rolamento, o efeito dinâmico decorrente da interação veículo-via é negativo, isto é, ocorre o alívio na força solicitante tanto para a solicitação por eixo, quanto para a solicitação combinada (somatório dos eixos). Cabe ressaltar que o veículo é representado pelo conjunto de eixos e que, na prática, os eixos não atuam separadamente, mas sempre de forma combinada. Assim, o gráfico da figura 10 indica o perfil de irregularidade crítica, no qual a carga atuante passa a ser maior que a carga solicitante, decorrente da interação 
veículo-via. Do gráfico, infere-se que, para o caminhão toco, o efeito dinâmico tornase desfavorável à via a partir do perfil longitudinal de IRI=3,1 $\mathrm{mm} / \mathrm{m}$.

Figura 10: Gráfico Efeito dinâmico (\%) x IRI (m/mm)

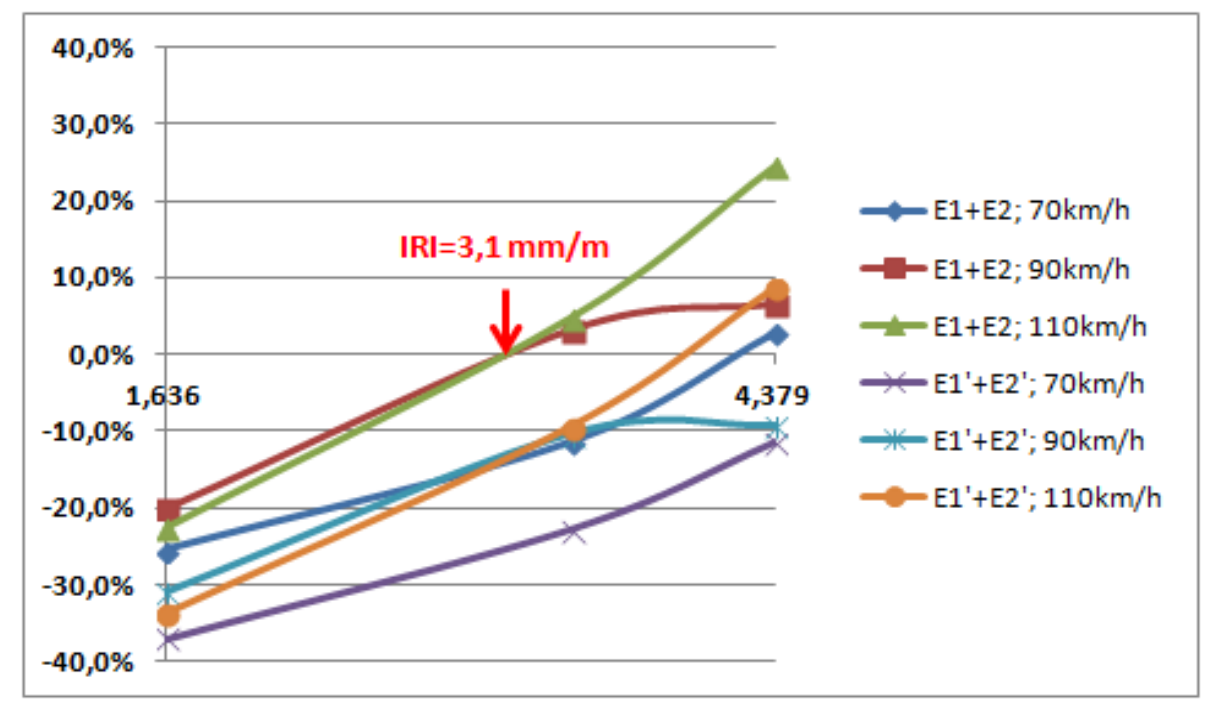

Outro ponto interessante, é que não houve relação de proporcionalidade entre o aumento da força solicitante e o da força atuante, sendo que um aumento na força solicitante resultou em aumento da força atuante muito inferior ao aumento da solicitação. Tem-se, por exemplo, que o aumento de $18,8 \%$ no carregamento, de $16 \mathrm{t}$ para $19 \mathrm{t}$, resulta no aumento máximo da força solicitante em 3,8\%, para o perfil de maior irregularidade e trafegando a velocidade de $110 \mathrm{~km} / \mathrm{h}$ (anexo 7). Ainda, como se observa no gráfico da figura 11, o limite de tolerância legal de 7,5\%, adotado atualmente, corresponde a um aumento na força solicitante de $1,5 \%$. 
Figura 11: Gráfico de Variação do efeito dinâmico com aumento da solicitação.

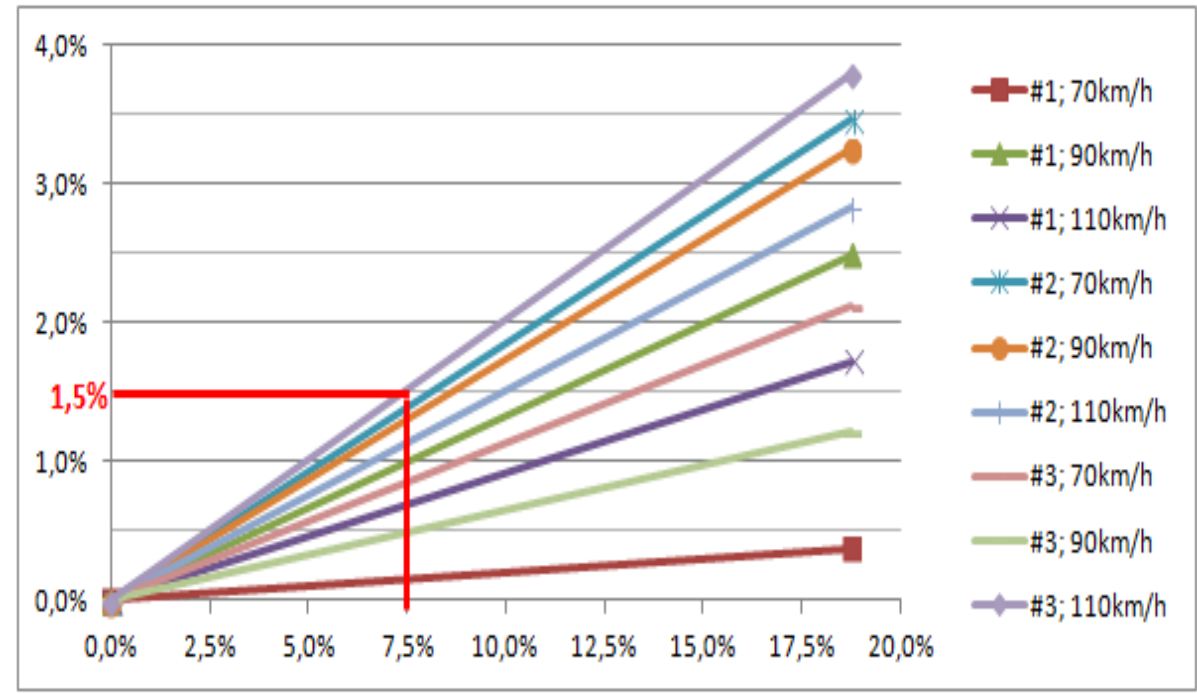

Feita a análise do comportamento dinâmico do veículo, decorrente de sua interação com o pavimento, parte-se para a análise qualitativa dos resultados, considerando-se o conceito de fator de equivalência de carga (FEC), utilizado para o dimensionamento do pavimento. Tal análise propõe o cálculo do FEC para a força solicitante no pavimento, que considera o efeito dinâmico da interação veículo-via, levando a um número $\mathrm{N}$ mais próximo da realidade e uma possível justificativa da redução da vida útil do pavimento.

O veículo $2 \mathrm{C}$ (caminhão toco) carregado com o limite legal de carga de $16 \mathrm{t}$, sendo $6 \mathrm{t}$ no eixo dianteiro e $10 \mathrm{t}$ no eixo traseiro, tem FEC de 2,722. O acréscimo de $20 \%$ no carregamento resulta em um FEC de 5,983. Isto significa que este veículo com $20 \%$ de excesso de carga representa 2,168 vezes o veículo com carregamento legal, podendo, em tese, reduzir a vida útil do pavimento em até $54 \%$, caso este pavimento fosse dimensionamento e solicitado apenas por este tipo de veículo.

Considerando-se o efeito dinâmico para o veículo trafegando em superfície em excelente condição de rolamento (perfil \#1), houve redução do FEC em até 75,1\% 
que, em primeira análise, poderia elevar a vida útil do pavimento em $33 \%$. Considerando-se o efeito dinâmico para o veículo trafegando em superfície com condição de rolamento ruim (perfil \#3), houve aumento do FEC em até $278 \%$, que confronta a constatação anterior, com redução da vida útil em até $74 \%$, dado que isto representa 3,78 vezes o FEC do veículo com carregamento legal (anexo 8). Do gráfico abaixo, infere-se a intensificação na redução da vida útil do pavimento a partir do perfil com IRI de $2,4 \mathrm{~mm} / \mathrm{m}$, quando o FEC solicitante, decorrente da interação dinâmica veículo-via, passa a ser maior que o FEC atuante, principalmente para velocidade acima de $90 \mathrm{~km} / \mathrm{h}$.

Figura 12: Gráfico Efeito dinâmico no FEC (\%) x IRI (m/mm)

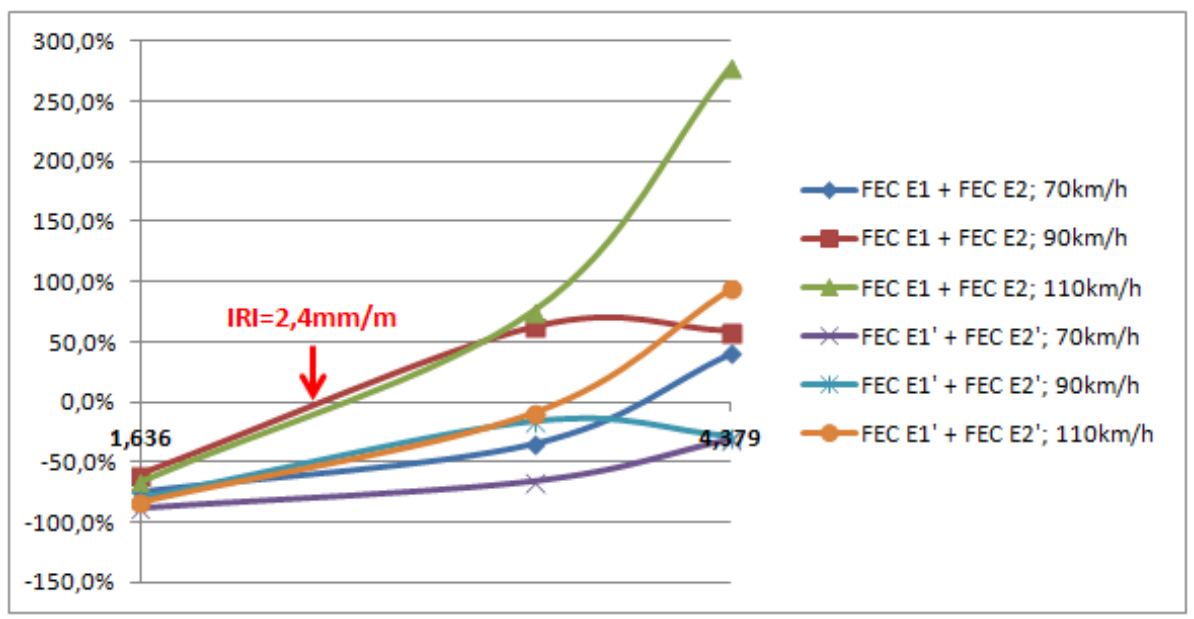

Por fim, o aumento de 18,8\% na carga (anexo 8), isto é, na força solicitante, representa um aumento do FEC solicitante de 116,8\%, elevando o FEC atuante em a até $320 \%$. Considerando-se o limite de tolerância legal de 7,5\%, o aumento no FEC passa de $36,7 \%$ a $130 \%$, que representa um aumento relativo de $254 \%$ e corresponde a redução da vida útil em até $72 \%$. 
Figura 13: Gráfico Impacto do incremento da carga no FEC, considerando o efeito dinâmico decorrente da interação veículo-via

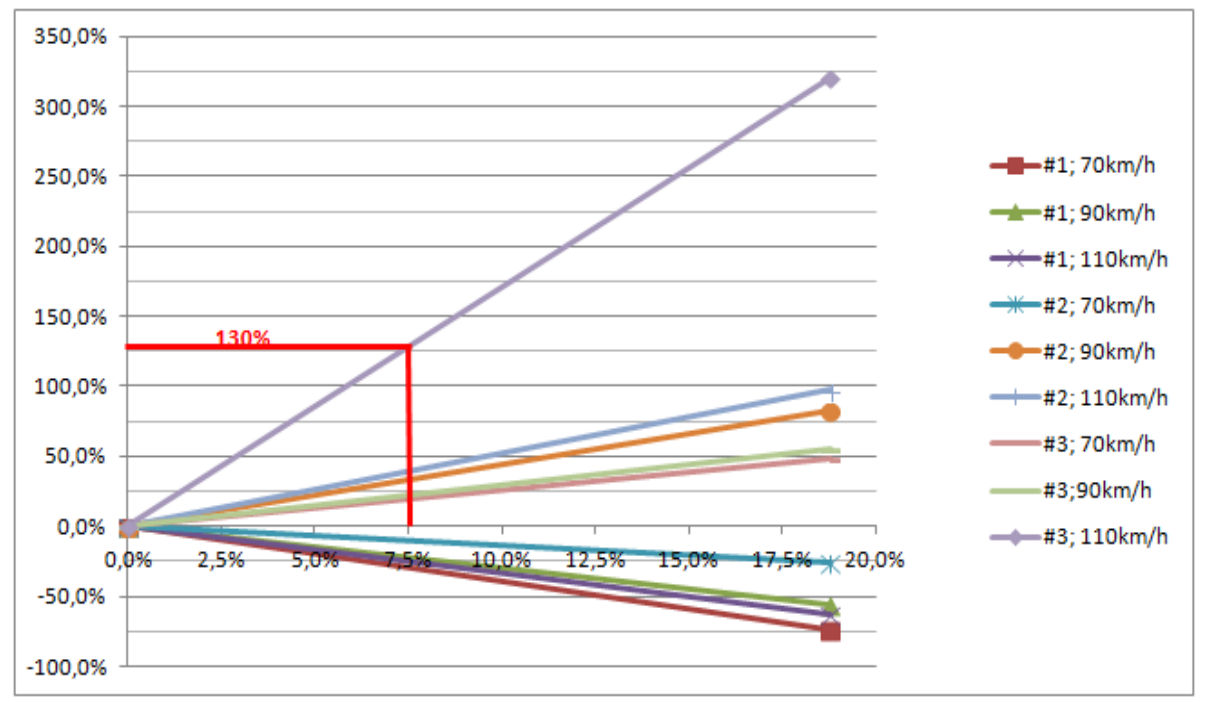

Adicionalmente, a comparação de rodagem simples e dupla (anexo 9), o veículo 2C com rodagem traseira simples e pneus extralargos apresentou efeito dinâmico maior que para rodagem traseira dupla, sendo que o efeito dinâmico aumentou com o aumento da velocidade e da irregularidade longitudinal da via.

\subsection{Veículo $3 \mathrm{~S} 2$}

O veículo 3S2, representado pela figura 14, é um caminhão extrapesado, composto de um caminhão trator trucado, com eixo dianteiro simples, de rodagem simples, e traseiro em tandem duplo, de rodagem dupla, e um semirreboque com eixo traseiro em tandem duplo, de rodagem dupla. A capacidade de carga deste tipo de veículo é 40 $\mathrm{t}$, sendo $6 \mathrm{t}$ no eixo dianteiro, $17 \mathrm{t}$ em cada um dos grupos de eixos traseiros em tandem duplo. 


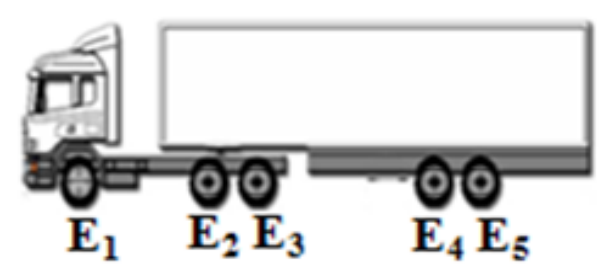

Figura 14: Veículo 3S2

Como o programa não permite a entrada de dados customizados, serão feitas simulações para valores próximos ao limite legal e ao limite legal acrescido de aproximadamente $20 \%$, limitado aos valores disponíveis no programa:

Cargas aplicadas:

Limite Legal (LL):

Limite Legal $+20 \%($ LL $+20 \%)$ :

$\mathrm{E}_{1}=6 \mathrm{t}$

$\mathrm{E}_{1}{ }^{\prime}=6 \mathrm{t}$

$\mathrm{E}_{2} \mathrm{E}_{3}=16 \mathrm{t}$

$\mathrm{E}_{2}{ }^{\prime} \mathrm{E}_{3}{ }^{\prime}=20 \mathrm{t}$

$\mathrm{E}_{4} \mathrm{E}_{5}=16 \mathrm{t}$

$\mathrm{E}_{4} \mathrm{E}_{5}^{\prime}=20 \mathrm{t}$

$E_{1}+E_{2} E_{3}+E_{4} E_{5}=38 t$

$E_{1}{ }^{\prime}+E_{2}{ }^{\prime} E_{3}{ }^{\prime}+E_{4}{ }^{\prime} E_{5}{ }^{\prime}=46 t$

Os resultados das forças solicitantes máximas estão representados no anexo 5, conjuntamente com o cálculo do efeito dinâmico para cada um dos eixos e grupo de eixos e para a combinação dos mesmos.

Considerando os eixos dianteiro e traseiro isoladamente, os resultados da simulação, utilizando o caminhão toco, apresentaram, para o eixo dianteiro, as forças atuantes maiores que as solicitantes, ou seja, o efeito dinâmico decorrente da interação veículovia provocou intensificação das forças solicitantes de $12,1 \%$ a $37,9 \%$ em relação à força atuante (anexo 10).

Para o primeiro grupo de eixos traseiros $\mathrm{E}_{2} \mathrm{E}_{3}$, em tandem duplo, houve desde alívio das forças solicitantes em até $20,8 \%$, para o caso do perfil de pavimento de menor irregularidade e trafegando a velocidade de $70 \mathrm{~km} / \mathrm{h}$, à intensificação das forças 
solicitantes em até 48,5\%, para o caso do perfil de pavimento de maior irregularidade e trafegado a velocidade de $110 \mathrm{~km} / \mathrm{h}$ (anexo 10).

Para o segundo grupo de eixos traseiros $\mathrm{E}_{4} \mathrm{E}_{5}$, em tandem duplo, a intensificação das forças solicitantes chegou ao valor de 86,3\% para o perfil de pavimento de maior irregularidade, trafegando a velocidade de $110 \mathrm{~km} / \mathrm{h}$. Para este conjunto de eixos não houve alívio das forças solicitantes em nenhuma situação (anexo 10).

Considerando a análise conjunta dos eixos, os resultados apresentaram, em geral, intensificação das forças solicitantes e chegaram até 62,1\%. Para a situação de excesso de $20 \%$ na carga, houve alívio de 6,6\%, para o veículo trafegando sob excelente condição de rolamento a velocidade de até $90 \mathrm{~km} / \mathrm{h}$ (anexo 10).

Observa-se, de forma generalizada, o aumento do efeito dinâmico com o aumento da velocidade e da irregularidade longitudinal. Diferentemente do veículo $2 \mathrm{C}$, houve intensificação das forças solicitantes na maioria dos casos, tanto para a solicitação por eixo ou grupo de eixos, quanto para a solicitação combinada dos eixos. Cabe ressaltar que o veículo é representado pelo conjunto de eixos e que, na prática, os eixos não atuam separadamente. Assim, o gráfico abaixo indica o perfil de irregularidade crítica, no qual a carga atuante passa a ser maior que a carga solicitante, decorrente da interação veículo-via. Do gráfico, infere-se que, para o caminhão semirreboque em tandem duplo, o efeito dinâmico é desfavorável a partir de perfil com IRI $=0,7$ $\mathrm{mm} / \mathrm{m}$. Como o efeito dinâmico foi positivo para a maioria dos casos, houve necessidade de extrapolação das curvas para verificação do IRI crítico, a partir do qual o efeito dinâmico decorrente da interação veículo-via provoca intensificação das forças solicitantes. 
Figura 15: Gráfico Efeito dinâmico (\%) x IRI (m/mm)

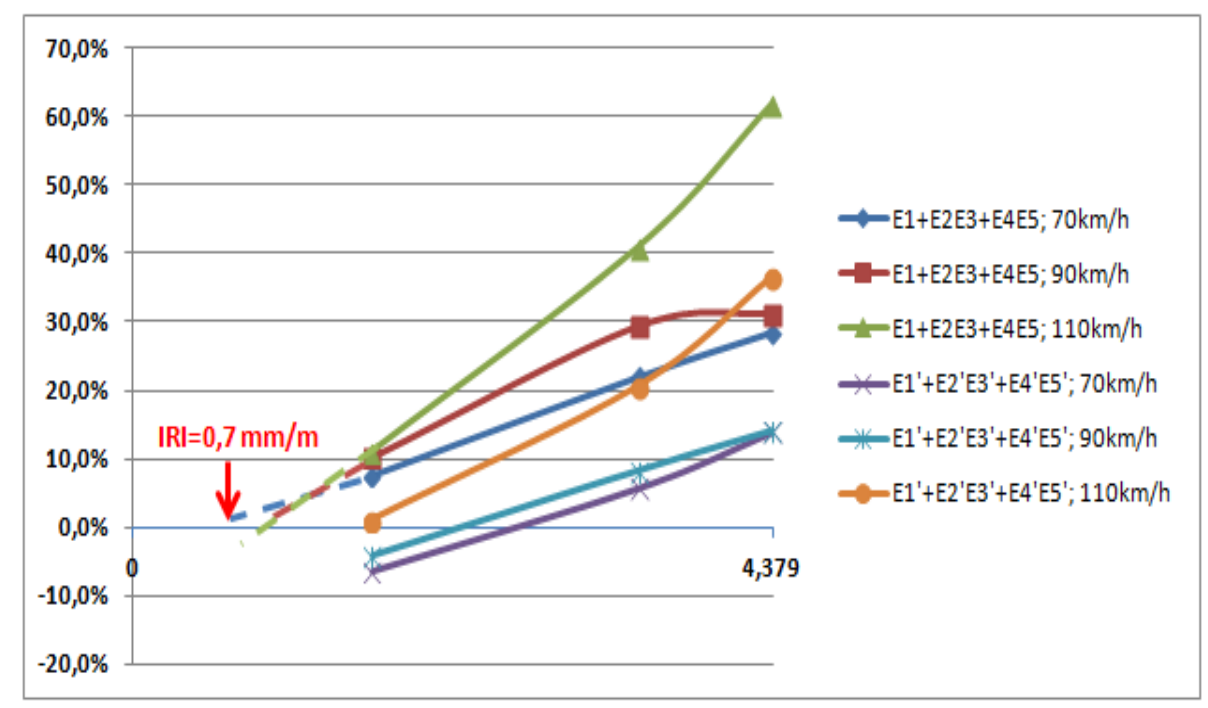

Outro ponto interessante, é que não houve relação de proporcionalidade entre o aumento da força solicitante e o da força atuante, sendo que um aumento na força solicitante resultou em aumento da força atuante inferior ao aumento da solicitação. Tem-se, por exemplo, que o aumento de $21,1 \%$ no carregamento, de $38 \mathrm{t}$ para $46 \mathrm{t}$, resulta no aumento máximo da força solicitante em $10,2 \%$, para o perfil de menor irregularidade e trafegando a velocidade de $110 \mathrm{~km} / \mathrm{h}$ (anexo 11). Ainda, como se observa no gráfico 6 , o limite de tolerância legal de 7,5\%, adotado atualmente, corresponde a um aumento na força solicitante de 3,7\%.

Feita a análise do comportamento dinâmico do veículo, decorrente de sua interação com o pavimento, parte-se para a análise qualitativa dos resultados, considerando-se o conceito de fator de equivalência de carga (FEC), utilizado para o dimensionamento do pavimento. Tal análise propõe o cálculo do FEC para a força solicitante no pavimento, que considera o efeito dinâmico da interação veículo-via, levando a um número $\mathrm{N}$ mais próximo da realidade e uma possível justificativa da redução da vida útil do pavimento. 
Figura 16: Gráfico de Variação do efeito dinâmico com aumento da solicitação.

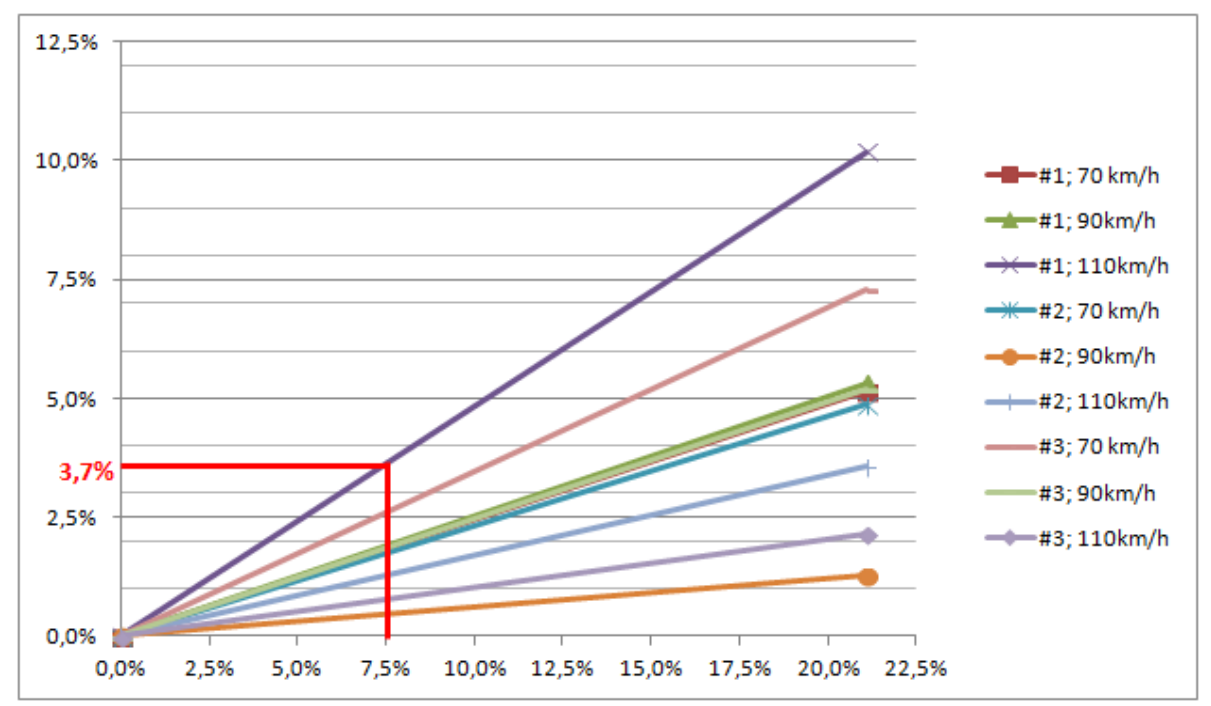

$\mathrm{O}$ veículo $3 \mathrm{~S} 2$ carregado com o limite legal de carga de $40 \mathrm{t}$, sendo $6 \mathrm{t}$ no eixo dianteiro e $17 \mathrm{t}$ em cada grupo de eixos traseiros, tem FEC de 3,612. O acréscimo de $20 \%$ no carregamento, chegando a $48 \mathrm{t}$, resulta em um FEC de 7,707. Isto significa que este veículo sobrecarregado representa 2,134 vezes o veículo com carregamento legal, podendo, em tese, reduzir a vida útil do pavimento em até $53 \%$, caso este pavimento fosse dimensionamento e solicitado apenas por este tipo de veículo.

Considerando-se o efeito dinâmico para o veículo trafegando em superfície em excelente condição de rolamento (perfil \#1), houve aumento do FEC em 81,5\% que, em primeira análise, poderia reduzir a vida útil do pavimento em $45 \%$. Considerandose o efeito dinâmico para o veículo trafegando em superfície com condição de rolamento ruim (perfil \#3), houve aumento do FEC em até $805 \%$, que confronta a constatação anterior, com redução da vida útil em até $89 \%$, dado que isto representa 9,05 vezes o FEC do veículo com carregamento legal (anexo12). Do gráfico da figura 17, infere-se a intensificação na redução da vida útil do pavimento a partir do perfil com IRI de $0,5 \mathrm{~mm} / \mathrm{m}$, quando o FEC solicitante, decorrente da interação dinâmica veículo-via, passa a ser maior que o FEC atuante, considerando velocidade de operação acima de $70 \mathrm{~km} / \mathrm{h}$. 
Figura 17: Gráfico Efeito dinâmico no FEC (\%) x IRI (m/mm)

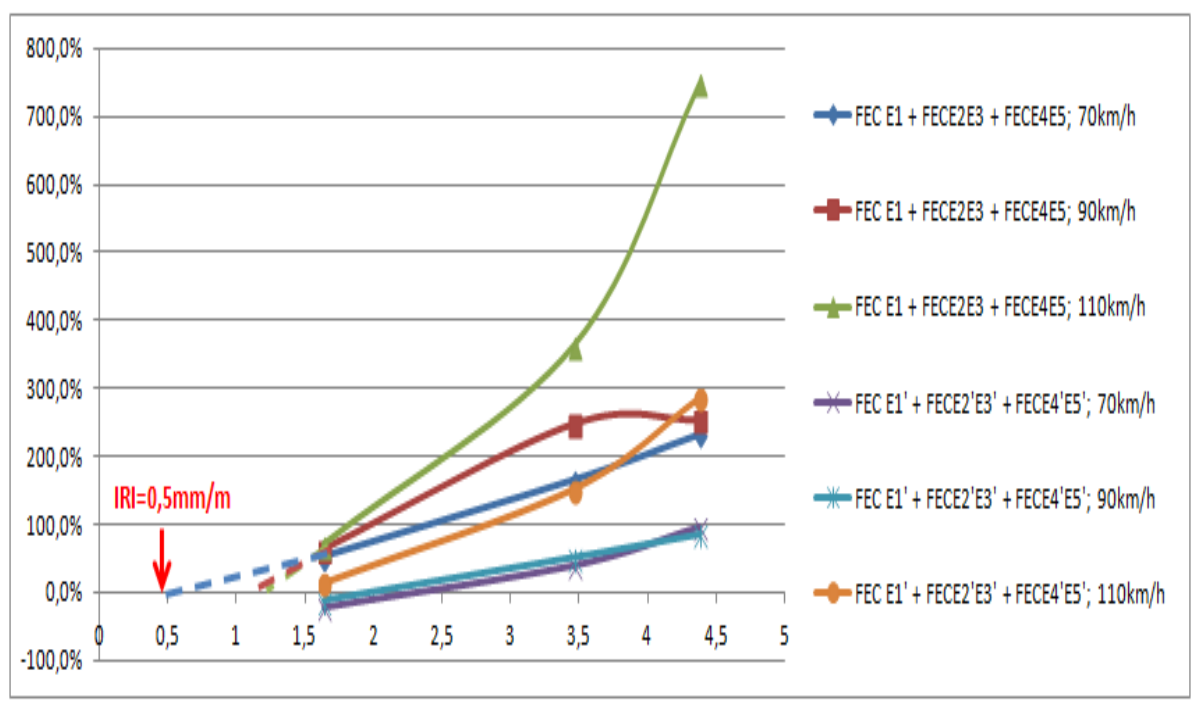

Por fim, o aumento de $21,1 \%$ na carga (anexo 12), isto é, na força solicitante, representa um aumento do FEC solicitante de 134,6\%, elevando o FEC atuante em a até $805 \%$. Considerando-se o limite de tolerância legal de 7,5\%, o aumento no FEC passa de $35,1 \%$ a $280 \%$, que representa um aumento relativo de $698 \%$ e corresponde a redução da vida útil em até $87 \%$.

Figura 18: Gráfico Impacto do incremento da carga no FEC, considerando o efeito dinâmico decorrente da interação veículo-via

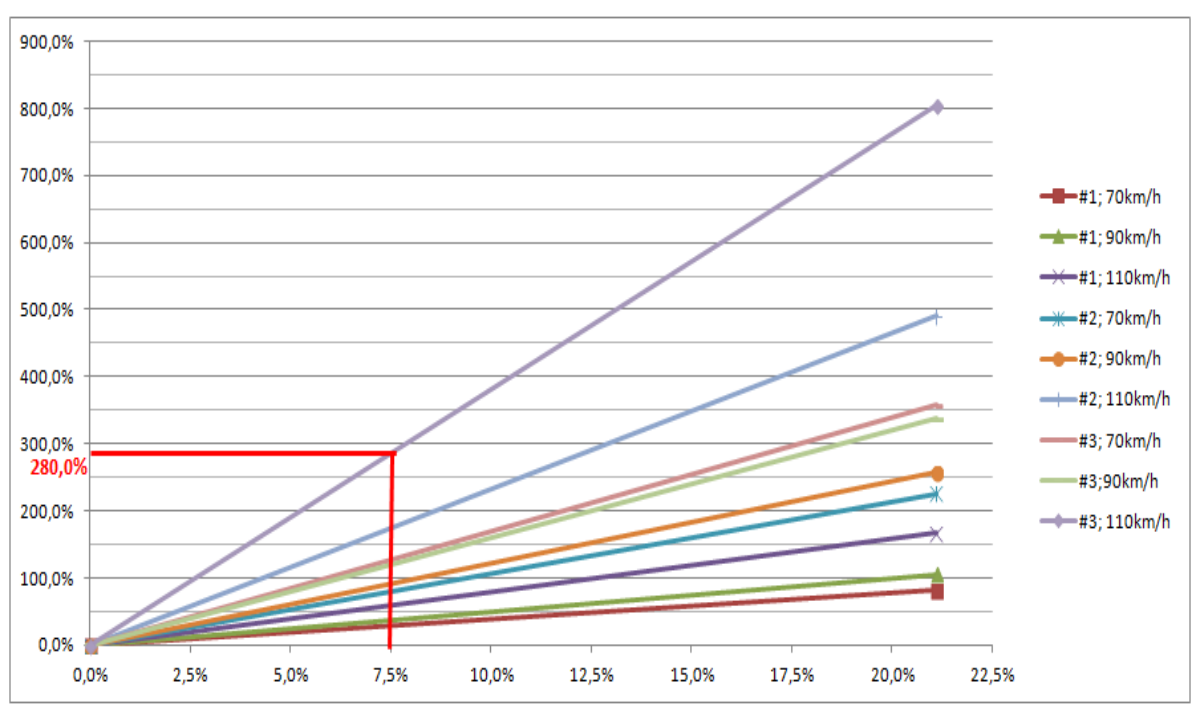


Adicionalmente, a comparação de rodagem simples e dupla (anexo 13), o veículo 3S2 com rodagem traseira simples e pneus extralargos apresentou efeito dinâmico menor que para rodagem traseira dupla, sendo que o efeito dinâmico aumentou com o aumento da velocidade e da irregularidade longitudinal da via. Entretanto, para este veículo, a força solicitante se apresentou menor que a força atuante para todas as simulação executadas para o veículo com eixos traseiros com rodagem simples e pneus extralargos.

\subsection{Veículo $2 \mathrm{S3}$}

$\mathrm{O}$ veículo $2 \mathrm{~S} 3$, representado pela figura 19 , é um caminhão extra-pesado, composto de um caminhão trator, com eixo dianteiro simples, de rodagem simples, e eixo traseiro simples, de rodagem dupla, e um semirreboque com eixo traseiro em tandem triplo, de rodagem dupla. A capacidade de carga deste tipo de veículo é 41,5 t, sendo $6 \mathrm{t}$ no eixo dianteiro, $10 \mathrm{t}$ no eixo traseiro do trator e $25,5 \mathrm{t}$ grupo de eixos traseiros em tandem triplo.

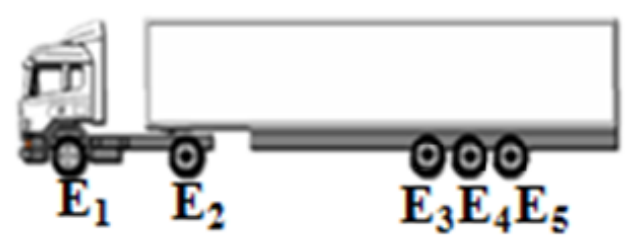

Figura 19: Veículo 2S3

Como o programa não permite a entrada de dados customizados, serão feitas simulações para valores próximos ao limite legal e ao limite legal acrescido de aproximadamente $20 \%$, limitado aos valores disponíveis no programa: 
Cargas aplicadas:

Limite Legal (LL):

$\mathrm{E}_{1}=6 \mathrm{t}$

$\mathrm{E}_{2}=10 \mathrm{t}$

$\mathrm{E}_{3} \mathrm{E}_{4} \mathrm{E}_{5}=24 \mathrm{t}$

$\mathrm{E}_{1}+\mathrm{E}_{2}+\mathrm{E}_{3} \mathrm{E}_{4} \mathrm{E}_{5}=40 \mathrm{t}$
Limite Legal + 20\% (LL + 20\%):

$\mathrm{E}_{1}{ }^{\prime}=7 \mathrm{t}$

$\mathrm{E}_{2}{ }^{\prime}=12 \mathrm{t}$

$\mathrm{E}_{3}{ }^{\prime} \mathrm{E}_{4}{ }^{\prime} \mathrm{E}_{5}{ }^{\prime}=30 \mathrm{t}$

$E_{1}{ }^{\prime}+E_{2}{ }^{\prime}+E_{3}{ }^{\prime} E_{4}{ }^{\prime} E_{5}{ }^{\prime}=49 t$

Os resultados das forças solicitantes máximas estão representados no anexo 14, conjuntamente com o cálculo do efeito dinâmico para cada um dos eixos e grupo de eixos e para a combinação dos mesmos.

Considerando os eixos dianteiros e o grupo de eixos traseiros isoladamente, os resultados da simulação apresentaram, para o eixo dianteiro, as forças atuantes variáveis em relação às solicitantes, ou seja, o efeito dinâmico decorrente da interação veículo-via provocou desde alívio das forças solicitantes de $17,1 \%$ a intensificação de $21,6 \%$ em relação à força atuante (anexo 14). Observou-se ainda, que a intensificação das forças solicitantes ocorreu para a situação de limite legal de carga $\left(E_{1}=6 \mathrm{t}\right)$, para a sobrecarga de $20 \%$, ocorreu, para a maioria das situações, alívio na força atuante, em relação à solicitante.

Para o eixo traseiro $E_{2}$, houve desde alívio das forças solicitantes em até $5,1 \%$, para o caso do perfil de pavimento de menor irregularidade e trafegando a velocidade de 70 $\mathrm{km} / \mathrm{h}$, à intensificação das forças solicitantes em até $47 \%$, para o caso do perfil de pavimento de maior irregularidade e trafegado a velocidade de $110 \mathrm{~km} / \mathrm{h}$ (anexo 14). Assim como para o eixo dianteiro, a situação de sobrecarga apresentou menores efeitos dinâmicos que a situação de limite legal de carga.

Para o grupo de eixos traseiros $\mathrm{E}_{3} \mathrm{E}_{4} \mathrm{E}_{5}$, em tandem triplo, a intensificação das forças solicitantes ocorreu para a situação de pior irregularidade, IRI $=4,379 \mathrm{~mm} / \mathrm{m}$, chegando ao valor máximo de $15,9 \%$ para o perfil de pavimento de maior 
irregularidade, trafegando a velocidade de $110 \mathrm{~km} / \mathrm{h}$, sob situação de carga abaixo do limite legal de carga $\left(\mathrm{E}_{3} \mathrm{E}_{4} \mathrm{E}_{5}=24 \mathrm{t}\right)$. Para a situação de sobrecarga, houve alívio na solicitação de até $38,8 \%$ (anexo 14).

Considerando a análise conjunta dos eixos, os resultados apresentaram intensificação das forças solicitantes em até $24,5 \%$, para perfil de irregularidade superior a 3,463 $\mathrm{mm} / \mathrm{m}$. Para o perfil de menor irregularidade (IRI $=1,636 \mathrm{~mm} / \mathrm{m}$ ), houve alívio na solicitação, isto é, forças atuantes até $27,3 \%$ menores que as solicitantes. Para a situação de sobrecarga, o máximo efeito dinâmico, para o perfil de maior irregularidade, trafegando a $110 \mathrm{~km} / \mathrm{h}$, foi $1,9 \%$.

Observa-se, de forma generalizada, o aumento do efeito dinâmico com o aumento da velocidade e da irregularidade longitudinal. Cabe ressaltar que o veículo é representado pelo conjunto de eixos e que, na prática, os eixos não atuam separadamente. Assim, o gráfico abaixo indica o perfil de irregularidade crítica, no qual a carga atuante passa a ser maior que a carga solicitante, decorrente da interação veículo-via. Do gráfico da figura 20 , infere-se que, para o caminhão semirreboque em tandem triplo, o efeito dinâmico é desfavorável a partir de perfil com IRI $=2,4 \mathrm{~mm} / \mathrm{m}$, independentemente da velocidade de operação do veículo, considerando o veículo carregado com o limite legal de carga. Para o veículo com excesso de carga, o efeito dinâmico passa a ser desfavorável para IRI acima de 4,3 mm/m.

Outro ponto interessante, é que não houve relação de proporcionalidade entre o aumento da força solicitante e o da força atuante, sendo que um aumento na força solicitante resultou em aumento da força atuante inferior ao aumento da solicitação. Tem-se, por exemplo, que o aumento de $22,5 \%$ no carregamento, de $40 \mathrm{t}$ para $49 \mathrm{t}$, resulta no aumento máximo da força solicitante em 5,2\%, para o perfil de menor irregularidade e trafegando a velocidade de $110 \mathrm{~km} / \mathrm{h}$ (anexo 15). Ainda, como se observa no gráfico da figura 21 , o limite de tolerância legal de 7,5\%, adotado atualmente, corresponde a um aumento na força solicitante de 1,7\%. 
Figura 20: Gráfico Efeito dinâmico (\%) x IRI (m/mm)

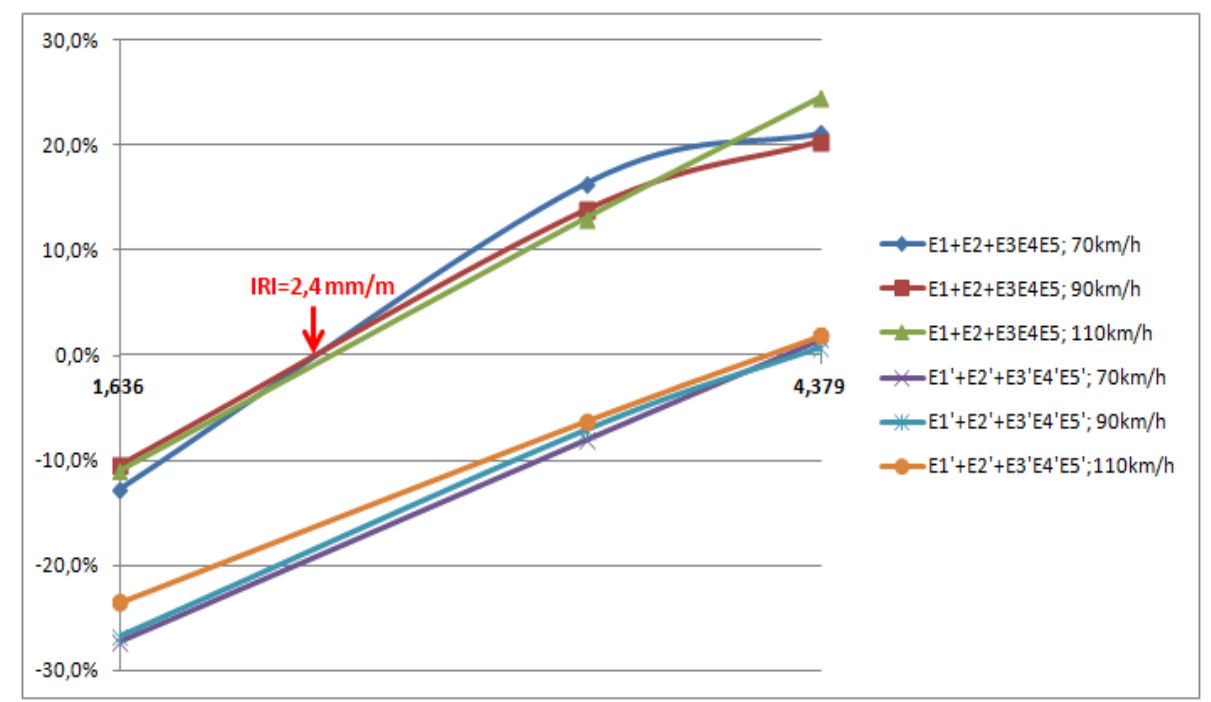

Figura 21: Gráfico de Variação do efeito dinâmico com aumento da solicitação.

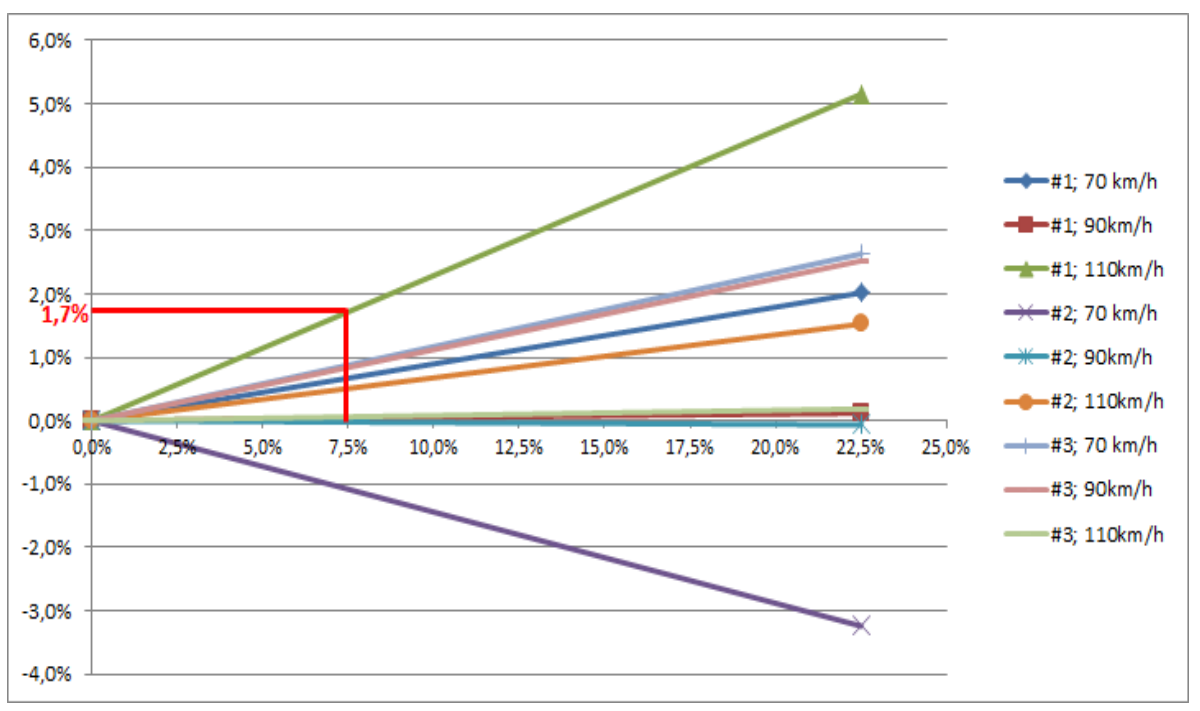

Feita a análise do comportamento dinâmico do veículo, decorrente de sua interação com o pavimento, parte-se para a análise qualitativa dos resultados, considerando-se o conceito de fator de equivalência de carga (FEC), utilizado para o dimensionamento do pavimento. Tal análise propõe o cálculo do FEC para a força solicitante no pavimento, que considera o efeito dinâmico da interação veículo-via, levando a um número $\mathrm{N}$ mais próximo da realidade e uma possível justificativa da redução da vida 
útil do pavimento.

O veículo 2S3 carregado com o limite legal de carga de 41,5 t, sendo 6 t no eixo dianteiro, $10 \mathrm{t}$ no primeiro eixo traseiro e $25,5 \mathrm{t}$ no grupo de eixos traseiros em tandem triplo, tem FEC de 4,282. O acréscimo de $20 \%$ no carregamento, chegando a 49,8 t, resulta em um FEC de 9,35. Isto significa que este veículo com $20 \%$ de excesso de carga representa 2,184 vezes o veículo com carregamento legal, podendo, em tese, reduzir a vida útil do pavimento em até $54 \%$, caso este pavimento fosse dimensionamento e solicitado apenas por este tipo de veículo.

Considerando-se o efeito dinâmico para o veículo trafegando em superfície em excelente condição de rolamento (perfil \#1), houve aumento do FEC em 50\% que, em primeira análise, poderia reduzir a vida útil do pavimento em 33,3\%. Considerando-se o efeito dinâmico para o veículo trafegando em superfície com condição de rolamento ruim (perfil \#3), houve aumento do FEC em até 434\%, com redução da vida útil em até $89 \%$, dado que isto representa 5,34 vezes o FEC do veículo com carregamento legal (anexo 16). Do gráfico (figura 22), infere-se a intensificação na redução da vida útil do pavimento a partir do perfil com IRI de $0,7 \mathrm{~mm} / \mathrm{m}$, quando o FEC solicitante, decorrente da interação dinâmica veículo-via, passa a ser maior que o FEC atuante, considerando velocidade de operação de $110 \mathrm{~km} / \mathrm{h}$. Para velocidade de operação de 90 $\mathrm{km} / \mathrm{h}$, a irregularidade crítica é próxima de $0,9 \mathrm{~mm} / \mathrm{m}$ e, para $70 \mathrm{~km} / \mathrm{h}$, é $1,4 \mathrm{~mm} / \mathrm{m}$.

Por fim, o aumento de 22,5\% na carga (anexo 16), isto é, na força solicitante, representa um aumento do FEC solicitante de 161\%, elevando o FEC atuante em a até 434\%. Considerando-se o limite de tolerância legal de 7,5\%, o aumento no FEC passa de $36,3 \%$ a $140 \%$ (figura 23 ), que representa um aumento relativo de $286 \%$ e corresponde a redução da vida útil em até $74 \%$. 
Figura 22: Gráfico Efeito dinâmico no FEC (\%) x IRI (m/mm)

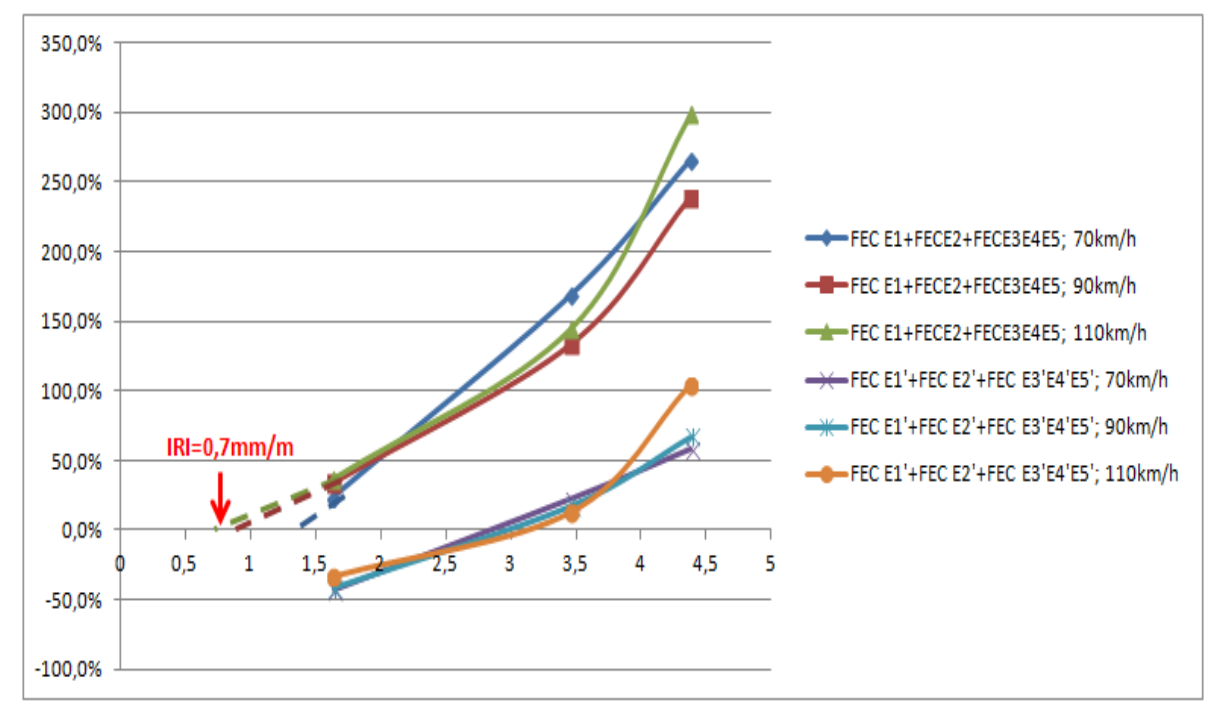

Adicionalmente, a comparação de rodagem simples e dupla (anexo 17), o veículo 2S3 com rodagem traseira simples e pneus extralargos apresentou efeito dinâmico menor que para rodagem traseira dupla, sendo que o efeito dinâmico aumentou com o aumento da velocidade e da irregularidade longitudinal da via. Entretanto, para este veículo, a força solicitante se apresentou menor que a força atuante nos eixos traseiros para todas as simulações executadas para o veículo com eixos traseiros com rodagem simples e pneus extralargos.

Figura 23: Gráfico de Impacto do incremento da carga no FEC, considerando o efeito dinâmico decorrente da interação veículo-via

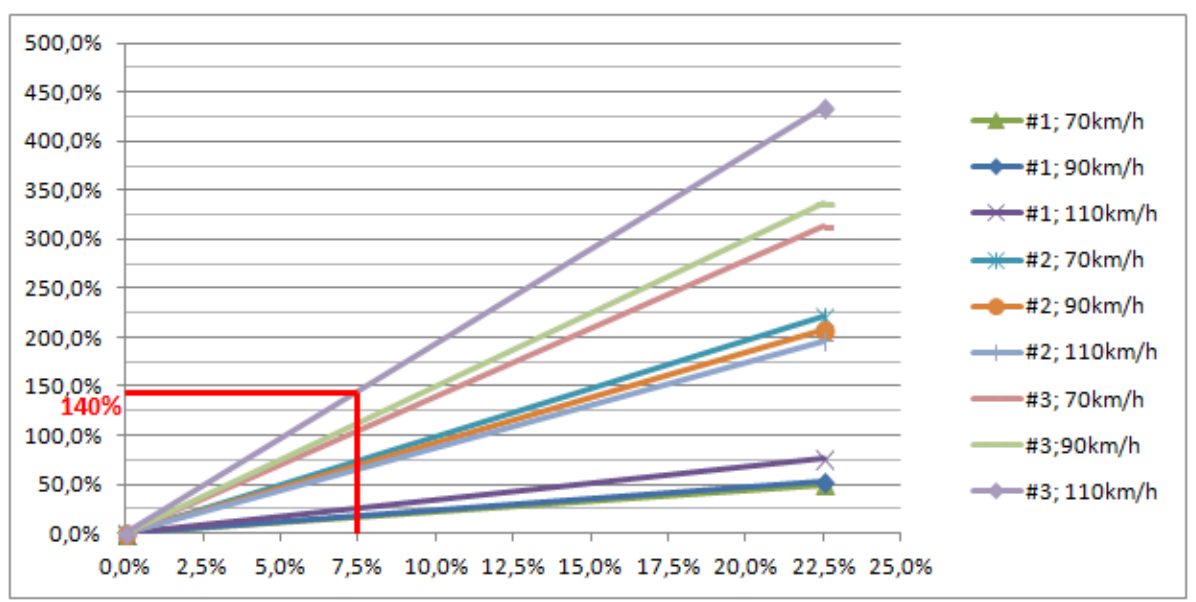




\subsection{Veículo $2 \mathrm{I} 3$}

O veículo $2 \mathrm{I} 3$, representado pela figura 24 , é um caminhão extrapesado, composto de um caminhão trator, com eixo dianteiro simples, de rodagem simples, e eixo traseiro simples, de rodagem dupla, e um semirreboque com três eixos traseiros espaçados, de rodagem dupla. A capacidade de carga deste tipo de veículo é $46 \mathrm{t}$, sendo $6 \mathrm{t}$ no eixo dianteiro, $10 \mathrm{t}$ no eixo traseiro do trator e $10 \mathrm{t}$ por eixo traseiro.

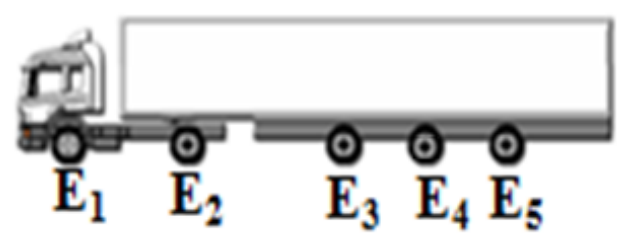

Figura 24: Veículo 2I3

Como o programa não permite a entrada de dados customizados, serão feitas simulações para valores próximos ao limite legal e ao limite legal acrescido de aproximadamente $20 \%$, limitado aos valores disponíveis no programa:

Cargas aplicadas:

Limite Legal (LL):

$\mathrm{E}_{1}=6 \mathrm{t}$

$\mathrm{E}_{2}=10 \mathrm{t}$

$\mathrm{E}_{3}=10 \mathrm{t}$

$\mathrm{E}_{4}=10 \mathrm{t}$

$\mathrm{E}_{5}=10 \mathrm{t}$

$\mathrm{E}_{1}+\mathrm{E}_{2}+\mathrm{E}_{3}+\mathrm{E}_{4}+\mathrm{E}_{5}=46 \mathrm{t}$
Limite Legal $+20 \%(\mathrm{LL}+20 \%)$

$\mathrm{E}_{1}{ }^{\prime}=7 \mathrm{t}$

$\mathrm{E}_{2}^{\prime}=12 \mathrm{t}$

$E_{3}{ }^{\prime}=12 \mathrm{t}$

$\mathrm{E}_{4}^{\prime}=12 \mathrm{t}$

$E_{5}{ }^{\prime}=12 \mathrm{t}$

$\mathrm{E}_{1}{ }^{\prime}+\mathrm{E}_{2}{ }^{\prime}+\mathrm{E}_{3}{ }^{\prime}+\mathrm{E}_{4}{ }^{\prime}+\mathrm{E}_{5}{ }^{\prime}=55 \mathrm{t}$

Os resultados das forças solicitantes máximas estão representados no anexo 18, conjuntamente com o cálculo do efeito dinâmico para cada um dos eixos e grupo de 
eixos e para a combinação dos mesmos.

Considerando os eixos dianteiros e traseiros isoladamente, os resultados da simulação apresentaram, para o eixo dianteiro, as forças atuantes variáveis em relação às solicitantes, ou seja, o efeito dinâmico decorrente da interação veículo-via provocou desde alívio das forças solicitantes de 17,1\% a intensificação de 21,6\% em relação à força atuante (anexo 18). Observou-se ainda, que a intensificação das forças solicitantes ocorreu para a situação de limite legal de carga $\left(E_{1}=6 t\right)$, para a sobrecarga de $20 \%$, ocorreu, para a maioria das situações, alívio na força atuante, em relação à solicitante, semelhante ao que ocorreu no veículo 2S3.

Para o eixo traseiro $\mathrm{E}_{2}$, houve desde alívio das forças solicitantes em até 4,6\%, para o caso do perfil de pavimento de menor irregularidade e trafegando a velocidade de 90 $\mathrm{km} / \mathrm{h}$, à intensificação das forças solicitantes em até $49,6 \%$, para o caso do perfil de pavimento de maior irregularidade e trafegado a velocidade de $110 \mathrm{~km} / \mathrm{h}$ (anexo 18). Assim como para o eixo dianteiro, a situação de sobrecarga apresentou menores efeitos dinâmicos que a situação de limite legal de carga.

Para os eixos traseiros $\mathrm{E}_{3}, \mathrm{E}_{4}$ e $\mathrm{E}_{5}$, ocorreu alívio para todas as situações de simulação, com variação do perfil de irregularidade e velocidade, sendo o alívio das forças solicitantes variando desde $15,7 \%$ até $53,1 \%$ (anexo 18). Assim como para o eixo dianteiro, a situação de sobrecarga apresentou menores efeitos dinâmicos que a situação de limite legal de carga.

Considerando a análise conjunta dos eixos, os resultados apresentaram intensificação máxima das forças solicitantes em 1,4\%, para perfil de maior de irregularidade, trafegando a velocidade de $110 \mathrm{~km} / \mathrm{h}$. Para o perfil de menor irregularidade (IRI=1,636mm/m), houve alívio na solicitação, isto é, forças atuantes até 34,8\% menores que as solicitantes. 
Observa-se, de forma generalizada, o aumento do efeito dinâmico com o aumento da velocidade e da irregularidade longitudinal. Cabe ressaltar que o veículo é representado pelo conjunto de eixos e que, na prática, os eixos não atuam separadamente. Assim, o gráfico abaixo indica o perfil de irregularidade crítica, no qual a carga atuante passa a ser maior que a carga solicitante, decorrente da interação veículo-via. Do gráfico (figura 25), infere-se que, para o caminhão semirreboque com três eixos espaçados, o efeito dinâmico é desfavorável a partir de perfil com IRI = 4,2 $\mathrm{mm} / \mathrm{m}$, para velocidade de operação do veículo acima de $110 \mathrm{~km} / \mathrm{h}$, considerando o veículo carregado com o limite legal de carga. Para o veículo com excesso de carga, o efeito dinâmico passa a ser desfavorável para IRI acima de $5 \mathrm{~mm} / \mathrm{m}$, não inserido no gráfico.

Figura 25: Gráfico Efeito dinâmico (\%) x IRI (m/mm)

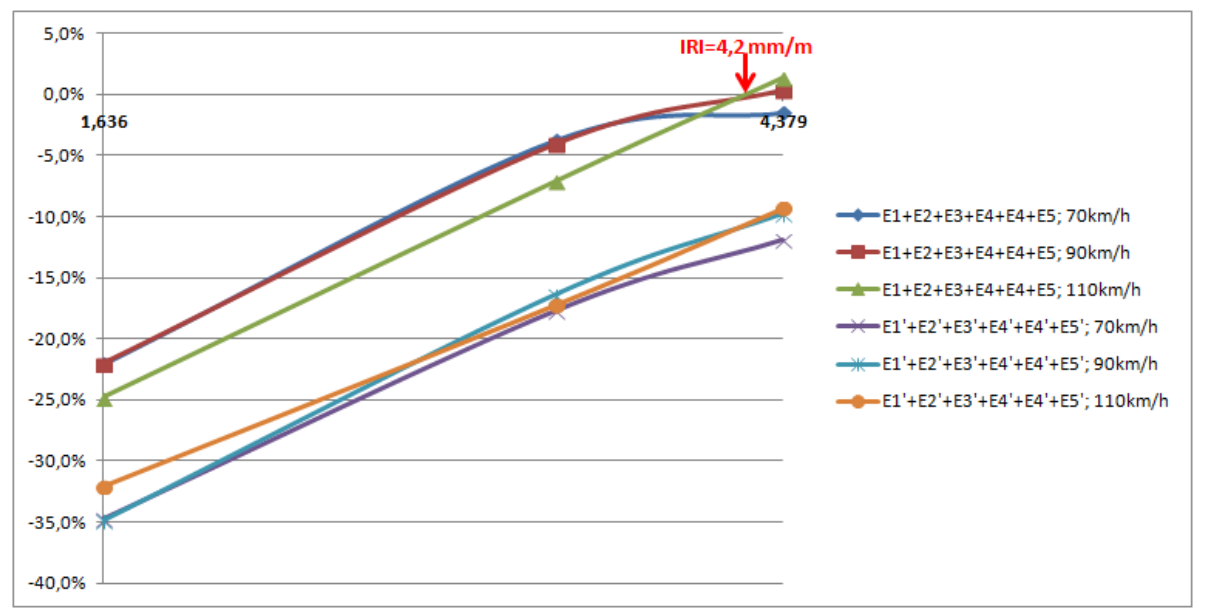

Outro ponto interessante, é que não houve relação de proporcionalidade entre o aumento da força solicitante e o da força atuante, sendo que um aumento na força solicitante resultou em aumento da força atuante inferior ao aumento da solicitação. Tem-se, por exemplo, que o aumento de 19,6\% no carregamento, de $46 \mathrm{t}$ para $55 \mathrm{t}$, resulta no aumento máximo da força solicitante em 7,9\%, para o perfil de menor irregularidade e trafegando a velocidade de $110 \mathrm{~km} / \mathrm{h}$ (anexo 19). Ainda, como se observa no gráfico (figura 26), o limite de tolerância legal de 7,5\%, adotado atualmente, corresponde a um aumento na força solicitante de 3,1\%. 
Figura 26: Gráfico de Variação do efeito dinâmico com aumento da solicitação.

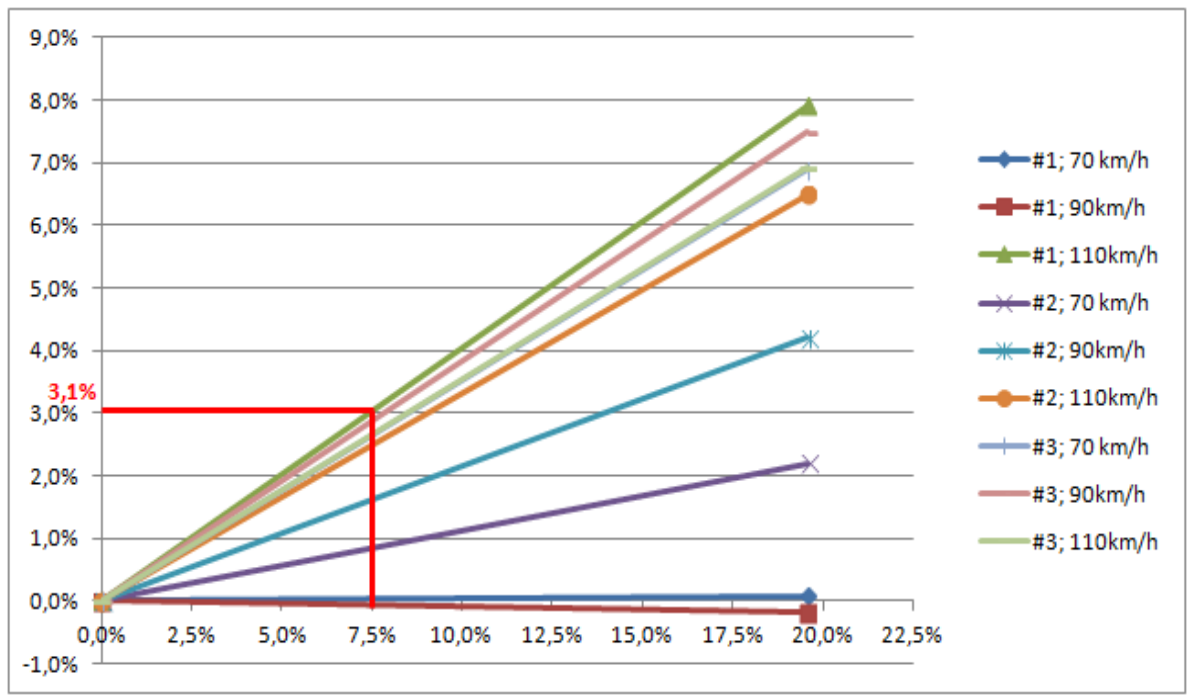

Feita a análise do comportamento dinâmico do veículo, decorrente de sua interação com o pavimento, parte-se para a análise qualitativa dos resultados, considerando-se o conceito de fator de equivalência de carga (FEC), utilizado para o dimensionamento do pavimento. Tal análise propõe o cálculo do FEC para a força solicitante no pavimento, que considera o efeito dinâmico da interação veículo-via, levando a um número $\mathrm{N}$ mais próximo da realidade e uma possível justificativa da redução da vida útil do pavimento.

O veículo 2I3 carregado com o limite legal de carga de 46 t, sendo 6 t no eixo dianteiro e em cada um dos quatro eixos traseiros, tem FEC de 9,905. O acréscimo de $20 \%$ no carregamento, chegando a 55,2 t, resulta em um FEC de 21,773. Isto significa que este veículo com $20 \%$ de excesso de carga representa 2,198 vezes o veículo com carregamento legal, podendo, em tese, reduzir a vida útil do pavimento em até 55\%, caso este pavimento fosse dimensionamento e solicitado apenas por este tipo de veículo.

Considerando-se o efeito dinâmico para o veículo trafegando em superfície em excelente condição de rolamento (perfil \#1), houve redução do FEC em até 74,5\% 
que, em primeira análise, poderia aumentar a vida útil do pavimento em até 292,2\%. Considerando-se o efeito dinâmico para o veículo trafegando em superfície com condição de rolamento ruim (perfil \#3), houve aumento do FEC em até 102,2\%, com redução da vida útil em até 50,5\%, dado que isto representa 2,02 vezes o FEC do veículo com carregamento legal (anexo 20). Do gráfico (figura 27), infere-se a intensificação na redução da vida útil do pavimento a partir do perfil com IRI de 2,6 $\mathrm{mm} / \mathrm{m}$, quando o FEC solicitante, decorrente da interação dinâmica veículo-via, passa a ser maior que o FEC atuante, considerando velocidade de operação a partir de 70 $\mathrm{km} / \mathrm{h}$.

Figura 27: Gráfico Efeito dinâmico no FEC (\%) x IRI (m/mm)

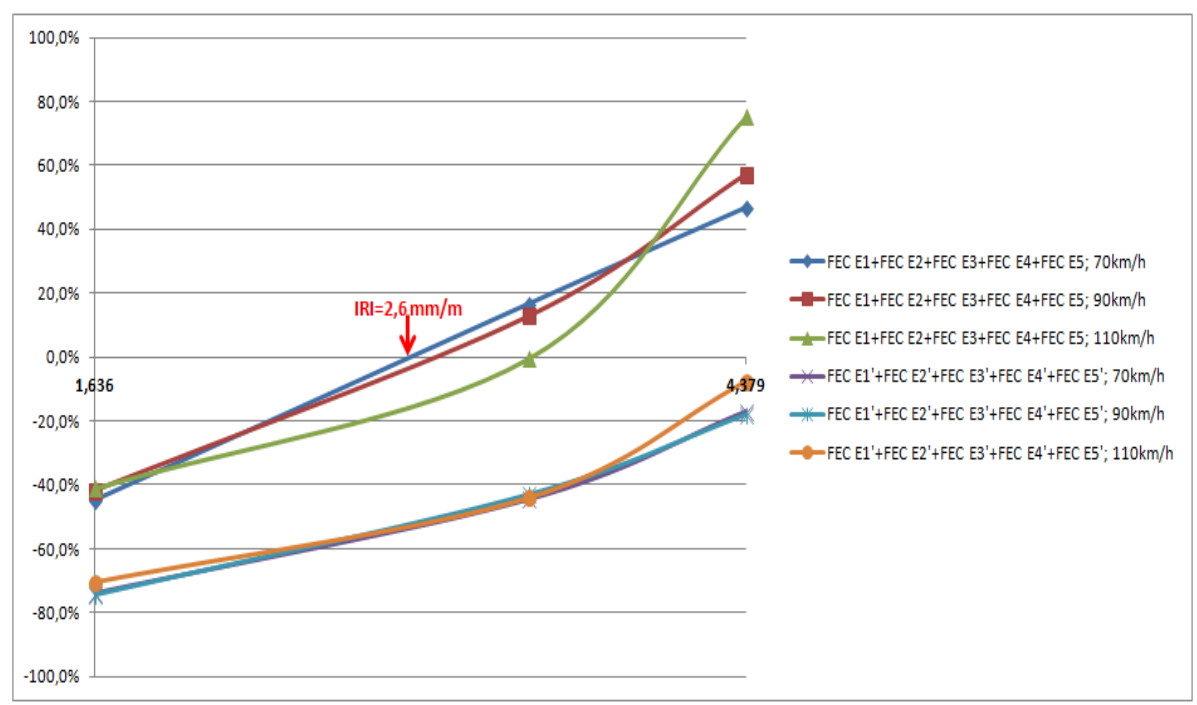

Por fim, o aumento de 19,6\% na carga (anexo 20), isto é, na força solicitante, representa um aumento do FEC solicitante de 119\%, elevando o FEC atuante em a até 102,2\%. Considerando-se o limite de tolerância legal de 7,5\%, o aumento no FEC passa de $36,7 \%$ a $40 \%$ (figura 28 ), que representa um aumento relativo de $9 \%$ e corresponde a redução da vida útil em até $8,3 \%$. 
Figura 28: Gráfico Impacto do incremento da carga no FEC, considerando o efeito dinâmico decorrente da interação veículo-via.

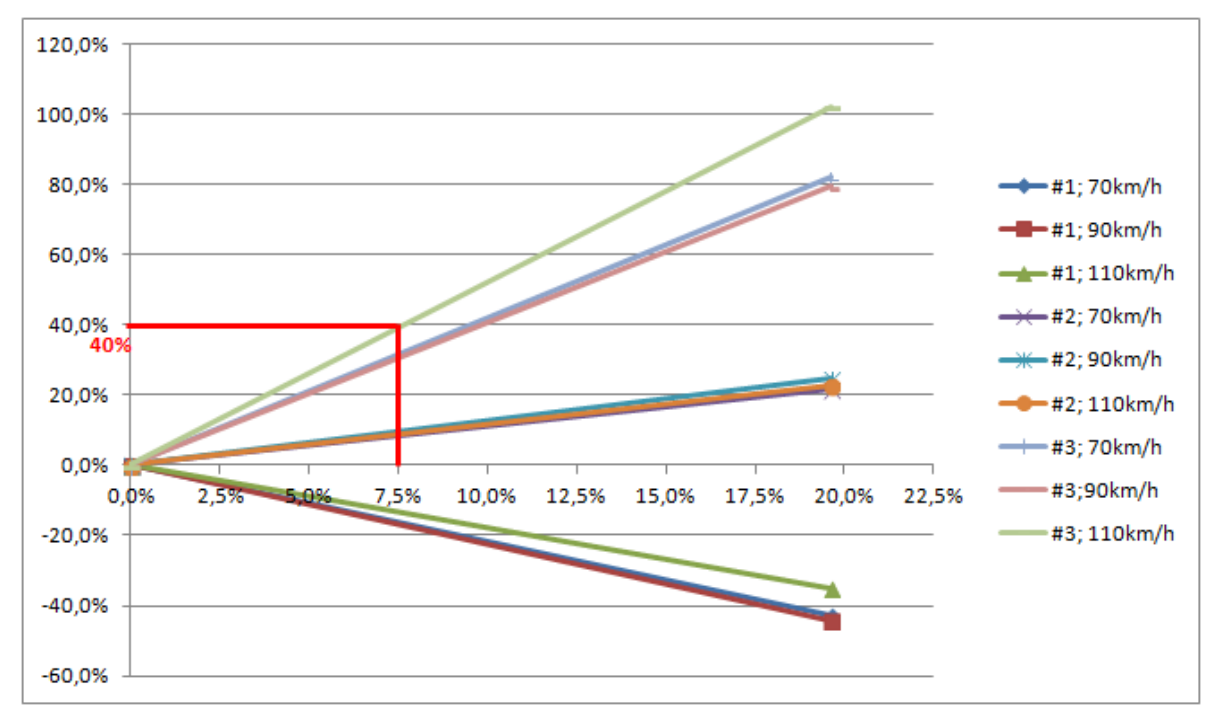

Adicionalmente, a comparação de rodagem simples e dupla (anexo 21), o veículo 2I3 com rodagem traseira simples e pneus extralargos apresentou efeito dinâmico menor que para rodagem traseira dupla, sendo que o efeito dinâmico aumentou com o aumento da velocidade e da irregularidade longitudinal da via. Entretanto, para este veículo, a força solicitante se apresentou menor que a força atuante nos eixos traseiros para todas as simulações executadas para o veículo com eixos traseiros com rodagem simples e pneus extralargos.

\subsection{Comparação de Resultados}

A tabela 9 apresenta a comparação dos resultados, demonstrando que o impacto no FEC decorrente do efeito dinâmico provocado pela irregularidade é mais sensível que o efeito dinâmico na própria carga. Ocorre, por exemplo, a intensificação da carga para IRI a partir de $3,1 \mathrm{~mm} / \mathrm{m}$, para o veículo $2 \mathrm{C}$, mas a intensificação do Fator de Equivalência de Carga se inicia para IRI a partir de $2,4 \mathrm{~mm} / \mathrm{m}$. Tal fato se dá devido aos comportamentos isolados de cada um dos eixos, sendo que o alívio eventual em um ou mais eixos, para os veículos analisados, não é suficiente para compensar a intensificação na carga atuante dos demais eixos. Em geral, tem-se que o impacto no 
FEC ocorre para índices de irregularidade longitudinal (IRI) inferiores ao impacto na carga.

Tabela 9: Comparação do IRI crítico para o Efeito Dinâmico na Carga e no FEC

\begin{tabular}{|c|c|c|}
\hline Veículo & $\begin{array}{c}\text { IRI crítico para } \\
\text { carga }(\mathbf{m m} / \mathbf{m})\end{array}$ & $\begin{array}{c}\text { IRI crítico para } \\
\mathbf{F E C}(\mathbf{m m} / \mathbf{m})\end{array}$ \\
\hline $\mathbf{2 C}$ & 3,1 & 2,4 \\
\hline $\mathbf{3 S 2}$ & 0,7 & 0,5 \\
\hline $\mathbf{2 S 3}$ & 2,4 & 0,7 \\
\hline $\mathbf{2 I 3}$ & 4,2 & 2,6 \\
\hline
\end{tabular}

A tabela 10 destaca que o excesso tolerado de carga de 7,5\%, que implica em um acréscimo de FEC médio dos veículos de 36,2\%, varia de 40\% para o veículo 2 I3 (caminhão trator + semirreboque em tandem triplo), chegando a $280 \%$ para o veículo 3S2 (caminhão trator trucado + semirreboque em tandem duplo). Cabe ressaltar que as curvas para o aumento dos FEC com aumento da carga não apresentaram comportamentos semelhantes sob situação de carregamento dinâmico, tal como para situação de carregamento estático, apresentado na figura 6 e reproduzido abaixo. 


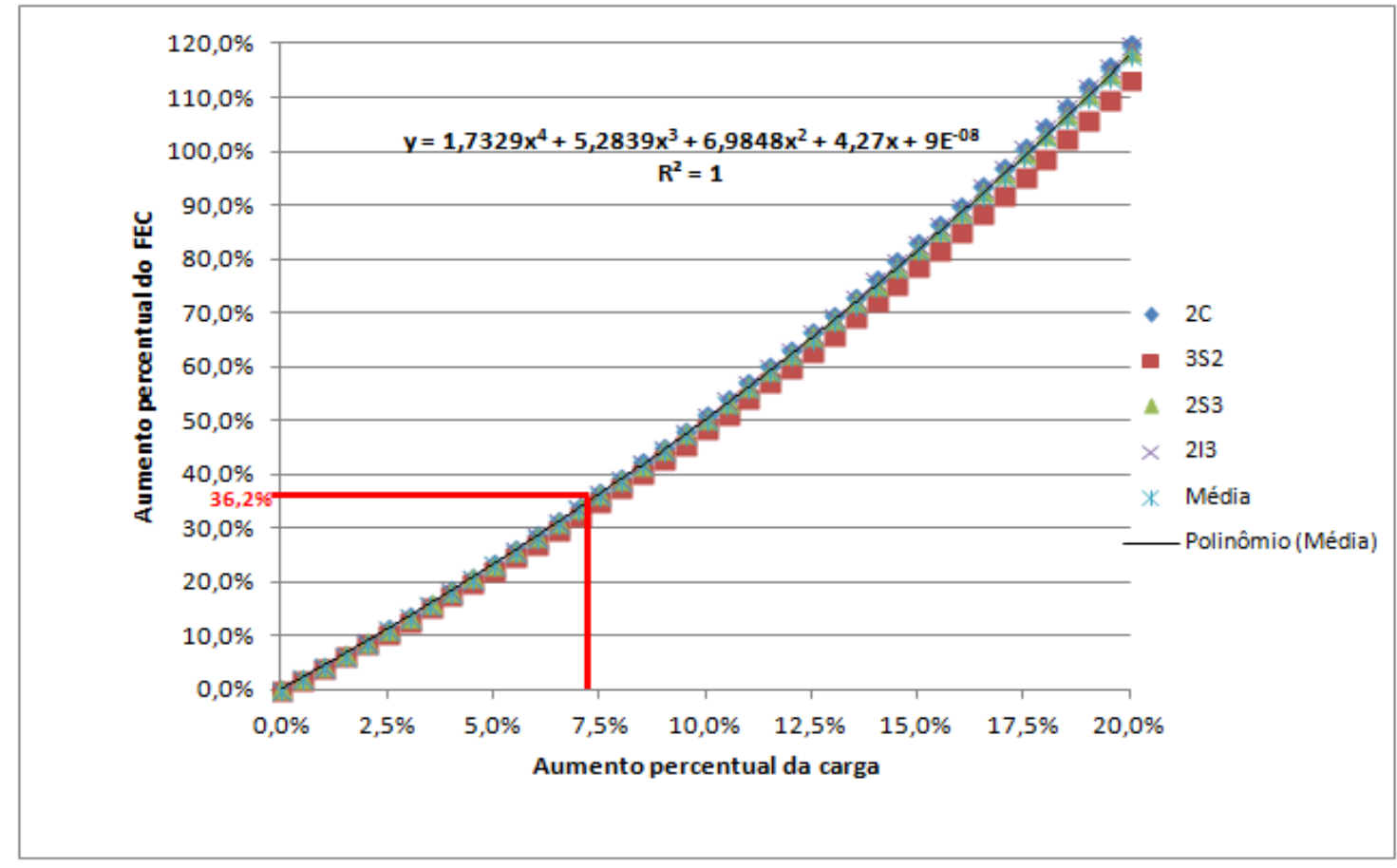

Figura 6: Impacto do incremento da carga no FEC (por veículo)

Tabela 10: Impacto máximo no FEC decorrente do Efeito Dinâmico para excesso de $7,5 \%$ na carga atuante

\begin{tabular}{|c|c|c|}
\hline Veículo & $\begin{array}{c}\text { Efeito dinâmico } \\
\text { máximo no FEC } \\
\text { para excesso de } \\
\text { carga de 7,5\% } \\
(\boldsymbol{\%})\end{array}$ & $\begin{array}{c}\text { Redução da vida } \\
\text { útil decorrente do } \\
\text { efeito dinâmico } \\
\text { para excesso de } \\
\text { carga de 7,5\% } \\
(\boldsymbol{\%})\end{array}$ \\
\hline 2C & 130 & 72 \\
\hline 3S2 & 280 & 87 \\
\hline $\mathbf{2 S 3}$ & 140 & 74 \\
\hline $\mathbf{2 I 3}$ & 40 & 8,3 \\
\hline
\end{tabular}

Por fim, tem-se que a consequência da tolerância de $7,5 \%$ pode ser a redução da vida útil em até $87 \%$. No entanto, tal conclusão não se aplica ao caso do veículo 2I3 (caminhão trator + semirreboque com três eixos traseiros espaçados), cuja tolerância implica em redução da vida útil em $8,3 \%$, isto é, muito menor que para os demais 
veículos, em especial para o veículo $2 \mathrm{~S} 3$, com capacidades de carga semelhantes. Por outro lado, o veículo $2 \mathrm{I} 3$ apresenta o maior valor de FEC entre os veículos analisados e é maior que o dobro do FEC para o veículo 2S3, sendo $\mathrm{FEC}_{213}=9,905$ e $\mathrm{FEC}_{2 \mathrm{~S} 3}=4,282$, para os limites de cargas legais segundo o CONTRAN, sendo o veículo 2I3, sob a luz do conceito do Fator de Equivalência de Carga, duplamente danoso ao pavimento, em relação ao veículo $2 \mathrm{~S} 3$. 


\section{CONCLUSÕES E SUGESTÕES PARA TRABALHOS FUTUROS}

O efeito dinâmico se dá pela interação veículo-via, decorrente de variáveis como irregularidade longitudinal da via, configuração do veículo, incluindo seu espaçamento entre eixos, velocidade de operação do veículo, características de suspensão e pressão de enchimento dos pneus, assim como pelo tipo de rodagem dos eixos traseiros (rodagens dupla e simples).

Uma conclusão relevante, à luz do conceito de Fator de Equivalência de Carga, é que o efeito dinâmico se torna nocivo ao pavimento para IRI inferiores em relação à abordagem do aumento da carga. Isto é, os valores de IRI críticos para o FEC são menores que os IRI crítico para carga. Tal fato devido aos comportamentos isolados de cada um dos eixos e grupos de eixos. Assim, embora haja alívio na força solicitante em relação a atuante para um determinado eixo, geralmente o dianteiro, decorrente do efeito dinâmico da interação veículo-via, em geral, não ocorre compensação nos demais eixos ou grupo de eixos, considerando o veículo como um todo.

O excesso tolerado de carga de 7,5\%, que implica em um acréscimo de FEC médio dos veículos de $36,2 \%$, com consequente redução teórica da vida útil de $26 \%$, quando considerado o efeito dinâmico da interação veículo-via, varia de $40 \%$ a $280 \%$, 
dependendo do tipo de veículo, o que representa redução teórica da via útil em até $87 \%$.

Dos veículos analisados, o que apresentou menor efeito dinâmico, tanto para carga, como para FEC, foi o 2I3 (caminhão trator + semirreboque com três eixos traseiros espaçados), com aumento do FEC, decorrente do excesso de 7,5\% na carga, de 40\%, que representa uma redução teórica na vida útil de $8,3 \%$, em relação à situação de carga estática. No entanto, não se pode concluir que este veículo apresenta menores danos ao pavimento, ou menor comprometimento de sua vida útil decorrente do efeito dinâmico e do excesso de carga, pois esta configuração de eixos apresenta o maior valore de FEC, dentre os veículos avaliados, chegando a ser maior que o dobro do FEC para o veículo 2S3, que tem capacidade de carga semelhante.

$\mathrm{Na}$ comparação entre rodagens simples e duplas para os eixos traseiros, apenas o veículo 2C apresentou efeitos dinâmicos maiores para rodagem simples e pneus extralargos que para rodagem dupla.

\subsection{Sugestões para Trabalhos Futuros}

Para trabalhos futuros, sugere-se o aprofundamento na comparação entre os veículos $2 \mathrm{~S} 3$ e 2I3, uma vez que estes possuem capacidade semelhante de carga, com Fatores de Equivalência de Carga muito distintos. No entanto, as análises apresentadas neste trabalho observaram menor acréscimo de danos decorrente do comportamento dinâmico para o veículo com três eixos traseiros espaçados (2I3) do que para o veículo com grupo de eixos traseiros em tandem triplo (2S3).

Do ponto de vista do dimensionamento do pavimento, sugere-se extrapolar este trabalho considerando a distribuição dos veículos apresentados na contagem de tráfego. Assim, pode-se realizar o real impacto do efeito dinâmico da carga na vida útil do pavimento, considerando o tráfego atuante na via, em vez dos veículos 
isoladamente.

Sugere-se, por fim, a avaliação, por meio de versões mais completas do TRUCKSIM, ou outro simulador de carga, do uso de suspensões ativas e semiativas em veículos de carga, assim como variação na pressão de enchimento dos pneus. As suspensões ativas e semiativas poderiam aliviar os efeitos dinâmicos decorrentes da interação veículo-via, uma vez que parte do impacto seria absorvida pelo sistema de suspensão. Ainda, a pressão de enchimento dos pneus interfere substancialmente na transferência de carga entre o veículo e a via, sugerindo-se considerar a variação do efeito dinâmico, com a variação da pressão de enchimento dos pneus. 


\section{REFERÊNCIAS BIBLIOGRÁFICAS}

Barbosa, R. E. (1999) - Efeito das cargas dinâmicas dos veículos rodoviários no desempenho dos pavimentos e pontes. Dissertação de Mestrado. Escola de Engenharia de São Carlos - Universidade de São Paulo. São Carlos-SP.

Côrte-Real, E. W. (2002) - Dessensibilização da estrutura de controle LQG aplicada ao modelo de uma suspensão ativa utilizando a técnica PRABI. Dissertação (mestrado) - Instituto Militar de Engenharia - Rio de Janeiro-RJ.

Fernandes Jr., J. L. (1994) - Investigação dos Efeitos das Solicitações do Tráfego Sobre o Desempenho de Pavimentos. Tese de Doutorado. Escola de Engenharia de São Carlos - Universidade de São Paulo. São Carlos-SP.

Gillespie, T. D. e S. M. Karamihas (1994). Heavy truck properties significant to pavement damage. Vehicle-Road Interaction Conference, ASTM STP 1225.

Hegmon, R. R. (1992) - Some Results from Ongoing Research on Road Roughness. Vehicle, Tyre, Pavement Interface ASTM STP 1164.

Kulakowski, B. T. (1994) - Vehicle-Road Interaction. Vehicle-Road Interaction Conference, ASTM STP 1225.

Lu, X. P. (1985) - Effects of Road Roughness on Vehicular Rolling Resistance. Measuring Road Roughness and its Effects on User Cost and Comfort. A Symposium, ASTM STP 884

Paterson, D. O. e Watanatada, T. (1985) - Relationships between vehicle speed, ride quality, and road roughness. Measuring Road Roughness and its Effects on User Cost and Comfort. . A Symposium, ASTM STP 884 
OECD (1998) - Organisation de Coopération et de Développement Economiques Relatório Técnico do Projeto DIVINE (Dynamic Interaction between Vehicles and Infrastructure Experiment).

Sayers, M.W.; Karamihas, S.M. (1998) - The little book of profiling . Basis information about measuring an interpreting road profiles. The Regent of the University of Michigan.

Ullidtz, P. (1987) - Pavement Analysis.Editora: Elsevier, Amsterdam.

Wambold, J. C. (1985) - Road Roughness Effects on Vehicle Dynamics. Measuring Road Roughness and its Effects on User Cost and Comfort. A Symposium, ASTM STP 884

Yi, K e Hedrick, K. (1992) - Use of Semi-Active Suspensions to Reduce Pavement Damage. Vehicle, Tire, Pavement Interface. Vehicle, Tire, Pavement Interface, ASTM STP 1164. 


\section{ANEXOS}

Anexo 1. Matriz Fatorial utilizada para agrupar os resultados de acordo com os fatores considerados nas simulações; resultados por eixo.

Anexo 2. Matriz Fatorial com resultados obtidos nas simulações; Caminhão $2 \mathrm{C}$

Anexo 3. Matriz Fatorial com resultados obtidos nas simulações; Caminhão 3S2

Anexo 4. Matriz Fatorial com resultados obtidos nas simulações; Caminhão 2S3

Anexo 5. Matriz Fatorial com resultados obtidos nas simulações; Caminhão 2I3

Anexo 6. Cálculo do efeito dinâmico a partir dos resultados obtidos nas simulações; Caminhão 2C

Anexo 7. Cálculo comparativo entre o incremento da carga e aumento no efeito dinâmico; Caminhão 2C

Anexo 8. Cálculo dos FEC a partir dos resultados obtidos nas simulações; Caminhão $2 \mathrm{C}$

Anexo 9. Comparação do efeito dinâmico para rodagens simples e dupla; Caminhão $2 \mathrm{C}$

Anexo 10. Cálculo do efeito dinâmico a partir dos resultados obtidos nas simulações; Caminhão 3S2

Anexo 11. Cálculo comparativo entre o incremento da carga e aumento no efeito dinâmico; Caminhão 3S2

Anexo 12. Cálculo dos FEC a partir dos resultados obtidos nas simulações; Caminhão $3 \mathrm{~S} 2$

Anexo 13. Comparação do efeito dinâmico para rodagens simples e dupla; Caminhão 
$3 \mathrm{~S} 2$

Anexo 14. Cálculo do efeito dinâmico a partir dos resultados obtidos nas simulações; Caminhão 2S3

Anexo 15. Cálculo comparativo entre o incremento da carga e aumento no efeito dinâmico; Caminhão 2S3

Anexo 16. Cálculo dos FEC a partir dos resultados obtidos nas simulações; Caminhão $2 \mathrm{~S} 3$

Anexo 17. Comparação do efeito dinâmico para rodagens simples e dupla; Caminhão $2 \mathrm{~S} 3$

Anexo 18. Cálculo do efeito dinâmico a partir dos resultados obtidos nas simulações; Caminhão 2I3

Anexo 19. Cálculo comparativo entre o incremento da carga e aumento no efeito dinâmico; Caminhão 2I3

Anexo 20. Cálculo dos FEC a partir dos resultados obtidos nas simulações; Caminhão $2 \mathrm{I} 3$

Anexo 21. Comparação do efeito dinâmico para rodagens simples e dupla; Caminhão $3 \mathrm{~S} 2$ 
Anexo 1. Matriz Fatorial utilizada para agrupar os resultados de acordo com os fatores considerados nas simulações; resultados por eixo.

\begin{tabular}{|c|c|c|c|c|c|c|c|c|c|c|c|c|c|c|c|c|c|c|c|c|c|c|}
\hline \multicolumn{3}{|c|}{ 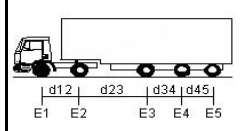 } & \multicolumn{20}{|c|}{ TIPO DE VEÍ́cULO DE CARGA - Caminhão Trator + Semi Reboque (213) } \\
\hline \multirow{6}{*}{\multicolumn{3}{|c|}{$\begin{array}{c}\text { Força Vertical } \\
\text { valores máximos } \\
{[\mathrm{kN}]}\end{array}$}} & \multicolumn{20}{|c|}{ TIPO DE EIXO } \\
\hline & & & \multicolumn{10}{|c|}{ rodas duplas } & \multicolumn{5}{|c|}{ rodas simples } & \multicolumn{5}{|c|}{ rodas duplas } \\
\hline & & & \multicolumn{20}{|c|}{ CARGA POR EIXO } \\
\hline & & & \multicolumn{5}{|c|}{$L L$} & \multicolumn{5}{|c|}{$L L+20 \%$} & \multicolumn{5}{|c|}{$7 t$} & \multicolumn{5}{|c|}{$8 t$} \\
\hline & & & E1 & E2 & E3 & E4 & E5 & E1 & E2 & E3 & $\mathrm{E}$ & E5 & E & E & E3 & E4 & E5 & E1 & E2 & E3 & E4 & E5 \\
\hline & & & 60 & 100 & 100 & 100 & 100 & 70 & 120 & 120 & 12 & 120 & 6 & 7 & 70 & 70 & 70 & 60 & 80 & 80 & 80 & 80 \\
\hline \multirow{9}{*}{ 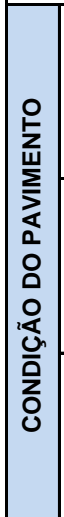 } & \multirow{3}{*}{$\mathbb{R}$} & $\stackrel{?}{\pi}$ & & & & & & & & & & & & & & & & & & & & \\
\hline & & ৪ & & & & & & & & & & & & & & & & & & & & \\
\hline & & $R$ & & & & & & & & & & & & & & & & & & & & \\
\hline & \multirow{3}{*}{ * } & $\stackrel{?}{\pi}$ & & & & & & & & & & & & & & & & & & & & \\
\hline & & ৪ & & & & & & & & & & & & & & & & & & & & \\
\hline & & $R$ & & & & & & & & & & & & & & & & & & & & \\
\hline & \multirow{3}{*}{$\bar{N}$} & $\stackrel{?}{\Gamma}$ & & & & & & & & & & & & & & & & & & & & \\
\hline & & ৪ & & & & & & & & & & & & & & & & & & & & \\
\hline & & $R$ & & & & & & & & & & & & & & & & & & & & \\
\hline
\end{tabular}



Anexo 2. Matriz Fatorial com resultados obtidos nas simulações; Caminhão 2C

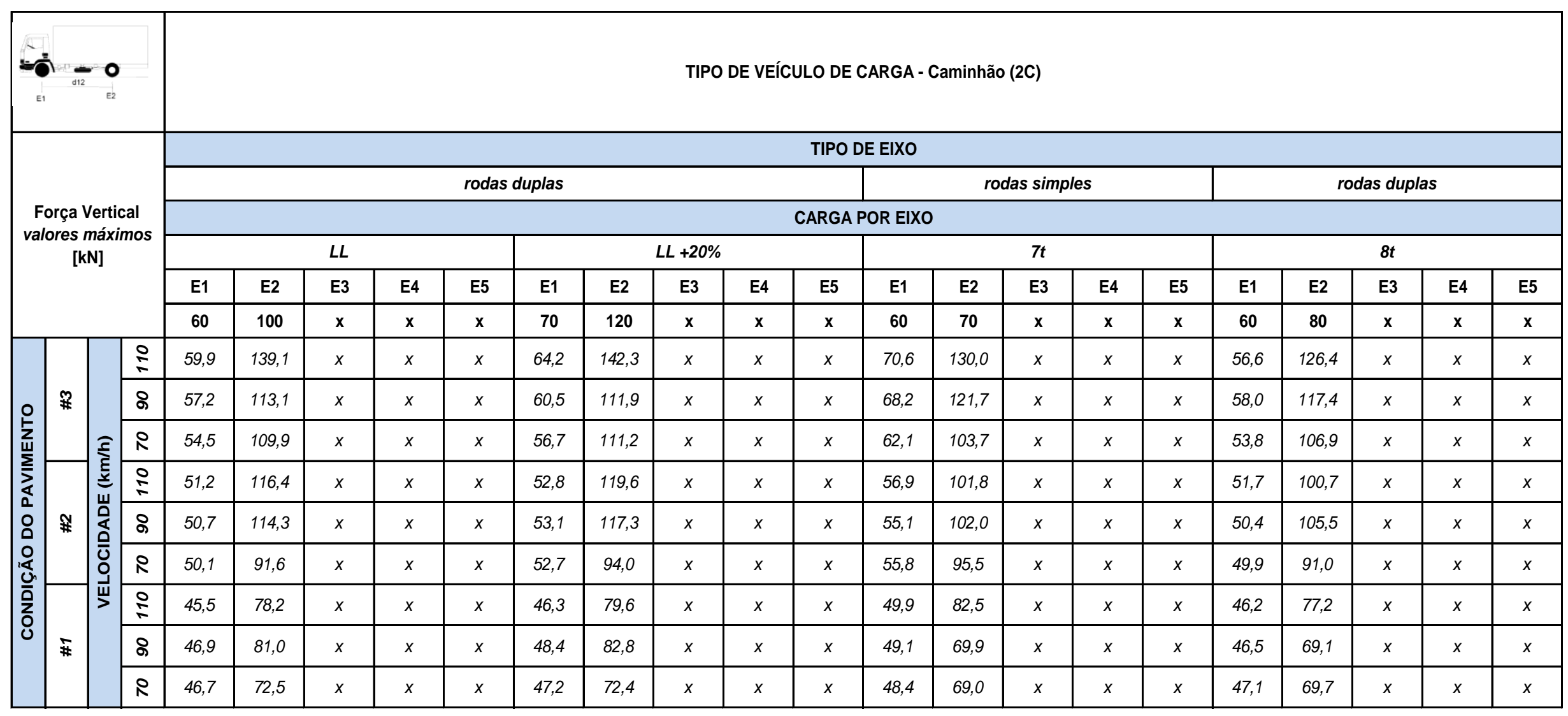



Anexo 3. Matriz Fatorial com resultados obtidos nas simulações; Caminhão 3S2

\begin{tabular}{|c|c|c|c|c|c|c|c|c|c|c|c|c|c|c|c|c|c|c|c|c|c|c|c|}
\hline \multicolumn{4}{|c|}{ 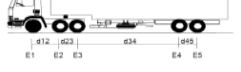 } & \multicolumn{20}{|c|}{ TIPO DE VEÍ́CULO DE CARGA - Caminhão Trator Trucado + Semi Reboque (3S2) } \\
\hline \multirow{6}{*}{\multicolumn{4}{|c|}{$\begin{array}{c}\text { Força Vertical } \\
\text { valores máximos } \\
{[\mathrm{kN}]}\end{array}$}} & \multicolumn{20}{|c|}{ TIPO DE EIXO } \\
\hline & & & & \multicolumn{10}{|c|}{ rodas duplas } & \multicolumn{5}{|c|}{ rodas simples } & \multicolumn{5}{|c|}{ rodas duplas } \\
\hline & & & & \multicolumn{20}{|c|}{ CARGA POR EIXO } \\
\hline & & & & \multicolumn{5}{|c|}{$L L$} & \multicolumn{5}{|c|}{$L L+20 \%$} & \multicolumn{5}{|c|}{$7 t$} & \multicolumn{5}{|c|}{$8 t$} \\
\hline & & & & E1 & E2E3 & E4E5 & $\mathbf{x}$ & $\mathbf{x}$ & E1 & E2E3 & E4E5 & $\mathrm{x}$ & $\mathbf{x}$ & E1 & E2E3 & E4E5 & $\mathbf{x}$ & $\mathbf{x}$ & E1 & E2E3 & E4E5 & $x$ & $\mathbf{x}$ \\
\hline & & & & 60 & 160 & 160 & $x$ & $\mathbf{x}$ & 60 & 200 & 200 & $\mathrm{x}$ & $\mathbf{x}$ & 60 & 140 & 140 & $\mathbf{x}$ & $x$ & 60 & 160 & 160 & $x$ & $\mathbf{x}$ \\
\hline \multirow{9}{*}{ 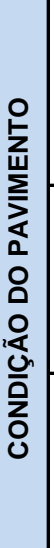 } & \multirow{3}{*}{ ? } & \multirow{9}{*}{ 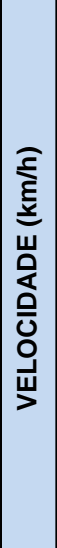 } & $\stackrel{9}{5}$ & 80,1 & 237,7 & 298,1 & $x$ & $x$ & 82,7 & 247,2 & 299,1 & $x$ & $x$ & 82,7 & 112,1 & 95,7 & $x$ & $x$ & 80,1 & 237,7 & 189,9 & $x$ & $x$ \\
\hline & & & ৪ & 74,5 & 180,5 & 243,6 & $x$ & $x$ & 75,6 & 192,8 & 256,2 & $x$ & $x$ & 72,9 & 91,0 & 80,0 & $x$ & $x$ & 77,6 & 191,8 & 159,2 & $x$ & $x$ \\
\hline & & & $R$ & 71,7 & 175,3 & 241,6 & $x$ & $x$ & 75,2 & 186,5 & 262,5 & $x$ & $x$ & 78,9 & 93,5 & 73,6 & $x$ & $x$ & 71,7 & 175,3 & 155,5 & $x$ & $x$ \\
\hline & \multirow{3}{*}{ 政 } & & $\stackrel{R}{1}$ & 74,6 & 205,7 & 255,9 & $x$ & $x$ & 76,2 & 198,9 & 280,2 & $x$ & $x$ & 77,8 & 91,8 & 79,9 & $x$ & $x$ & 74,6 & 205,7 & 151,8 & $x$ & $x$ \\
\hline & & & ஃ & 73,5 & 172,6 & 245,5 & $x$ & $x$ & 74,4 & 178,3 & 245,1 & $x$ & $x$ & 76,7 & 94,3 & 76,2 & $x$ & $x$ & 73,5 & 172,6 & 157,7 & $x$ & $x$ \\
\hline & & & $R$ & 72,7 & 162,7 & 228,3 & $x$ & $x$ & 73,2 & 172,7 & 240,3 & $x$ & $x$ & 71,4 & 88,0 & 75,7 & $x$ & $x$ & 72,7 & 162,7 & 144,4 & $x$ & $x$ \\
\hline & \multirow{3}{*}{ ॠ } & & $\stackrel{9}{1}$ & 68,3 & 152,4 & 201,2 & $x$ & $x$ & 68,9 & 167,9 & 228,2 & $x$ & $x$ & 67,3 & 72,1 & 65,2 & $x$ & $x$ & 68,3 & 152,4 & 124,4 & $x$ & $x$ \\
\hline & & & 8 & 68,3 & 151,5 & 198,6 & $x$ & $x$ & 68,2 & 161,0 & 211,3 & $x$ & $x$ & 66,7 & 69,5 & 61,0 & $x$ & $x$ & 68,3 & 151,5 & 121,8 & $x$ & $x$ \\
\hline & & & $R$ & 67,2 & 143,9 & 197,5 & $x$ & $x$ & 67,9 & 158,4 & 203,3 & $x$ & $x$ & 66,1 & 71,7 & 61,1 & $x$ & $x$ & 67,2 & 143,9 & 120,7 & $x$ & $x$ \\
\hline
\end{tabular}



Anexo 4. Matriz Fatorial com resultados obtidos nas simulações; Caminhão 2S3

\begin{tabular}{|c|c|c|c|c|c|c|c|c|c|c|c|c|c|c|c|c|c|c|c|c|c|c|c|}
\hline 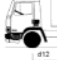 & $0=$ & -0 & & \multicolumn{20}{|c|}{ TIPO DE VEÍCULO DE CARGA - Caminhão Trator + Semi Reboque (2S3) } \\
\hline \multirow{6}{*}{\multicolumn{4}{|c|}{$\begin{array}{c}\text { Força Vertical } \\
\text { valores máximos } \\
\text { [kN] }\end{array}$}} & \multicolumn{20}{|c|}{ TIPO DE EIXO } \\
\hline & & & & \multicolumn{10}{|c|}{ rodas duplas } & \multicolumn{5}{|c|}{ rodas simples } & \multicolumn{5}{|c|}{ rodas duplas } \\
\hline & & & & \multicolumn{20}{|c|}{ CARGA POR EIXO } \\
\hline & & & & \multicolumn{5}{|c|}{$L L$} & \multicolumn{5}{|c|}{$L L+20 \%$} & \multicolumn{5}{|c|}{$7 t$} & \multicolumn{5}{|c|}{$8 t$} \\
\hline & & & & E1 & E2 & E3E4E5 & $x$ & $\mathrm{x}$ & E1 & E2 & E3E4E5 & $x$ & $\mathrm{x}$ & E1 & E2 & E3E4E5 & $x$ & $\mathbf{x}$ & E1 & E2 & E3E4E5 & $x$ & $\mathrm{x}$ \\
\hline & & & & 60 & 100 & 240 & $x$ & $\mathbf{x}$ & 70 & 120 & 300 & $x$ & $\mathbf{x}$ & 60 & 70 & 210 & $\mathbf{x}$ & $\mathbf{x}$ & 60 & 80 & 240 & $x$ & $\mathbf{x}$ \\
\hline \multirow{9}{*}{ 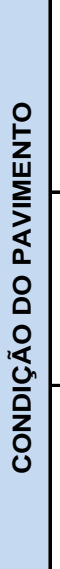 } & \multirow{3}{*}{ * } & \multirow{9}{*}{ 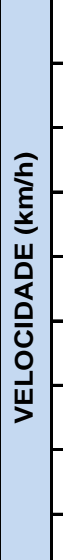 } & $\stackrel{1}{1}$ & 73,0 & 147,0 & 278,1 & $x$ & $x$ & 75,7 & 151,8 & 271,6 & $x$ & $x$ & 75,2 & 69,9 & 107,8 & $x$ & $x$ & 74,1 & 138,7 & 251,8 & $x$ & $x$ \\
\hline & & & 8 & 66,0 & 141,5 & 273,9 & $x$ & $x$ & 71,4 & 143,6 & 278,5 & $x$ & $x$ & 78,3 & 68,1 & 118,7 & $x$ & $x$ & 68,1 & 136,2 & 253,7 & $x$ & $x$ \\
\hline & & & $R$ & 63,1 & 144,5 & 277,3 & $x$ & $x$ & 61,5 & 140,6 & 295,5 & $x$ & $x$ & 67,0 & 67,1 & 115,4 & $x$ & $x$ & 64,8 & 136,2 & 251,9 & $x$ & $x$ \\
\hline & \multirow{3}{*}{ * } & & $\frac{1}{1}$ & 67,7 & 130,4 & 254,4 & $x$ & $x$ & 70,7 & 130,3 & 258,4 & $\lambda$ & $x$ & 71,7 & 63,7 & 101,8 & $x$ & $x$ & 68,5 & 123,8 & 259,2 & $x$ & $x$ \\
\hline & & & 8 & 65,8 & 128,0 & 261,7 & $x$ & $x$ & 67,7 & 132,3 & 255,2 & $x$ & $x$ & 69,3 & 62,4 & 113,8 & $x$ & $x$ & 68,5 & 124,1 & 255,1 & $x$ & $x$ \\
\hline & & & $R$ & 62,0 & 132,9 & 271,0 & $x$ & $x$ & 62,9 & 134,5 & 253,5 & $\lambda$ & $x$ & 63,0 & 62,0 & 110,0 & $x$ & $x$ & 68,5 & 124,1 & 255,1 & $x$ & $x$ \\
\hline & \multirow{3}{*}{ \$ } & & $\stackrel{1}{1}$ & 61,5 & 116,7 & 178,1 & $x$ & $x$ & 61,6 & 117,9 & 195,2 & $\lambda$ & $x$ & 64,0 & 62,0 & 83,1 & $x$ & $x$ & 62,1 & 112,6 & 170,3 & $x$ & $x$ \\
\hline & & & ৪ & 60,3 & 116,2 & 182,1 & $x$ & $x$ & 61,3 & 114,0 & 183,6 & $x$ & $x$ & 62,7 & 60,0 & 85,1 & $x$ & $x$ & 61,5 & 113,4 & 182,8 & $x$ & $x$ \\
\hline & & & $R$ & 56,6 & 114,4 & 178,1 & $x$ & $x$ & 58,0 & 113,9 & 184,3 & $x$ & $x$ & 58,3 & 58,0 & 83,5 & $x$ & $x$ & 58,4 & 112,4 & 182,0 & $x$ & $x$ \\
\hline
\end{tabular}



Anexo 5. Matriz Fatorial com resultados obtidos nas simulações; Caminhão $2 \mathrm{I3}$

\begin{tabular}{|c|c|c|c|c|c|c|c|c|c|c|c|c|c|c|c|c|c|c|c|c|c|c|c|}
\hline \multicolumn{4}{|c|}{ 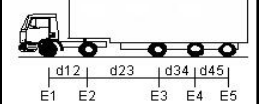 } & \multicolumn{20}{|c|}{ TIPO DE VEÍcULO DE CARGA - Caminhão Trator + Semi Reboque (213) } \\
\hline \multirow{6}{*}{\multicolumn{4}{|c|}{$\begin{array}{c}\text { Força Vertical } \\
\text { valores máximos } \\
{[\mathrm{kN}]}\end{array}$}} & \multicolumn{20}{|c|}{ TIPO DE EIXO } \\
\hline & & & & \multicolumn{10}{|c|}{ rodas duplas } & \multicolumn{5}{|c|}{ rodas simples } & \multicolumn{5}{|c|}{ rodas duplas } \\
\hline & & & & \multicolumn{20}{|c|}{ CARGA POR EIXO } \\
\hline & & & & \multicolumn{5}{|c|}{$L L$} & \multicolumn{5}{|c|}{$L L+20 \%$} & \multicolumn{5}{|c|}{$7 t$} & \multicolumn{5}{|c|}{$8 t$} \\
\hline & & & & E1 & E2 & E3 & E4 & E5 & E1 & E2 & E3 & E4 & E5 & E1 & E2 & E3 & E4 & E5 & E1 & E2 & E3 & E4 & E5 \\
\hline & & & & 60 & 100 & 100 & 100 & 100 & 70 & 120 & 120 & 120 & 120 & 60 & 70 & 70 & 70 & 70 & 60 & 80 & 80 & 80 & 80 \\
\hline \multirow{9}{*}{ 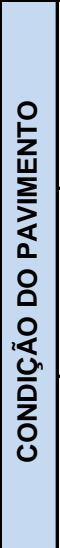 } & \multirow{3}{*}{$\$$} & \multirow{9}{*}{ 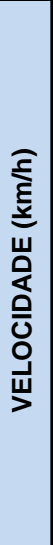 } & $\frac{9}{1}$ & 73,0 & 149,6 & 78,6 & 84,3 & 80,8 & 75,7 & 151,6 & 86,2 & 93,0 & 92,1 & 82,7 & 60,4 & 51,7 & 50,4 & 45,3 & 80,1 & 129,4 & 108,3 & 100,8 & 89,1 \\
\hline & & & 8 & 66,0 & 144,4 & 79,5 & 82,8 & 88,8 & 71,4 & 144,4 & 91,2 & 91,7 & 97,4 & 72,9 & 45,6 & 45,4 & 41,4 & 38,6 & 77,6 & 93,8 & 98,0 & 83,4 & 75,7 \\
\hline & & & $R$ & 63,1 & 142,1 & 78,6 & 82,8 & 86,4 & 61,5 & 145,9 & 79,7 & 96,3 & 100,8 & 78,9 & 47,9 & 45,6 & 37,8 & 35,9 & 71,7 & 89,2 & 86,1 & 78,2 & 77,3 \\
\hline & \multirow{3}{*}{ N } & & $\stackrel{9}{1}$ & 67,7 & 127,5 & 69,9 & 79,7 & 82,8 & 70,7 & 131,8 & 75,0 & 90,9 & 86,8 & 77,8 & 43,8 & 48,0 & 39,0 & 40,9 & 74,6 & 101,7 & 104,0 & 75,0 & 76,8 \\
\hline & & & ৪ & 65,8 & 130,5 & 73,2 & 82,4 & 89,2 & 67,7 & 131,4 & 79,7 & 90,5 & 90,4 & 76,7 & 43,2 & 51,1 & 41,0 & 35,3 & 73,5 & 84,8 & 87,8 & 77,5 & 80,2 \\
\hline & & & R & 62,0 & 131,4 & 77,9 & 79,3 & 92,0 & 62,9 & 131,4 & 78,7 & 88,7 & 90,7 & 71,4 & 42,4 & 45,6 & 37,5 & 38,1 & 72,7 & 78,8 & 83,9 & 70,9 & 73,5 \\
\hline & \multirow{3}{*}{ * } & & $\stackrel{2}{1}$ & 61,5 & 118,0 & 53,3 & 55,1 & 58,3 & 61,6 & 118,5 & 62,1 & 64,1 & 67,3 & 67,3 & 35,8 & 36,2 & 34,5 & 30,8 & 68,3 & 75,6 & 76,8 & 64,0 & 60,4 \\
\hline & & & ৪ & 60,3 & 116,3 & 57,8 & 58,3 & 65,9 & 61,3 & 114,5 & 55,2 & 61,2 & 65,8 & 66,7 & 35,0 & 34,5 & 31,0 & 30,0 & 68,3 & 74,6 & 76,8 & 61,8 & 60,0 \\
\hline & & & $R$ & 56,6 & 114,0 & 56,8 & 62,7 & 68,4 & 58,0 & 115,4 & 56,2 & 63,9 & 65,3 & 66,1 & 34,7 & 37,0 & 30,4 & 30,7 & 67,2 & 67,0 & 76,8 & 59,5 & 61,2 \\
\hline
\end{tabular}



Anexo 6. Cálculo do efeito dinâmico a partir dos resultados obtidos nas simulações; Caminhão 2C

\begin{tabular}{|c|c|c|c|c|c|c|c|c|c|c|c|c|c|c|c|}
\hline \multirow{4}{*}{\multicolumn{4}{|c|}{\begin{tabular}{|c|} 
\\
$\begin{array}{c}\text { Força Vertical } \\
\text { valores máximos } \\
{[\mathrm{kN}]}\end{array}$
\end{tabular}}} & \multicolumn{12}{|c|}{ TIPO DE VEÍCULO DE CARGA - Caminhão (2C) } \\
\hline & & & & \multicolumn{6}{|c|}{ Limite de carga } & \multicolumn{6}{|c|}{ Limite de carga $+20 \%$} \\
\hline & & & & \multirow{2}{*}{$\begin{array}{l}\mathrm{E} 1 \\
60 \\
\end{array}$} & \multirow{2}{*}{$\begin{array}{c}\text { Efeito } \\
\text { Dinâmico }\end{array}$} & \multirow{2}{*}{$\begin{array}{l}\text { E2 } \\
100\end{array}$} & \multirow{2}{*}{$\begin{array}{c}\text { Efeito } \\
\text { Dinâmico }\end{array}$} & \multirow{2}{*}{$\frac{E 1+E 2}{160}$} & \multirow{2}{*}{$\begin{array}{c}\text { Efeito } \\
\text { Dinâmico }\end{array}$} & \multirow{2}{*}{$\begin{array}{c}\text { E1' } \\
70\end{array}$} & \multirow{2}{*}{$\begin{array}{c}\text { Efeito } \\
\text { Dinâmico }\end{array}$} & \multirow{2}{*}{$\begin{array}{l}\text { E2' } \\
120\end{array}$} & \multirow{2}{*}{$\begin{array}{c}\text { Efeito } \\
\text { Dinâmico }\end{array}$} & \multirow{2}{*}{$\frac{E 1^{\prime}+E 2 '}{190}$} & \multirow{2}{*}{$\begin{array}{c}\text { Efeito } \\
\text { Dinâmico }\end{array}$} \\
\hline & & & & & & & & & & & & & & & \\
\hline \multirow{9}{*}{ 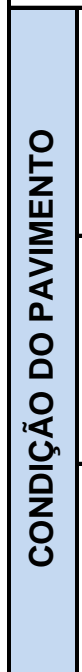 } & \multirow{3}{*}{ 急 } & \multirow{9}{*}{ 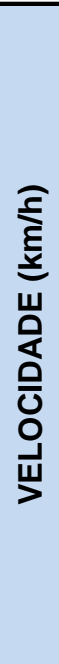 } & $\frac{1}{5}$ & 59,9 & $-0,1 \%$ & 139,1 & $39,1 \%$ & 199,0 & $24,4 \%$ & 64,2 & $-8,2 \%$ & 142,3 & $18,6 \%$ & 206,6 & $8,7 \%$ \\
\hline & & & 8 & 57,2 & $-4,6 \%$ & 113,1 & $13,1 \%$ & 170,3 & $6,4 \%$ & 60,5 & $-13,6 \%$ & 111,9 & $-6,7 \%$ & 172,4 & $-9,3 \%$ \\
\hline & & & s & 54,5 & $-9,1 \%$ & 109,9 & $9,9 \%$ & 164,5 & $2,8 \%$ & 56,7 & $-19,0 \%$ & 111,2 & $-7,3 \%$ & 168,0 & $-11,6 \%$ \\
\hline & \multirow{3}{*}{ * } & & $\frac{9}{1}$ & 51,2 & $-14,7 \%$ & 116,4 & $16,4 \%$ & 167,6 & $4,7 \%$ & 52,8 & $-24,6 \%$ & 119,6 & $-0,4 \%$ & 172,3 & $-9,3 \%$ \\
\hline & & & 8 & 50,7 & $-15,5 \%$ & 114,3 & $14,3 \%$ & 165,0 & $3,1 \%$ & 53,1 & $-24,2 \%$ & 117,3 & $-2,2 \%$ & 170,4 & $-10,3 \%$ \\
\hline & & & $R$ & 50,1 & $-16,5 \%$ & 91,6 & $-8,4 \%$ & 141,7 & $-11,4 \%$ & 52,7 & $-24,7 \%$ & 94,0 & $-21,7 \%$ & 146,7 & $-22,8 \%$ \\
\hline & \multirow{3}{*}{ \$ } & & $\frac{1}{2}$ & 45,5 & $-24,1 \%$ & 78,2 & $-21,8 \%$ & 123,8 & $-22,6 \%$ & 46,3 & $-33,8 \%$ & 79,6 & $-33,7 \%$ & 125,9 & $-33,7 \%$ \\
\hline & & & ஃ & 46,9 & $-21,8 \%$ & 81,0 & $-19,0 \%$ & 128,0 & $-20,0 \%$ & 48,4 & $-30,8 \%$ & 82,8 & $-31,0 \%$ & 131,2 & $-31,0 \%$ \\
\hline & & & R & 46,7 & $-22,2 \%$ & 72,5 & $-27,5 \%$ & 119,2 & $-25,5 \%$ & 47,2 & $-32,6 \%$ & 72,4 & $-39,6 \%$ & 119,6 & $-37,0 \%$ \\
\hline
\end{tabular}



Anexo 7. Cálculo comparativo entre o incremento da carga e aumento no efeito dinâmico; Caminhão 2C

\begin{tabular}{|c|c|c|c|c|c|c|c|c|c|c|c|c|}
\hline \multicolumn{13}{|c|}{\begin{tabular}{|l} 
TIPO DE VEÍCULO DE CARGA - Caminhão (2C) \\
\end{tabular}} \\
\hline \multirow{2}{*}{\multicolumn{4}{|c|}{$\begin{array}{c}\text { Força Vertical } \\
\text { valores máximos } \\
{[\mathrm{kN}]}\end{array}$}} & E1 & E1' & Comparativo & E2 & E2' & Comparativo & $E 1+E 2$ & $E 1^{\prime}+E 2^{\prime}$ & Comparativo \\
\hline & & & & 60 & 70 & $16,7 \%$ & 100 & 120 & $20,0 \%$ & 160 & 190 & $18,8 \%$ \\
\hline \multirow{9}{*}{ 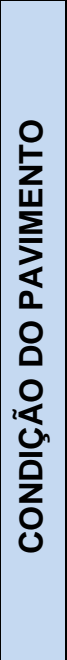 } & \multirow{3}{*}{ * } & \multirow{9}{*}{ 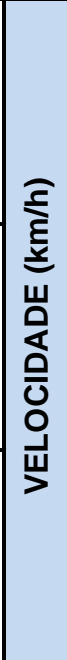 } & $\frac{0}{1}$ & 59,9 & 64,2 & $7,2 \%$ & 139,1 & 142,3 & $2,3 \%$ & 199,0 & 206,6 & $3,8 \%$ \\
\hline & & & ஃ & 57,2 & 60,5 & $5,6 \%$ & 113,1 & 111,9 & $-1,0 \%$ & 170,3 & 172,4 & $1,2 \%$ \\
\hline & & & $R$ & 54,5 & 56,7 & $4,0 \%$ & 109,9 & 111,2 & $1,2 \%$ & 164,5 & 168,0 & $2,1 \%$ \\
\hline & \multirow{3}{*}{ พ } & & $\stackrel{0}{\pi}$ & 51,2 & 52,8 & $3,1 \%$ & 116,4 & 119,6 & $2,7 \%$ & 167,6 & 172,3 & $2,8 \%$ \\
\hline & & & ஃ & 50,7 & 53,1 & $4,7 \%$ & 114,3 & 117,3 & $2,6 \%$ & 165,0 & 170,4 & $3,3 \%$ \\
\hline & & & $R$ & 50,1 & 52,7 & $5,1 \%$ & 91,6 & 94,0 & $2,5 \%$ & 141,7 & 146,7 & $3,5 \%$ \\
\hline & \multirow{3}{*}{ W } & & $\frac{0}{\pi}$ & 45,5 & 46,3 & $1,7 \%$ & 78,2 & 79,6 & $1,7 \%$ & 123,8 & 125,9 & $1,7 \%$ \\
\hline & & & 8 & 46,9 & 48,4 & $3,1 \%$ & 81,0 & 82,8 & $2,1 \%$ & 128,0 & 131,2 & $2,5 \%$ \\
\hline & & & R & 46,7 & 47,2 & $1,1 \%$ & 72,5 & 72,4 & $-0,1 \%$ & 119,2 & 119,6 & $0,4 \%$ \\
\hline
\end{tabular}



Anexo 8. Cálculo dos FEC a partir dos resultados obtidos nas simulações; Caminhão 2C

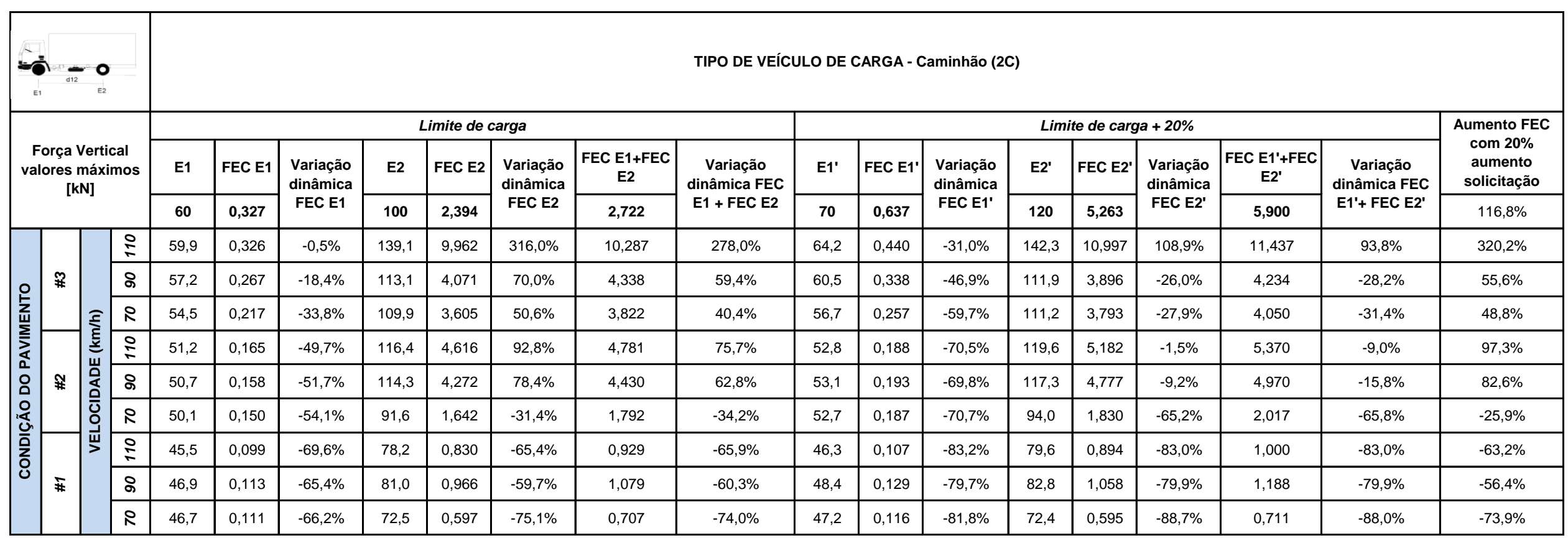



Anexo 9. Comparação do efeito dinâmico para rodagens simples e dupla; Caminhão 2C

\begin{tabular}{|c|c|c|c|c|c|c|c|c|c|c|c|c|c|c|c|}
\hline \multicolumn{4}{|c|}{$=0$} & \multicolumn{12}{|c|}{ TIPO DE VEÍCULO DE CARGA - Caminhão (2C) } \\
\hline \multirow{6}{*}{\multicolumn{4}{|c|}{$\begin{array}{c}\text { Força Vertical } \\
\text { valores máximos } \\
{[\mathrm{kN}]}\end{array}$}} & \multicolumn{12}{|c|}{ TIPO DE EIXO } \\
\hline & & & & \multicolumn{6}{|c|}{ rodagem simples } & \multicolumn{6}{|c|}{ rodagem dupla } \\
\hline & & & & \multicolumn{12}{|c|}{ Carga atuante nos eixos traseiros } \\
\hline & & & & \multicolumn{6}{|c|}{$7 t$} & \multicolumn{6}{|c|}{$8 t$} \\
\hline & & & & E1 & Ef. Din. E1 & E2 & Ef. Din. E2 & $\mathrm{E} 1+\mathrm{E} 2$ & Ef. Din. E1+E2 & E1' & Ef. Din. E1' & E2' & Ef. Din. E2' & $E 1^{\prime}+E 2$ & Ef. Din. E1'+E2' \\
\hline & & & & 60 & $0,0 \%$ & 70 & $0,0 \%$ & 130 & $0,0 \%$ & 60 & $0,0 \%$ & 80 & $0,0 \%$ & 140 & $0,0 \%$ \\
\hline \multirow{9}{*}{ 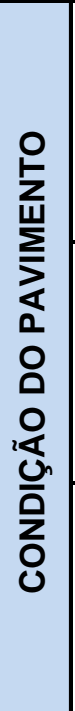 } & \multirow{3}{*}{ 急 } & \multirow{9}{*}{ 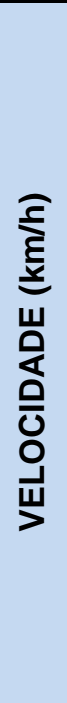 } & $\frac{R}{1}$ & 70,6 & $17,7 \%$ & 130,0 & $85,7 \%$ & 200,575 & $54,3 \%$ & 56,6 & $-5,7 \%$ & 126,4 & $58,0 \%$ & 182,999 & $30,7 \%$ \\
\hline & & & 8 & 68,2 & $13,7 \%$ & 121,7 & $73,8 \%$ & 189,936 & $46,1 \%$ & 58,0 & $-3,3 \%$ & 117,4 & $46,8 \%$ & 175,456 & $25,3 \%$ \\
\hline & & & R & 62,1 & $3,5 \%$ & 103,7 & $48,2 \%$ & 165,823 & $27,6 \%$ & 53,8 & $-10,3 \%$ & 106,9 & $33,6 \%$ & 160,729 & $14,8 \%$ \\
\hline & \multirow{3}{*}{ * } & & $\frac{1}{5}$ & 56,9 & $-5,2 \%$ & 101,8 & $45,4 \%$ & 158,7 & $22,1 \%$ & 51,7 & $-13,9 \%$ & 100,7 & $25,9 \%$ & 152,403 & $8,9 \%$ \\
\hline & & & 8 & 55,1 & $-8,2 \%$ & 102,0 & $45,8 \%$ & 157,124 & $20,9 \%$ & 50,4 & $-15,9 \%$ & 105,5 & $31,9 \%$ & 155,944 & $11,4 \%$ \\
\hline & & & $R$ & 55,8 & $-7,0 \%$ & 95,5 & $36,4 \%$ & 151,281 & $16,4 \%$ & 49,9 & $-16,8 \%$ & 91,0 & $13,8 \%$ & 140,944 & $0,7 \%$ \\
\hline & \multirow{3}{*}{$\bar{*}$} & & 온 & 49,9 & $-16,9 \%$ & 82,5 & $17,8 \%$ & 132,332 & $1,8 \%$ & 46,2 & $-22,9 \%$ & 77,2 & $-3,5 \%$ & 123,415 & $-11,8 \%$ \\
\hline & & & 8 & 49,1 & $-18,2 \%$ & 69,9 & $-0,1 \%$ & 118,987 & $-8,5 \%$ & 46,5 & $-22,5 \%$ & 69,1 & $-13,6 \%$ & 115,628 & $-17,4 \%$ \\
\hline & & & $R$ & 48,4 & $-19,4 \%$ & 69,0 & $-1,4 \%$ & 117,424 & $-9,7 \%$ & 47,1 & $-21,5 \%$ & 69,7 & $-12,8 \%$ & 116,826 & $-16,6 \%$ \\
\hline
\end{tabular}



Anexo 10. Cálculo do efeito dinâmico a partir dos resultados obtidos nas simulações; Caminhão 3S2

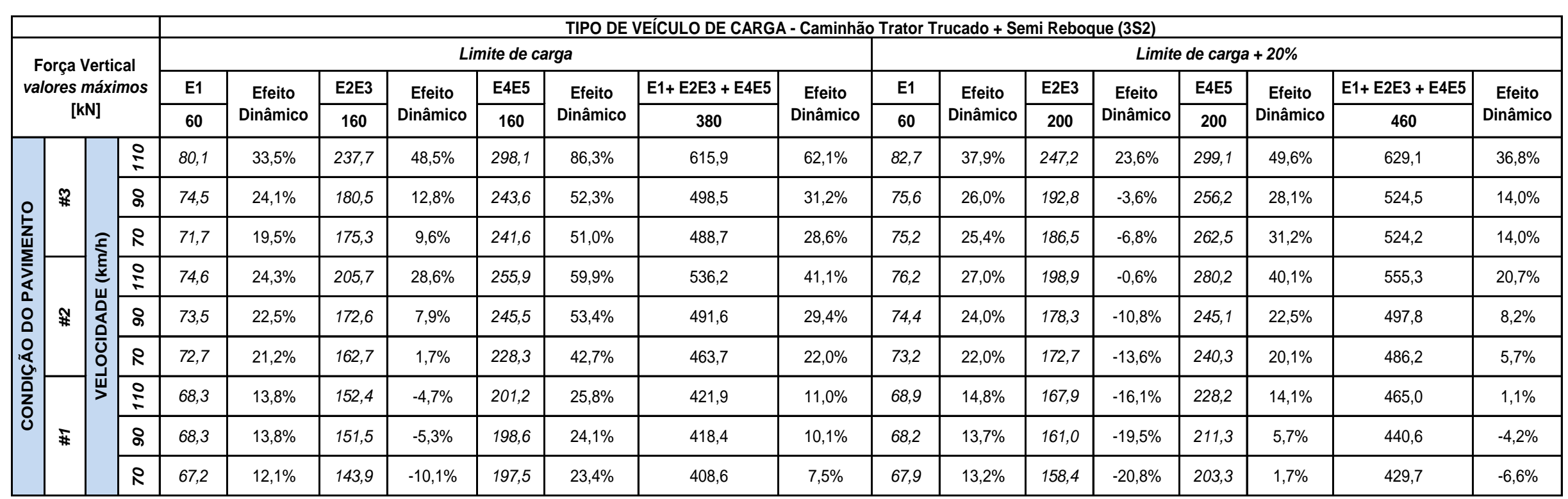



Anexo 11. Cálculo comparativo entre o incremento da carga e aumento no efeito dinâmico; Caminhão 3S2

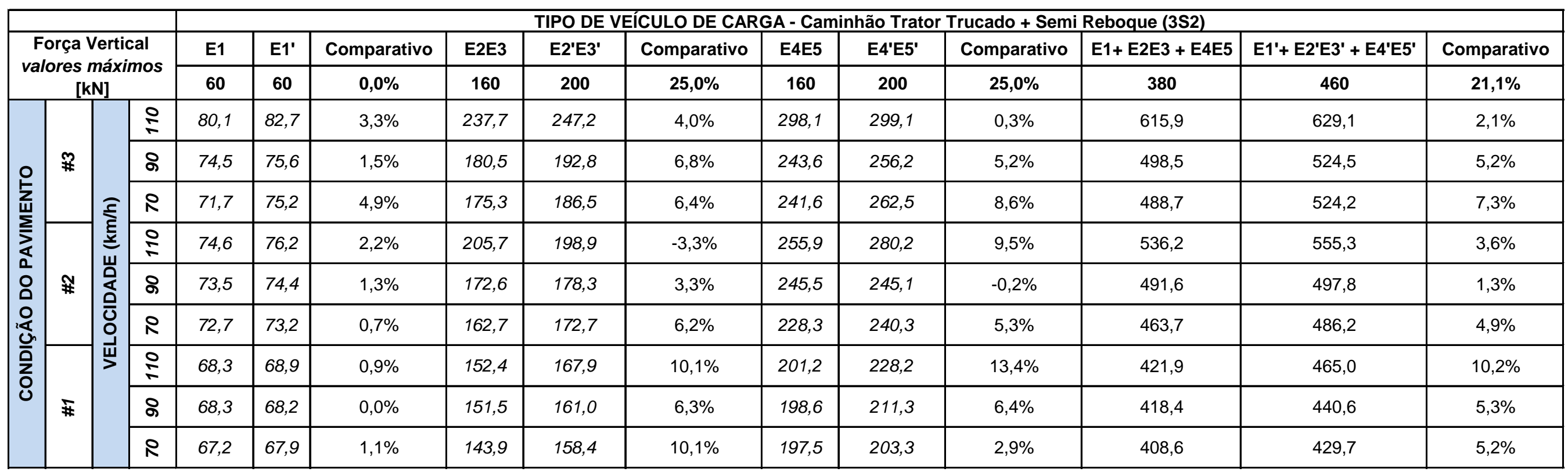



Anexo 12. Cálculo dos FEC a partir dos resultados obtidos nas simulações; Caminhão 3S2

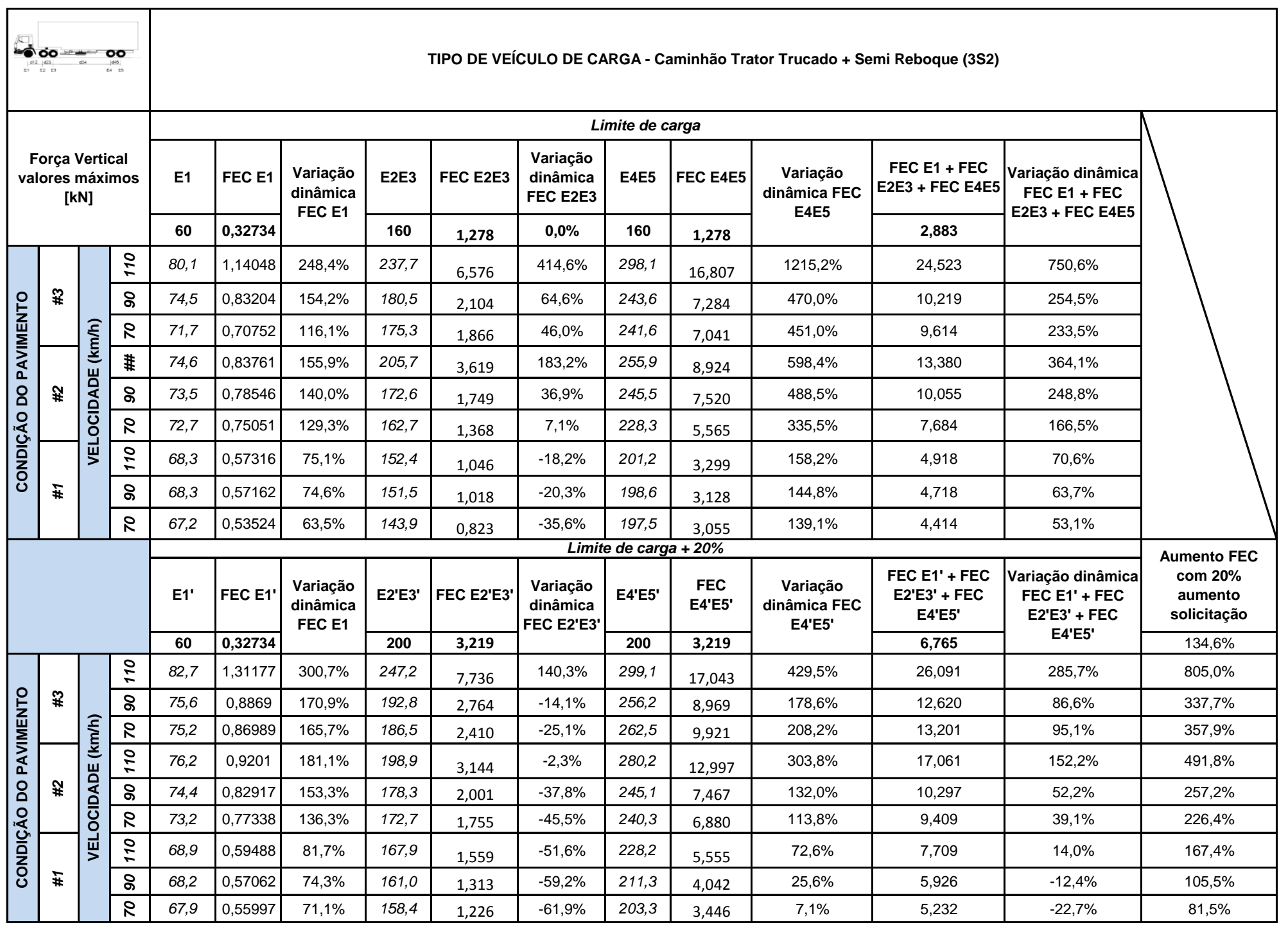





\section{Anexo 13. Comparação do efeito dinâmico para rodagens simples e dupla; Caminhão 3S2}

\begin{tabular}{|c|c|c|c|c|c|c|c|c|c|c|c|c|c|c|c|c|c|c|c|}
\hline \multicolumn{4}{|c|}{$b o-\infty$} & \multicolumn{16}{|c|}{ TIPO DE VEÍCULO DE CARGA - Caminhão Trator Trucado + Semi Reboque (3S2) } \\
\hline \multirow{6}{*}{\multicolumn{4}{|c|}{$\begin{array}{c}\text { Força Vertical } \\
\text { valores máximos } \\
{[\mathrm{kN}]}\end{array}$}} & \multicolumn{16}{|c|}{ TIPO DE EIXO } \\
\hline & & & & \multicolumn{8}{|c|}{ rodagem simples } & \multicolumn{8}{|c|}{ rodagem dupla } \\
\hline & & & & \multicolumn{16}{|c|}{ Carga atuante nos eixos traseiros } \\
\hline & & & & \multicolumn{8}{|c|}{$7 t$} & \multicolumn{8}{|c|}{$8 t$} \\
\hline & & & & E1 & Ef. Din. E1 & E2E3 & Ef. Din. E2E3 & E4E5 & \begin{tabular}{|l|} 
Ef. Din. E4E5 \\
\end{tabular} & E1+E2E3+E4E5 & Ef. Din. (E1+E2E3+E4E5) & E1' & Ef. Din. E1' & E2'E3' & \begin{tabular}{|l|} 
Ef. Din. E2'E3' \\
\end{tabular} & E4'E5' & Ef. Din. E4'E5' & E1'+E2'E3'+E4'E5' & Ef. Din. (E1'+E2'E3'+E4'E5') \\
\hline & & & & 60 & $0,0 \%$ & 140 & $0,0 \%$ & 140 & $0,0 \%$ & 340 & $0,0 \%$ & 60 & $0,0 \%$ & 160 & $0,0 \%$ & 160 & $0,0 \%$ & 380 & $0,0 \%$ \\
\hline \multirow{9}{*}{ 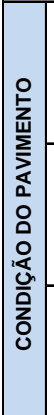 } & \multirow{3}{*}{ \$ } & \multirow{9}{*}{ 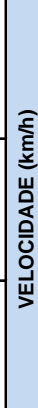 } & $?$ & 82,7 & $37,8 \%$ & 112,1 & $-19,9 \%$ & 95,7 & $-31,6 \%$ & 290,5 & $-14,6 \%$ & 80,1 & $33,5 \%$ & 237,7 & $48,5 \%$ & 189,9 & $18,7 \%$ & 507,6 & $33,6 \%$ \\
\hline & & & \& & 72,9 & $21,5 \%$ & 91,0 & $-35,0 \%$ & 80,0 & $-42,9 \%$ & 243,9 & $-28,3 \%$ & 77,6 & $29,3 \%$ & 191,8 & $19,9 \%$ & 159,2 & $-0,5 \%$ & 428,6 & $12,8 \%$ \\
\hline & & & R & 78,9 & $31,4 \%$ & 93,5 & $-33,2 \%$ & 73,6 & $-47,4 \%$ & 246,0 & $-27,6 \%$ & 71,7 & $19,5 \%$ & 175,3 & $9,6 \%$ & 155,5 & $-2,8 \%$ & 402,5 & $5,9 \%$ \\
\hline & & & ? & 77,8 & $29,7 \%$ & 91,8 & $-34,5 \%$ & 79,9 & $-42,9 \%$ & 249,5 & $-26,6 \%$ & 74,6 & $24,3 \%$ & 205,7 & $28,6 \%$ & 151,8 & $-5,1 \%$ & 432,2 & $13,7 \%$ \\
\hline & $\approx$ & & ஃ & 76,7 & $27,9 \%$ & 94,3 & $-32,6 \%$ & 76,2 & $-45,6 \%$ & 247,3 & $-27,3 \%$ & 73,5 & $22,5 \%$ & 172,6 & $7,9 \%$ & 157,7 & $-1,5 \%$ & 403,8 & $6,3 \%$ \\
\hline & & & $R$ & 71,4 & $19,0 \%$ & 88,0 & $-37,1 \%$ & 75,7 & $-46,0 \%$ & 235,1 & $-30,8 \%$ & 72,7 & $21,2 \%$ & 162,7 & $1,7 \%$ & 144,4 & $-9,8 \%$ & 379,8 & $-0,1 \%$ \\
\hline & & & $\stackrel{9}{1}$ & 67,3 & $12,2 \%$ & 72,1 & $-48,5 \%$ & 65,2 & $-53,4 \%$ & 204,6 & $-39,8 \%$ & 68,3 & $13,8 \%$ & 152,4 & $-4,7 \%$ & 124,4 & $-22,3 \%$ & 345,1 & $-9,2 \%$ \\
\hline & 雨 & & 8 & 66,7 & $11,2 \%$ & 69,5 & $-50,4 \%$ & 61,0 & $-56,4 \%$ & 197,2 & $-42,0 \%$ & 68,3 & $13,8 \%$ & 151,5 & $-5,3 \%$ & 121,8 & $-23,9 \%$ & 341,5 & $-10,1 \%$ \\
\hline & & & $R$ & 66,1 & $10,2 \%$ & 71,7 & $-48,8 \%$ & 61,1 & $-56,4 \%$ & 198,9 & $-41,5 \%$ & 67,2 & $12,1 \%$ & 143,9 & $-10,1 \%$ & 120,7 & $-24,6 \%$ & 331,8 & $-12,7 \%$ \\
\hline
\end{tabular}



Anexo 14. Cálculo do efeito dinâmico a partir dos resultados obtidos nas simulações; Caminhão 2S3

\begin{tabular}{|c|c|c|c|c|c|c|c|c|c|c|c|c|c|c|c|c|c|c|c|}
\hline \multirow{4}{*}{\multicolumn{4}{|c|}{\begin{tabular}{|c|} 
Força Vertical \\
valores máximos \\
{$[\mathrm{kN}]$}
\end{tabular}}} & \multicolumn{16}{|c|}{ TIPO DE VEÍCULO DE CARGA - Caminhão Trator + Semi Reboque (2S3) } \\
\hline & & & & \multicolumn{8}{|c|}{ Limite de carga } & \multicolumn{8}{|c|}{ Limite de carga $+20 \%$} \\
\hline & & & & \multirow{2}{*}{$\begin{array}{l}\mathrm{E} 1 \\
60\end{array}$} & \multirow{2}{*}{$\begin{array}{l}\text { Efeito } \\
\text { Dinâmico }\end{array}$} & \multirow{2}{*}{$\begin{array}{c}\text { E2 } \\
100\end{array}$} & \multirow{2}{*}{$\begin{array}{c}\text { Efeito } \\
\text { Dinâmico }\end{array}$} & \multirow{2}{*}{\begin{tabular}{|c|} 
E3E4E5 \\
240 \\
\end{tabular}} & \multirow{2}{*}{$\begin{array}{c}\text { Efeito } \\
\text { Dinâmico }\end{array}$} & \multirow{2}{*}{\begin{tabular}{|c|}
$E 1+E 2+E 3 E 4 E 5$ \\
400
\end{tabular}} & \multirow{2}{*}{$\begin{array}{c}\text { Efeito } \\
\text { Dinâmico }\end{array}$} & \multirow{2}{*}{$\begin{array}{l}\text { E1' } \\
70\end{array}$} & \multirow{2}{*}{$\begin{array}{l}\text { Efeito } \\
\text { Dinâmico }\end{array}$} & \multirow{2}{*}{$\begin{array}{l}\text { E2' } \\
120\end{array}$} & \multirow{2}{*}{$\begin{array}{c}\text { Efeito } \\
\text { Dinâmico }\end{array}$} & \multirow{2}{*}{\begin{tabular}{|c|} 
E3'E4'E5' \\
300 \\
\end{tabular}} & \multirow{2}{*}{$\begin{array}{l}\text { Efeito } \\
\text { Dinâmico }\end{array}$} & \multirow{2}{*}{$\frac{E 1^{\prime}+E 22^{\prime}+E^{\prime} 3^{\prime} 4^{\prime} E 5 '}{490}$} & \multirow{2}{*}{$\begin{array}{c}\text { Efeito } \\
\text { Dinâmico }\end{array}$} \\
\hline & & & & & & & & & & & & & & & & & & & \\
\hline \multirow{9}{*}{ 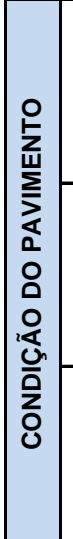 } & \multirow{3}{*}{$\Re$} & \multirow{9}{*}{ 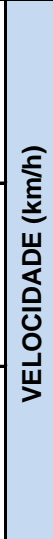 } & $\stackrel{2}{1}$ & 73,0 & $21,6 \%$ & 147,0 & $47,0 \%$ & 278,1 & $15,9 \%$ & 498,2 & $24,5 \%$ & 75,7 & $8,2 \%$ & 151,8 & $26,5 \%$ & 271,6 & $-9,5 \%$ & 499,1 & $1,9 \%$ \\
\hline & & & ๑ & 66,0 & $9,9 \%$ & 141,5 & $41,5 \%$ & 273,9 & $14,1 \%$ & 481,4 & $20,3 \%$ & 71,4 & $2,0 \%$ & 143,6 & $19,7 \%$ & 278,5 & $-7,2 \%$ & 493,5 & $0,7 \%$ \\
\hline & & & $R$ & 63,1 & $5,2 \%$ & 144,5 & $44,5 \%$ & 277,3 & $15,5 \%$ & 484,9 & $21,2 \%$ & 61,5 & $-12,1 \%$ & 140,6 & $17,2 \%$ & 295,5 & $-1,5 \%$ & 497,7 & $1,6 \%$ \\
\hline & \multirow{3}{*}{ * } & & 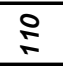 & 67,7 & $12,8 \%$ & 130,4 & $30,4 \%$ & 254,4 & $6,0 \%$ & 452,5 & $13,1 \%$ & 70,7 & $1,0 \%$ & 130,3 & $8,6 \%$ & 258,4 & $-13,9 \%$ & 459,4 & $-6,3 \%$ \\
\hline & & & ๑ి & 65,8 & $9,6 \%$ & 128,0 & $28,0 \%$ & 261,7 & $9,0 \%$ & 455,5 & $13,9 \%$ & 67,7 & $-3,3 \%$ & 132,3 & $10,3 \%$ & 255,2 & $-14,9 \%$ & 455,2 & $-7,1 \%$ \\
\hline & & & $R$ & 62,0 & $3,3 \%$ & 132,9 & $32,9 \%$ & 271,0 & $12,9 \%$ & 465,9 & $16,5 \%$ & 62,9 & $-10,1 \%$ & 134,5 & $12,1 \%$ & 253,5 & $-15,5 \%$ & 450,8 & $-8,0 \%$ \\
\hline & \multirow{3}{*}{ * } & & $\stackrel{0}{5}$ & 61,5 & $2,5 \%$ & 116,7 & $16,7 \%$ & 178,1 & $-25,8 \%$ & 356,3 & $-10,9 \%$ & 61,6 & $-12,0 \%$ & 117,9 & $-1,8 \%$ & 195,2 & $-34,9 \%$ & 374,7 & $-23,5 \%$ \\
\hline & & & 8 & 60,3 & $0,5 \%$ & 116,2 & $16,2 \%$ & 182,1 & $-24,1 \%$ & 358,5 & $-10,4 \%$ & 61,3 & $-12,4 \%$ & 114,0 & $-5,0 \%$ & 183,6 & $-38,8 \%$ & 358,9 & $-26,7 \%$ \\
\hline & & & $R$ & 56,6 & $-5,7 \%$ & 114,4 & $14,4 \%$ & 178,1 & $-25,8 \%$ & 349,1 & $-12,7 \%$ & 58,0 & $-17,1 \%$ & 113,9 & $-5,1 \%$ & 184,3 & $-38,6 \%$ & 356,2 & $-27,3 \%$ \\
\hline
\end{tabular}



Anexo 15. Cálculo comparativo entre o incremento da carga e aumento no efeito dinâmico; Caminhão 2S3

\begin{tabular}{|c|c|c|c|c|c|c|c|c|c|c|c|c|c|c|c|}
\hline \multirow{3}{*}{\multicolumn{4}{|c|}{$\begin{array}{c}\text { Força Vertical } \\
\text { valores máximos } \\
{[\mathrm{kN}]}\end{array}$}} & \multicolumn{12}{|c|}{ TIPO DE VEÍCULO DE CARGA - Caminhão Trator + Semi Reboque (2S3) } \\
\hline & & & & \multirow{2}{*}{$\begin{array}{ll}E 1 \\
60 \\
\end{array}$} & \multirow{2}{*}{$\begin{array}{l}\text { E1' } \\
70 \\
\end{array}$} & \multirow{2}{*}{$\begin{array}{c}\text { Comparativo } \\
16,7 \% \\
\end{array}$} & \multirow{2}{*}{$\begin{array}{c}\text { E2 } \\
100 \\
\end{array}$} & \multirow{2}{*}{\begin{tabular}{|c|}
$E 2 '$ \\
120 \\
\end{tabular}} & \multirow{2}{*}{$\begin{array}{c}\text { Comparativo } \\
20,0 \% \\
\end{array}$} & \multirow{2}{*}{\begin{tabular}{|c|} 
E3E4E5 \\
240 \\
\end{tabular}} & \multirow{2}{*}{$\begin{array}{c}\text { E3'E4'E5' } \\
300 \\
\end{array}$} & \multirow{2}{*}{$\begin{array}{c}\text { Comparativo } \\
25,0 \% \\
\end{array}$} & \multirow{2}{*}{$\frac{E 1+E 2 \text { + E3E4E5 }}{400}$} & \multirow{2}{*}{$\begin{array}{c}\text { E1' + E2' + E3'E4'E5' }^{\prime} \\
490 \\
\end{array}$} & \multirow{3}{*}{$\begin{array}{c}\text { Comparativo } \\
\mathbf{2 2 , 5} \% \\
0,2 \%\end{array}$} \\
\hline & & & & & & & & & & & & & & & \\
\hline \multirow{9}{*}{ 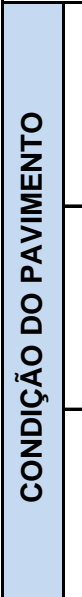 } & \multirow{3}{*}{ * } & \multirow{9}{*}{ 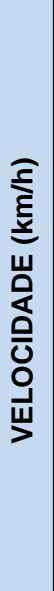 } & $\stackrel{2}{1}$ & 73,0 & 75,7 & $3,8 \%$ & 147,0 & 151,8 & $3,2 \%$ & 278,1 & 271,6 & $-2,4 \%$ & 498,2 & 499,1 & \\
\hline & & & ৪ & 66,0 & 71,4 & $8,3 \%$ & 141,5 & 143,6 & $1,5 \%$ & 273,9 & 278,5 & $1,7 \%$ & 481,4 & 493,5 & $2,5 \%$ \\
\hline & & & $R$ & 63,1 & 61,5 & $-2,5 \%$ & 144,5 & 140,6 & $-2,7 \%$ & 277,3 & 295,5 & $6,6 \%$ & 484,9 & 497,7 & $2,6 \%$ \\
\hline & \multirow{3}{*}{ \$ } & & $\stackrel{9}{2}$ & 67,7 & 70,7 & $4,5 \%$ & 130,4 & 130,3 & $-0,1 \%$ & 254,4 & 258,4 & $1,6 \%$ & 452,5 & 459,4 & $1,5 \%$ \\
\hline & & & 8 & 65,8 & 67,7 & $2,8 \%$ & 128,0 & 132,3 & $3,3 \%$ & 261,7 & 255,2 & $-2,5 \%$ & 455,5 & 455,2 & $-0,1 \%$ \\
\hline & & & R & 62,0 & 62,9 & $1,5 \%$ & 132,9 & 134,5 & $1,2 \%$ & 271,0 & 253,5 & $-6,5 \%$ & 465,9 & 450,8 & $-3,2 \%$ \\
\hline & \multirow{3}{*}{$\$$} & & $\stackrel{?}{1}$ & 61,5 & 61,6 & $0,2 \%$ & 116,7 & 117,9 & $1,0 \%$ & 178,1 & 195,2 & $9,6 \%$ & 356,3 & 374,7 & $5,2 \%$ \\
\hline & & & 8 & 60,3 & 61,3 & $1,6 \%$ & 116,2 & 114,0 & $-1,8 \%$ & 182,1 & 183,6 & $0,9 \%$ & 358,5 & 358,9 & $0,1 \%$ \\
\hline & & & $R$ & 56,6 & 58,0 & $2,5 \%$ & 114,4 & 113,9 & $-0,5 \%$ & 178,1 & 184,3 & $3,5 \%$ & 349,1 & 356,2 & $2,0 \%$ \\
\hline
\end{tabular}



Anexo 16. Cálculo dos FEC a partir dos resultados obtidos nas simulações; Caminhão 2S3

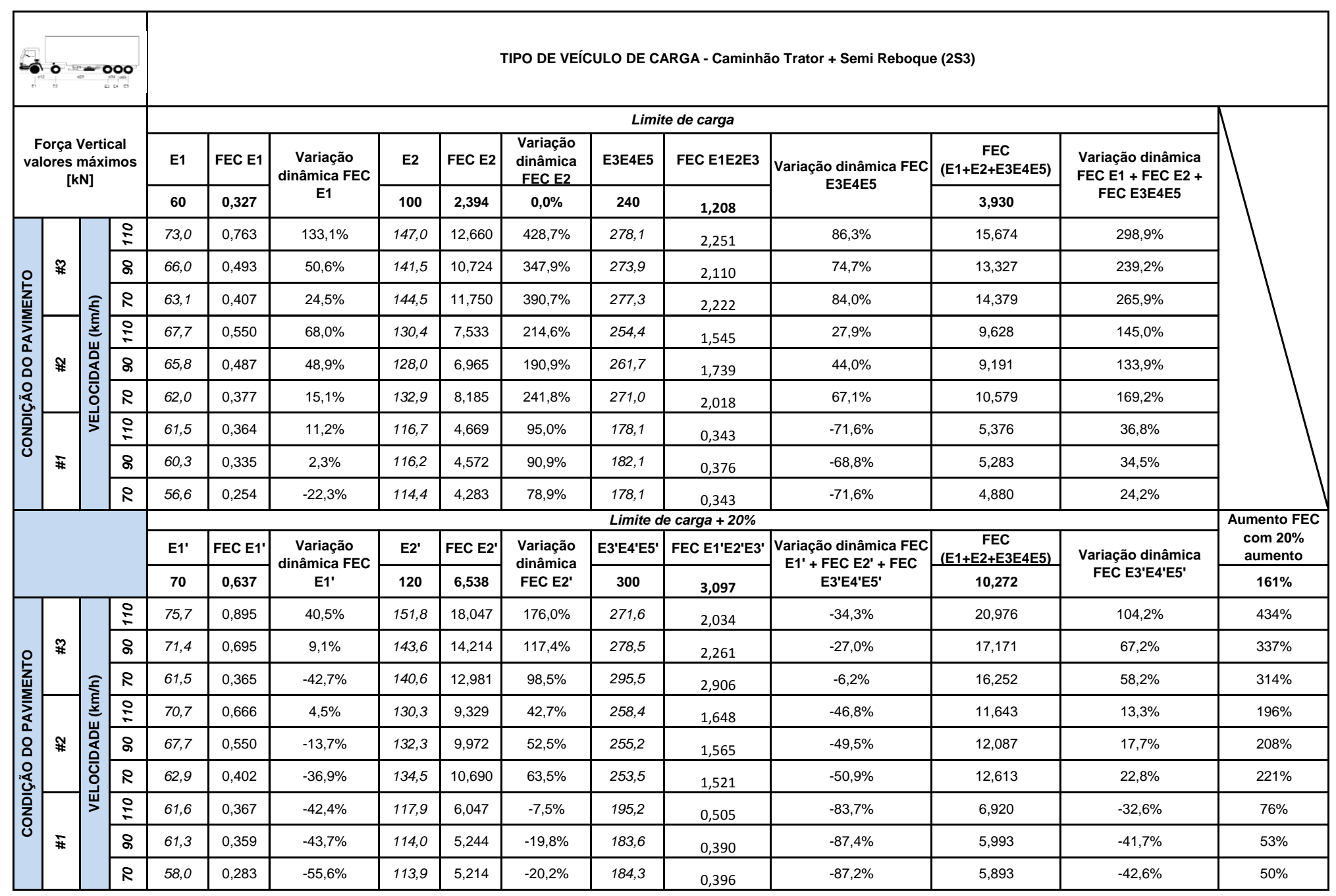





\section{Anexo 17. Comparação do efeito dinâmico para rodagens simples e dupla; Caminhão 2S3}

\begin{tabular}{|c|c|c|c|c|c|c|c|c|c|c|c|c|c|c|c|c|c|c|c|}
\hline \multicolumn{4}{|c|}{$-\infty 0=-00$} & \multicolumn{16}{|c|}{ TIPO DE VEícULO DE CARGA - Caminhão Trator + Semi Reboque (2S3) } \\
\hline \multirow{6}{*}{\multicolumn{4}{|c|}{$\begin{array}{c}\text { Força Vertical } \\
\text { valores máximos } \\
{[\mathrm{kN}]}\end{array}$}} & \multicolumn{16}{|c|}{ TIPO DE EIXO } \\
\hline & & & & \multicolumn{8}{|c|}{ rodagem simples } & \multicolumn{8}{|c|}{ rodagem duplas } \\
\hline & & & & \multicolumn{16}{|c|}{ Carga atuante nos eixos traseiros } \\
\hline & & & & \multicolumn{8}{|c|}{$7 t$} & \multicolumn{8}{|c|}{$8 t$} \\
\hline & & & & E1 & Ef. Din. E1 & E2 & Ef. Din. E2 & E3E4E5 & \begin{tabular}{|l|} 
Ef. Din. E3E4E5 \\
\end{tabular} & E1+E2+E3E4E5 & Ef. Din. E1+E2+E3E4E5 & E1' & Ef. Din. E1' & E2' & \begin{tabular}{|l|} 
Ef. Din. E2' \\
\end{tabular} & E3'E4'E5' & Ef. Din. E3'E4'E5' & $E 1^{\prime}+E 2^{\prime}+E 3^{\prime} E 4^{\prime} E 5^{\prime}$ & Ef. Din. E1'+E2'+E3'E4'E5' \\
\hline & & & & 60 & $0,0 \%$ & 70 & $0,0 \%$ & 210 & $0,0 \%$ & 340 & $0,0 \%$ & 60 & $0,0 \%$ & 80 & $0,0 \%$ & 240 & $0,0 \%$ & 380 & $0,0 \%$ \\
\hline \multirow{9}{*}{ 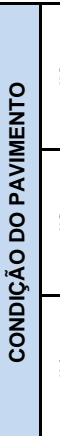 } & \multirow{2}{*}{\multicolumn{2}{|c|}{ * }} & $\frac{1}{1}$ & 75,2 & $25,3 \%$ & 69,9 & $-0,1 \%$ & 107,8 & $-48,7 \%$ & 252,8 & $-25,6 \%$ & 74,1 & $23,6 \%$ & 138,7 & $73,4 \%$ & 251,8 & $4,9 \%$ & 464,7 & $22,3 \%$ \\
\hline & & & \& & 78,3 & $30,6 \%$ & 68,1 & $-2,7 \%$ & 118,7 & $-43,5 \%$ & 265,1 & $-22,0 \%$ & 68,1 & $13,5 \%$ & 136,2 & $70,2 \%$ & 253,7 & $5,7 \%$ & 458,0 & $20,5 \%$ \\
\hline & & \multirow{7}{*}{ 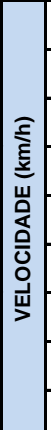 } & s & 67,0 & $11,7 \%$ & 67,1 & $-4,1 \%$ & 115,4 & $-45,0 \%$ & 249,6 & $-26,6 \%$ & 64,8 & $8,0 \%$ & 136,2 & $70,3 \%$ & 251,9 & $4,9 \%$ & 452,9 & $19,2 \%$ \\
\hline & & & $\frac{1}{2}$ & 71,7 & $19,4 \%$ & 63,7 & $-9,0 \%$ & 101,8 & $-51,5 \%$ & 237,2 & $-30,2 \%$ & 68,5 & $14,1 \%$ & 123,8 & $54,7 \%$ & 259,2 & $8,0 \%$ & 451,4 & $18,8 \%$ \\
\hline & * & & \& & 69,3 & $15,5 \%$ & 62,4 & $-10,9 \%$ & 113,8 & $-45,8 \%$ & 245,5 & $-27,8 \%$ & 68,5 & $14,2 \%$ & 124,1 & $55,1 \%$ & 255,1 & $6,3 \%$ & 447,7 & $17,8 \%$ \\
\hline & & & R & 63,0 & $5,0 \%$ & 62,0 & $-11,4 \%$ & 110,0 & $-47,6 \%$ & 235,0 & $-30,9 \%$ & 68,5 & $14,2 \%$ & 124,1 & $55,1 \%$ & 255,1 & $6,3 \%$ & 447,7 & $17,8 \%$ \\
\hline & & & ? & 64,0 & $6,7 \%$ & 62,0 & $-11,4 \%$ & 83,1 & $-60,4 \%$ & 209,2 & $-38,5 \%$ & 62,1 & $3,5 \%$ & 112,6 & $40,7 \%$ & 170,3 & $-29,1 \%$ & 344,9 & $-9,2 \%$ \\
\hline & 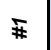 & & 8 & 62,7 & $4,6 \%$ & 60,0 & $-14,3 \%$ & 85,1 & $-59,5 \%$ & 207,8 & $-38,9 \%$ & 61,5 & $2,5 \%$ & 113,4 & $41,8 \%$ & 182,8 & $-23,8 \%$ & 357,8 & $-5,9 \%$ \\
\hline & & & $R$ & 58,3 & $-2,9 \%$ & 58,0 & $-17,1 \%$ & 83,5 & $-60,3 \%$ & 199,8 & $-41,2 \%$ & 58,4 & $-2,7 \%$ & 112,4 & $40,5 \%$ & 182,0 & $-24,2 \%$ & 352,7 & $-7,2 \%$ \\
\hline
\end{tabular}



Anexo 18. Cálculo do efeito dinâmico a partir dos resultados obtidos nas simulações; Caminhão 2 I3

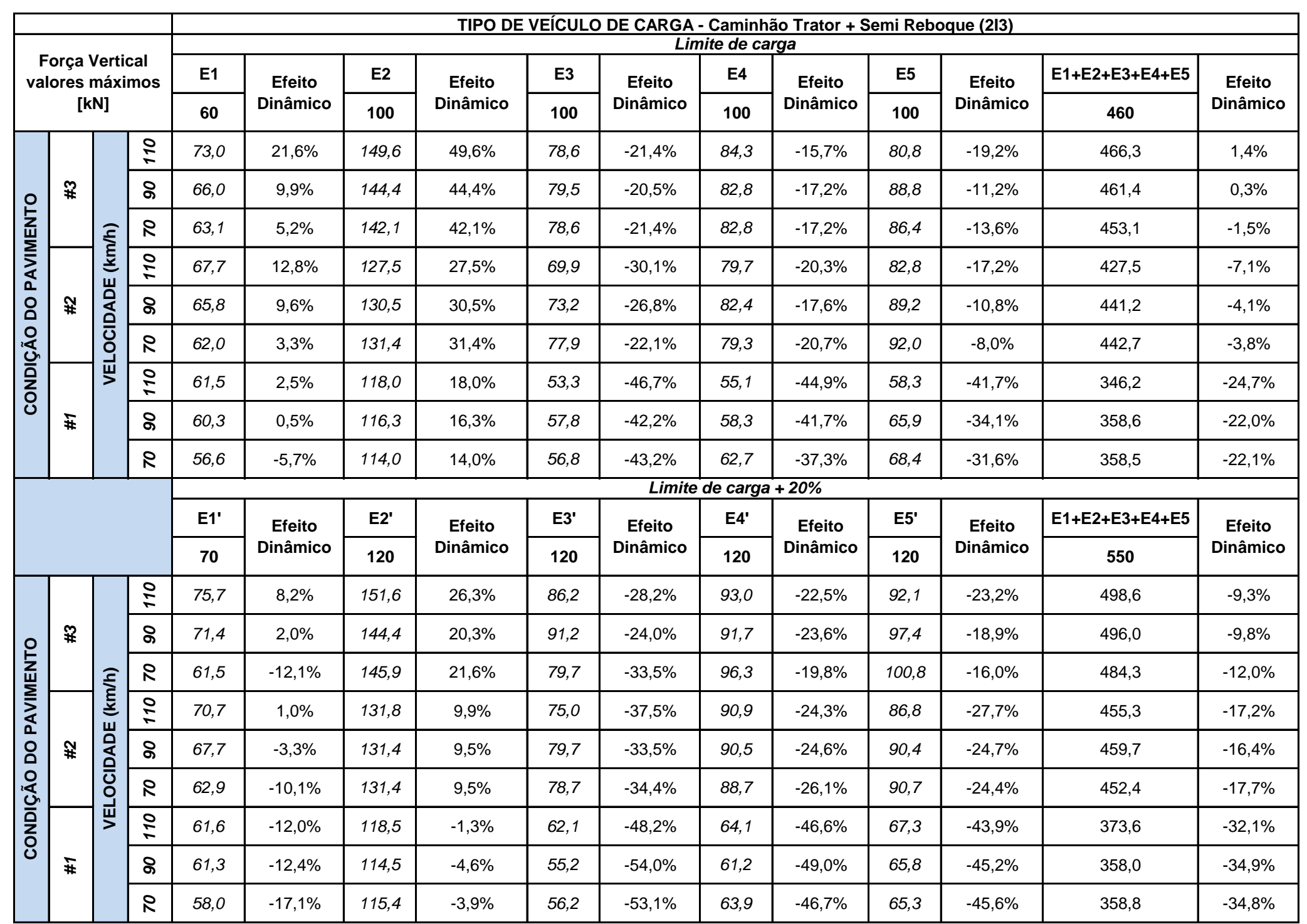



Anexo 19. Cálculo comparativo entre o incremento da carga e aumento no efeito dinâmico; Caminhão 2 I3

\begin{tabular}{|c|c|c|c|c|c|c|c|c|c|c|c|c|c|c|c|c|c|c|c|c|c|}
\hline \multirow{3}{*}{\multicolumn{4}{|c|}{\begin{tabular}{|c|} 
Força Vertical \\
valores máximos \\
{$[\mathrm{kN}]$}
\end{tabular}}} & \multicolumn{18}{|c|}{ TIPO DE VEÍCULO DE CARGA - Caminhão Trator + Semi Reboque (213) } \\
\hline & & & & \multirow{2}{*}{$\begin{array}{l}\mathrm{E} 1 \\
60\end{array}$} & \multirow{2}{*}{$\begin{array}{l}\text { E1' } \\
70\end{array}$} & \multirow{2}{*}{$\begin{array}{c}\text { Comparativo } \\
16,7 \%\end{array}$} & \multirow{2}{*}{$\begin{array}{c}\text { E2 } \\
100\end{array}$} & \multirow{2}{*}{$\begin{array}{l}\text { E2' } \\
120\end{array}$} & \multirow{2}{*}{$\begin{array}{c}\text { Comparativo } \\
20,0 \%\end{array}$} & \multirow{2}{*}{$\begin{array}{c}\text { E3 } \\
100\end{array}$} & \multirow{2}{*}{$\begin{array}{l}\text { E3' } \\
120\end{array}$} & \multirow{2}{*}{$\begin{array}{c}\text { Comparativo } \\
20,0 \%\end{array}$} & \multirow{2}{*}{$\begin{array}{c}\text { E4 } \\
100\end{array}$} & \multirow{2}{*}{$\begin{array}{l}\text { E4' } \\
120\end{array}$} & \multirow{2}{*}{$\begin{array}{c}\text { Comparativo } \\
20,0 \%\end{array}$} & \multirow{2}{*}{\begin{tabular}{|c|} 
E5 \\
100
\end{tabular}} & \multirow{2}{*}{\begin{tabular}{|c|} 
E5' \\
120
\end{tabular}} & \multirow{2}{*}{$\begin{array}{c}\text { Comparativo } \\
20,0 \%\end{array}$} & \multirow{2}{*}{\begin{tabular}{|c|}
$\begin{array}{c}\mathrm{E} 1+\mathrm{E} 2+\mathrm{E} 3+ \\
\mathrm{E} 4+\mathrm{E} 6\end{array}$ \\
460,0
\end{tabular}} & \multirow{2}{*}{\begin{tabular}{|c|}
$\begin{array}{c}\mathrm{E} 1^{\prime}+\mathrm{E2}^{\prime}+\mathrm{E} 3^{\prime}+ \\
\mathrm{E} 4^{\prime}+\mathrm{E} 5^{\prime}\end{array}$ \\
550,0
\end{tabular}} & \multirow{2}{*}{$\begin{array}{c}\text { Comparativo } \\
19,6 \%\end{array}$} \\
\hline & & & & & & & & & & & & & & & & & & & & & \\
\hline \multirow{9}{*}{ 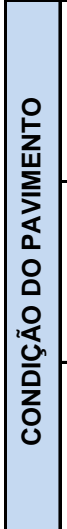 } & \multirow{3}{*}{ 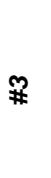 } & \multirow{9}{*}{ 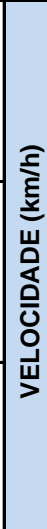 } & $\frac{1}{1}$ & 73,0 & 75,7 & $3,8 \%$ & 149,6 & 151,6 & $1,3 \%$ & 78,6 & 86,2 & $9,6 \%$ & 84,3 & 93,0 & $10,3 \%$ & 80,8 & 92,1 & $14,0 \%$ & 466,3 & 498,6 & $6,9 \%$ \\
\hline & & & ৪ & 66,0 & 71,4 & $8,3 \%$ & 144,4 & 144,4 & $0,0 \%$ & 79,5 & 91,2 & $14,8 \%$ & 82,8 & 91,7 & $10,7 \%$ & 88,8 & 97,4 & $9,7 \%$ & 461,4 & 496,0 & $7,5 \%$ \\
\hline & & & R & 63,1 & 61,5 & $-2,5 \%$ & 142,1 & 145,9 & $2,6 \%$ & 78,6 & 79,7 & $1,5 \%$ & 82,8 & 96,3 & $16,3 \%$ & 86,4 & 100,8 & $16,7 \%$ & 453,1 & 484,3 & $6,9 \%$ \\
\hline & \multirow{3}{*}{ * } & & $\frac{1}{1}$ & 67,7 & 70,7 & $4,5 \%$ & 127,5 & 131,8 & $3,4 \%$ & 69,9 & 75,0 & $7,4 \%$ & 79,7 & 90,9 & $14,1 \%$ & 82,8 & 86,8 & $4,9 \%$ & 427,5 & 455,3 & $6,5 \%$ \\
\hline & & & ஃ & 65,8 & 67,7 & $2,8 \%$ & 130,5 & 131,4 & $0,7 \%$ & 73,2 & 79,7 & $8,9 \%$ & 82,4 & 90,5 & $9,8 \%$ & 89,2 & 90,4 & $1,4 \%$ & 441,2 & 459,7 & $4,2 \%$ \\
\hline & & & $R$ & 62,0 & 62,9 & $1,5 \%$ & 131,4 & 131,4 & $0,0 \%$ & 77,9 & 78,7 & $1,0 \%$ & 79,3 & 88,7 & $11,8 \%$ & 92,0 & 90,7 & $-1,4 \%$ & 442,7 & 452,4 & $2,2 \%$ \\
\hline & \multirow{3}{*}{ F } & & $\stackrel{9}{1}$ & 61,5 & 61,6 & $0,2 \%$ & 118,0 & 118,5 & $0,4 \%$ & 53,3 & 62,1 & $16,4 \%$ & 55,1 & 64,1 & $16,3 \%$ & 58,3 & 67,3 & $15,4 \%$ & 346,2 & 373,6 & $7,9 \%$ \\
\hline & & & 8 & 60,3 & 61,3 & $1,6 \%$ & 116,3 & 114,5 & $-1,5 \%$ & 57,8 & 55,2 & $-4,5 \%$ & 58,3 & 61,2 & $5,0 \%$ & 65,9 & 65,8 & $-0,2 \%$ & 358,6 & 358,0 & $-0,2 \%$ \\
\hline & & & $R$ & 56,6 & 58,0 & $2,5 \%$ & 114,0 & 115,4 & $1,2 \%$ & 56,8 & 56,2 & $-0,9 \%$ & 62,7 & 63,9 & $1,9 \%$ & 68,4 & \begin{tabular}{|l|}
65,3 \\
\end{tabular} & $-4,6 \%$ & 358,5 & 358,8 & $0,1 \%$ \\
\hline
\end{tabular}



Anexo 20. Cálculo dos FEC a partir dos resultados obtidos nas simulações; Caminhão 2I3

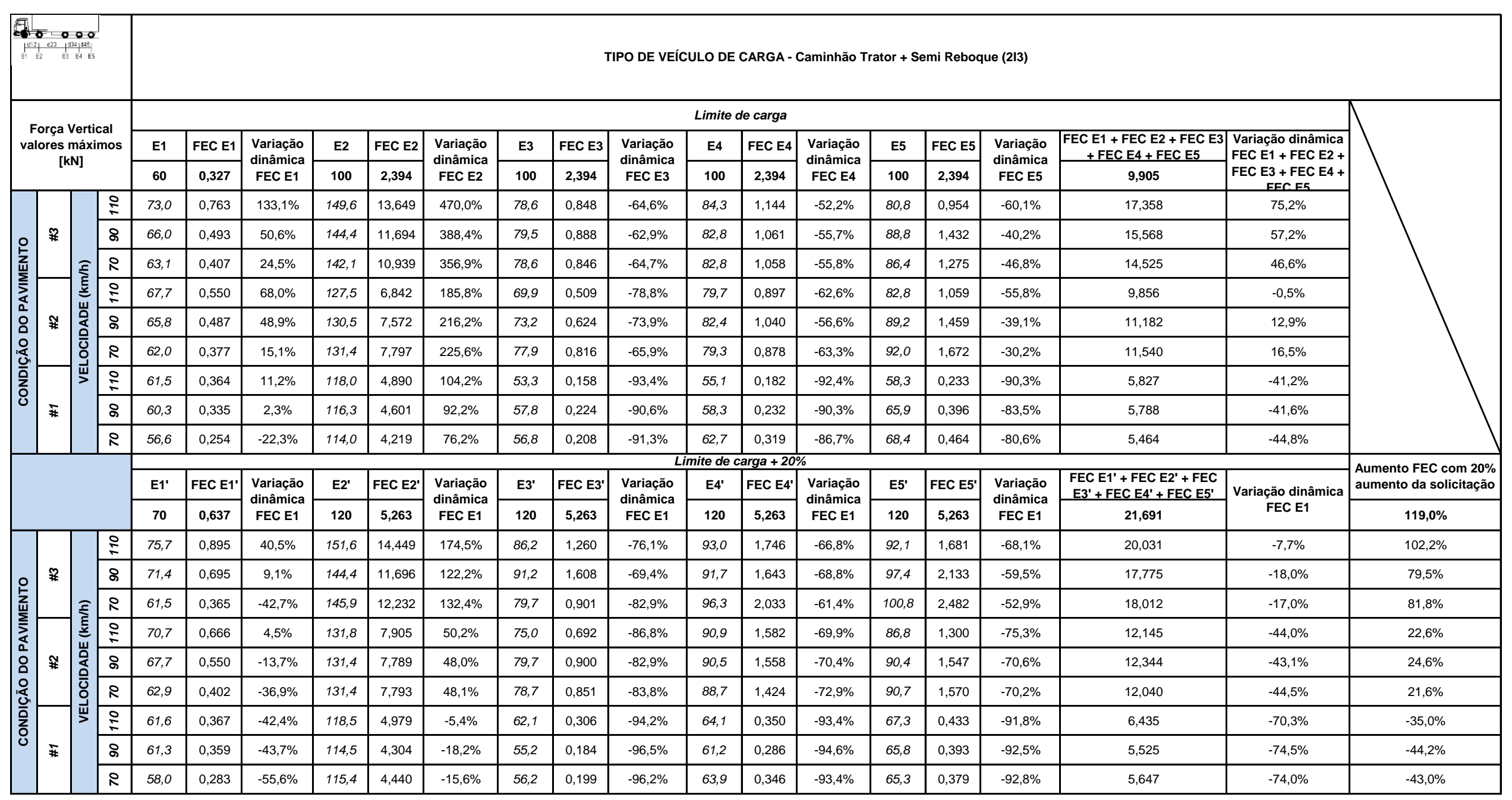





\section{Anexo 21. Comparação do efeito dinâmico para rodagens simples e dupla; Caminhão 3S2}

\begin{tabular}{|c|c|c|c|c|c|c|c|c|c|c|c|c|c|c|c|}
\hline \multicolumn{4}{|c|}{ 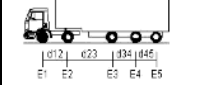 } & \multicolumn{12}{|c|}{ TIPO DE VEÍCULO DE CARGA - Caminhão Trator + Semi Reboque (213) } \\
\hline \multirow{6}{*}{\multicolumn{4}{|c|}{$\begin{array}{c}\text { Força Vertical } \\
\text { valores máximos } \\
{[\mathrm{kN}]}\end{array}$}} & \multicolumn{12}{|c|}{ TIPO DE EIXO } \\
\hline & & & & \multicolumn{12}{|c|}{ rodagem simples } \\
\hline & & & & \multicolumn{4}{|c|}{ Carga atuante nos eixos traseiros } & & & & & & & & \\
\hline & & & & \multicolumn{12}{|c|}{$7 t$} \\
\hline & & & & E1 & Ef. Din. E1 & E2 & Ef. Din. E2 & E3 & Ef. Din. E3 & E4 & Ef. Din. E4 & E5 & Ef. Din. E5 & E1+E2+E3+E4+E5 & Ef. Din. E1+E2+E3+E4+E5 \\
\hline & & & & 60 & $0,0 \%$ & 70 & $0,0 \%$ & 70 & $0,0 \%$ & 70 & $0,0 \%$ & 70 & $0,0 \%$ & 340 & $0,0 \%$ \\
\hline \multirow{9}{*}{ 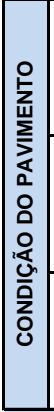 } & \multirow{3}{*}{$\Re$} & \multirow{9}{*}{ 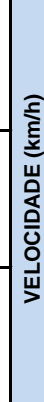 } & 挈 & 82,7 & $37,8 \%$ & 60,4 & $-13,8 \%$ & 51,7 & $-26,1 \%$ & 50,4 & $-27,9 \%$ & 45,3 & $-35,3 \%$ & 290,5 & $-14,6 \%$ \\
\hline & & & ৪ & 72,9 & $21,5 \%$ & 45,6 & $-34,9 \%$ & 45,4 & $-35,1 \%$ & 41,4 & $-40,9 \%$ & 38,6 & $-44,9 \%$ & 243,9 & $-28,3 \%$ \\
\hline & & & R & 78,9 & $31,4 \%$ & 47,9 & $-31,6 \%$ & 45,6 & $-34,8 \%$ & 37,8 & $-46,0 \%$ & 35,9 & $-48,8 \%$ & 246,0 & $-27,6 \%$ \\
\hline & & & 极 & 77,8 & $29,7 \%$ & 43,8 & $-37,5 \%$ & 48,0 & $-31,5 \%$ & 39,0 & $-44,3 \%$ & 40,9 & $-41,5 \%$ & 249,5 & $-26,6 \%$ \\
\hline & * & & 8 & 76,7 & $27,9 \%$ & 43,2 & $-38,2 \%$ & 51,1 & $-27,0 \%$ & 41,0 & $-41,5 \%$ & 35,3 & $-49,6 \%$ & 247,3 & $-27,3 \%$ \\
\hline & & & $R$ & 71,4 & $19,0 \%$ & 42,4 & $-39,4 \%$ & 45,6 & $-34,9 \%$ & 37,5 & $-46,4 \%$ & 38,1 & $-45,5 \%$ & 235,1 & $-30,8 \%$ \\
\hline & & & 帮 & 67,3 & $12,2 \%$ & 35,8 & $-48,8 \%$ & 36,2 & $-48,2 \%$ & 34,5 & $-50,8 \%$ & 30,8 & $-56,0 \%$ & 204,6 & $-39,8 \%$ \\
\hline & $\mp$ & & 8 & 66,7 & $11,2 \%$ & 35,0 & $-50,0 \%$ & 34,5 & $-50,7 \%$ & 31,0 & $-55,8 \%$ & 30,0 & $-57,1 \%$ & 197,2 & $-42,0 \%$ \\
\hline & & & $R$ & 66,1 & $10,2 \%$ & 34,7 & $-50,5 \%$ & 37,0 & $-47,1 \%$ & 30,4 & $-56,6 \%$ & 30,7 & $-56,2 \%$ & 198,9 & $-41,5 \%$ \\
\hline & & & & \multicolumn{12}{|c|}{ rodagem dupla } \\
\hline & & & & & & & & & & & $8 t$ & & & & \\
\hline & & & & E1 & \begin{tabular}{|l|} 
Ef. Din. E1 \\
\end{tabular} & E2 & \begin{tabular}{|l|} 
Ef. Din. E2 \\
\end{tabular} & E3 & \begin{tabular}{|l|} 
Ef. Din. E3 \\
\end{tabular} & E4 & \begin{tabular}{|l|} 
Ef. Din. E4 \\
\end{tabular} & E5 & \begin{tabular}{|l} 
Ef. Din. E5 \\
\end{tabular} & E1+E2+E3+E4+E5 & Ef. Din. E1+E2+E3+E4+E5 \\
\hline & & & & 60 & $0,0 \%$ & 80 & $0,0 \%$ & 80 & $0,0 \%$ & 80 & $0,0 \%$ & 80 & $0,0 \%$ & 380 & $0,0 \%$ \\
\hline \multirow{9}{*}{ 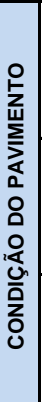 } & \multirow{3}{*}{$\Re$} & \multirow{9}{*}{ 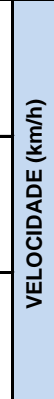 } & 帮 & 80,1 & $33,5 \%$ & 129,4 & $61,8 \%$ & 108,3 & $35,3 \%$ & 100,8 & $26,0 \%$ & 89,1 & $11,4 \%$ & 507,6 & $33,6 \%$ \\
\hline & & & 8 & 77,6 & $29,3 \%$ & 93,8 & $17,3 \%$ & 98,0 & $22,5 \%$ & 83,4 & $4,3 \%$ & 75,7 & $-5,3 \%$ & 428,6 & $12,8 \%$ \\
\hline & & & $R$ & 71,7 & $19,5 \%$ & 89,2 & $11,5 \%$ & 86,1 & $7,7 \%$ & 78,2 & $-2,3 \%$ & 77,3 & $-3,4 \%$ & 402,5 & $5,9 \%$ \\
\hline & & & W & 74,6 & $24,3 \%$ & 101,7 & $27,1 \%$ & 104,0 & $30,0 \%$ & 75,0 & $-6,2 \%$ & 76,8 & $-4,0 \%$ & 432,2 & $13,7 \%$ \\
\hline & * & & 8 & 73,5 & $22,5 \%$ & 84,8 & $6,0 \%$ & 87,8 & $9,8 \%$ & 77,5 & $-3,1 \%$ & 80,2 & $0,2 \%$ & 403,8 & $6,3 \%$ \\
\hline & & & $R$ & 72,7 & $21,2 \%$ & 78,8 & $-1,5 \%$ & 83,9 & $4,9 \%$ & 70,9 & $-11,4 \%$ & 73,5 & $-8,1 \%$ & 379,8 & $-0,1 \%$ \\
\hline & & & 楼 & 68,3 & $13,8 \%$ & 75,6 & $-5,5 \%$ & 76,8 & $-3,9 \%$ & 64,0 & $-20,1 \%$ & 60,4 & $-24,5 \%$ & 345,1 & $-9,2 \%$ \\
\hline & 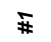 & & 8 & 68,3 & $13,8 \%$ & 74,6 & $-6,7 \%$ & 76,8 & $-3,9 \%$ & 61,8 & $-22,7 \%$ & 60,0 & $-25,1 \%$ & 341,5 & $-10,1 \%$ \\
\hline & & & $R$ & 67,2 & $12,1 \%$ & 67,0 & $-16,2 \%$ & 76,8 & $-3,9 \%$ & 59,5 & $-25,6 \%$ & 61,2 & $-23,6 \%$ & 331,8 & $-12,7 \%$ \\
\hline
\end{tabular}


